\title{
SIMULATION OF AN OXIDIZER-COOLED HYBRID ROCKET THROAT: \\ METHODOLOGY VALIDATION FOR DESIGN OF A \\ COOLED AEROSPIKE NOZZLE
}

\author{
A Thesis \\ presented to \\ the Faculty of California Polytechnic State University, \\ San Luis Obispo
}

\author{
In Partial Fulfillment \\ of the Requirements for the Degree \\ Master of Science in Mechanical Engineering \\ by
}

Peter Alexander Brennen

June 2009 
(C) 2009

Peter Alexander Brennen

ALL RIGHTS RESERVED 
TITLE:

AUTHOR:

DATE SUBMITTED:

COMMITTEE CHAIR:

COMMITTEE MEMBER:

COMMITTEE MEMBER:
SIMULATION OF AN OXIDIZER-COOLED HYBRID ROCKET THROAT: METHODOLOGY VALIDATION FOR DESIGN OF A COOLED AEROSPIKE NOZZLE

Peter Alexander Brennen

June 2009

Dr. William R. Murray, Professor

Dr. Patrick Lemieux, Professor 


\begin{abstract}
SIMULATION OF AN OXIDIZER-COOLED HYBRID ROCKET THROAT: METHODOLOGY VALIDATION FOR DESIGN OF A

COOLED AEROSPIKE NOZZLE
\end{abstract}

Peter Alexander Brennen

A study was undertaken to create a finite element model of a cooled throat converging/diverging rocket nozzle to be used as a tool in designing a cooled aerospike nozzle. Using ABAQUS, a simplified 2D axisymmetric model was created featuring only the copper throat and stainless steel support ring, which were brazed together for the experimental test firings. This analysis was a sequentially coupled thermal/mechanical model. The steady state thermal data matched closely to experimental data. The subsequent mechanical model predicted a life of over 300 cycles using the MansonHalford fatigue life criteria. A mesh convergence study was performed to establish solution mesh independence.

This model was expanded by adding the remainder of the parts of the nozzle aft of the rocket motor so as to attempt to match the transient nature of the experimental data. This model included variable hot gas side coefficients in the nozzle calculated using the Bartz coefficients and mapped onto the surface of the model using a FORTRAN subroutine. Additionally, contact resistances were accounted for between the additional parts. The results from the preliminary run suggested the need for a parameter re-evaluation for cold 
side gas conditions. Parametric studies were performed on contact resistance and cold side film coefficient. This data led to the final thermal contact conductance of $\mathrm{k}=0.005$ $\mathrm{BTU} / \mathrm{s} \cdot \mathrm{in} .{ }^{\circ} \mathrm{R}$ for contact between metals, $\mathrm{k}=0.001 \mathrm{BTU} / \mathrm{s} \cdot \mathrm{in} .{ }^{\circ} \mathrm{R}$ for contact between graphite and metal, and $\mathrm{h}=0.03235 \mathrm{BTU} / \mathrm{s}^{2} \cdot \mathrm{in} .{ }^{\circ} \mathrm{R}$ for the cold side film coefficient. The transient curves matched closely and the results were judged acceptable.

Finally, a 3D sector model was created using identical parameters as the 2D model except that a variable cold side film condition was added. Instead of modeling a symmetric one or two inlet/one or two outlet cooling channel, this modeled a one inlet/one outlet nozzle in which the coolant traveled almost the full $360^{\circ}$ around the cooling annulus. To simplify the initial simulation, the model was cut at the barrier between inlet and outlet to form one large sector, rather than account for thermal gradients across this barrier. This simplified nozzle produced expected data, and a 3D full nozzle model was created. The cold side film coefficients were calculated from previous experimental data using a simplified 2D finite difference approach. The full nozzle model was created in the same manner as the 2D full nozzle model. A mesh convergence study was performed to establish solution mesh independence. The 3D model results matched well to experimental data, and the model was considered a useful tool for the design of an oxidizer cooled aerospike nozzle.

Keywords: Aerospike, cooled nozzle, ABAQUS, computational heat transfer, FORTRAN subroutine, rocket nozzle, hybrid rocket, rocket motor, rocket engine, model validation 


\section{ACKNOWLEDGMENTS}

Special thanks to, in no particular order: NASA \& C3RP for funding the experimental work on this project. Dr. Joseph Mello for insight and advice on the project. Dr. William Murray for his editing skills and liaison skills which helped procure the aforementioned funding. Dr. Patrick Lemieux for his help with all things thermal and fluid. Terry Cooke for being the rocket guru and making the experimental data gathering possible. Lauren Nelson for her work on the Bartz equations and energy methods. Jim Gerhardt for his excellent solid models and fabrication expertise. 


\section{TABLE OF CONTENTS}

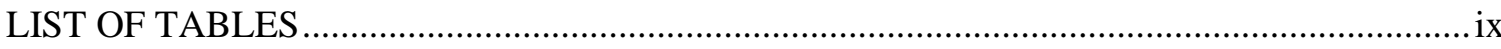

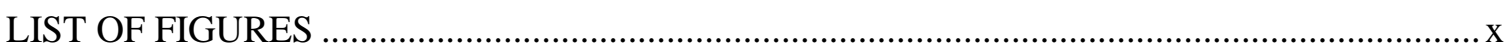

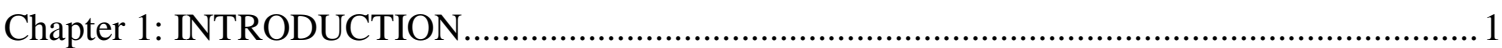

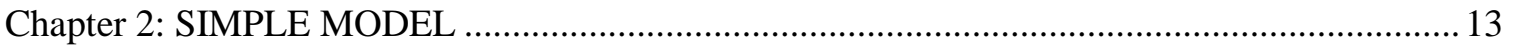

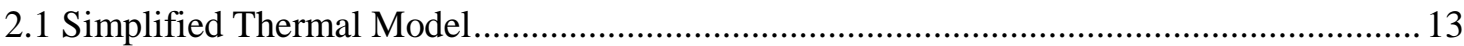

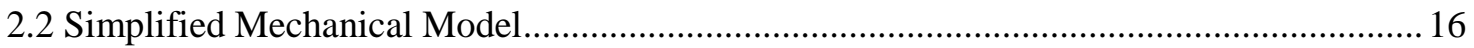

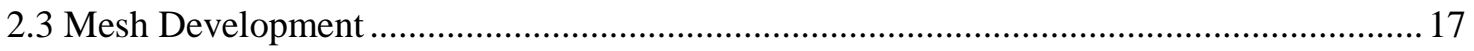

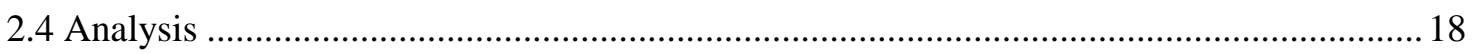

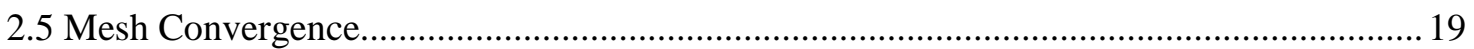

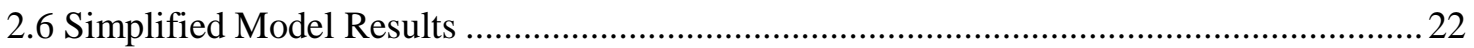

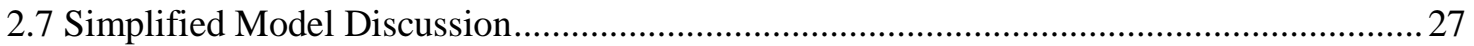

Chapter 3: EXPANDED THERMAL MODELING METHODOLOGY ….................................. 29

3.1 Simplified Model with Variable Film Coefficients ........................................................... 31

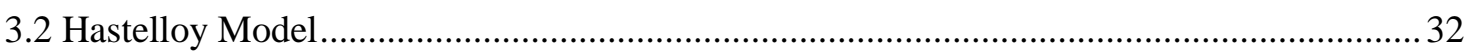

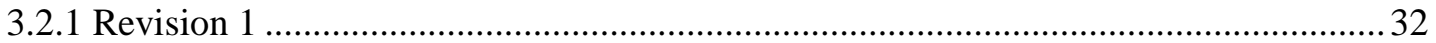

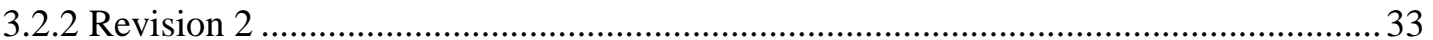

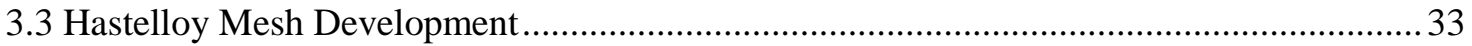

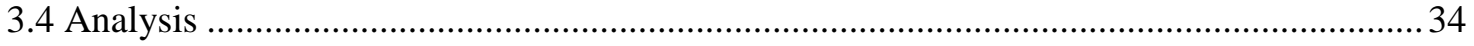

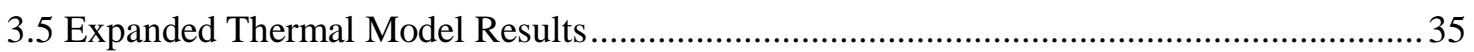

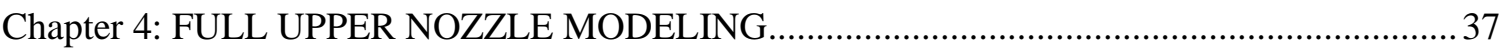

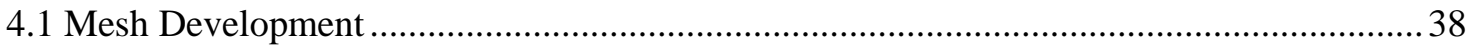

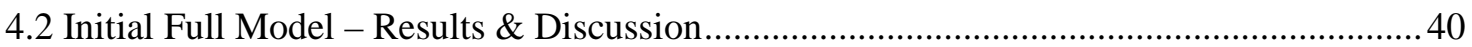

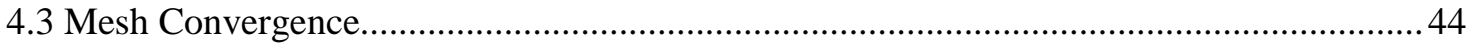

4.4 Finalized Full Nozzle - Model Parameters and Results ...................................................46

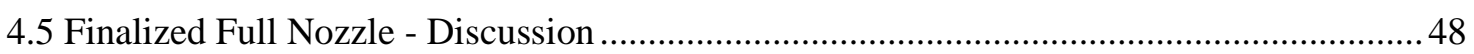

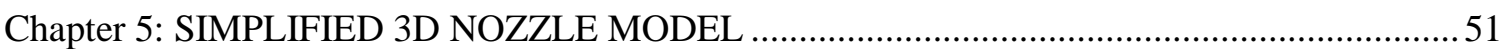

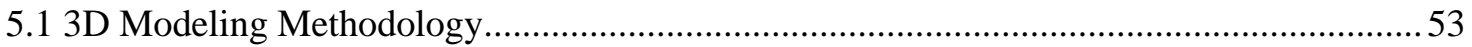

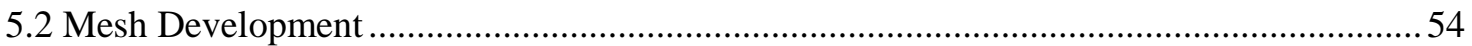

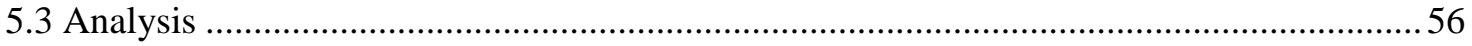

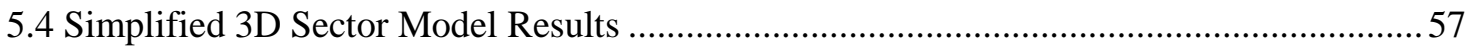

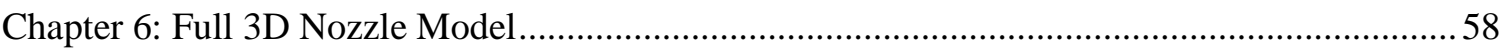

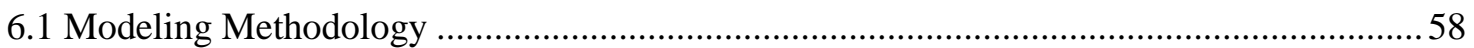

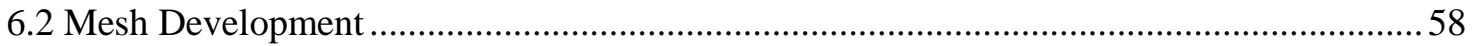

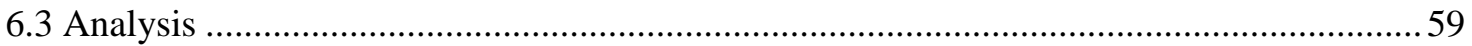

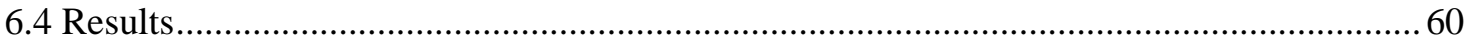




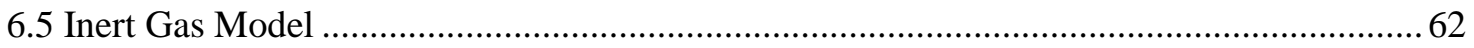

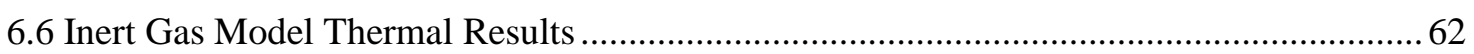

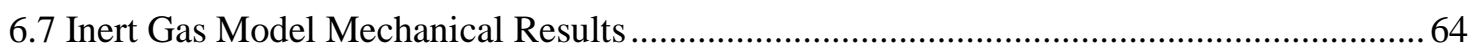

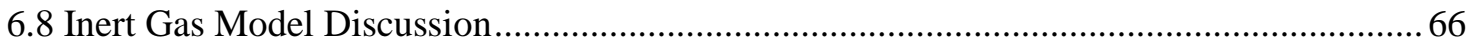

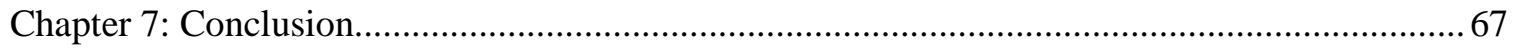

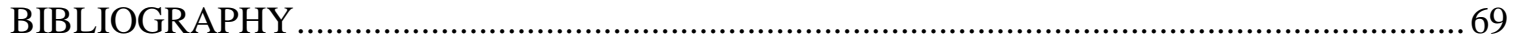

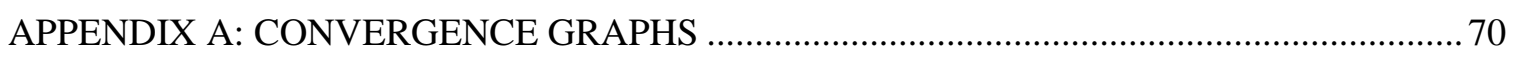

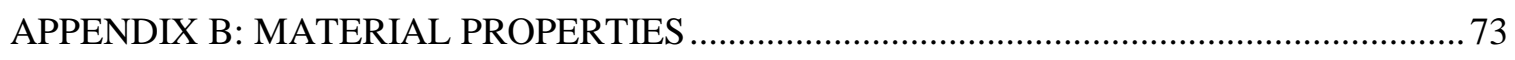

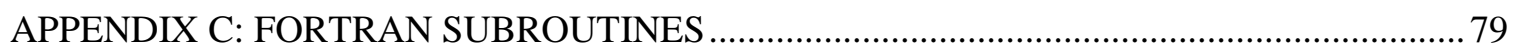




\section{LIST OF TABLES}

Table 1: Cold and hot side fluid sink temperatures and film coefficients ...............................................14

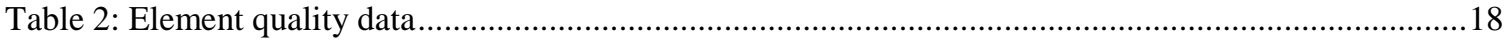

Table 3: Experimental and simulated average temperature data .......................................................24

Table 4: Location, time, and magnitude of key plastic strains shown in Figure 11 \& Figure 12................26

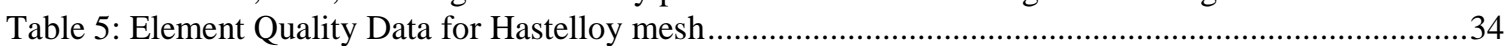

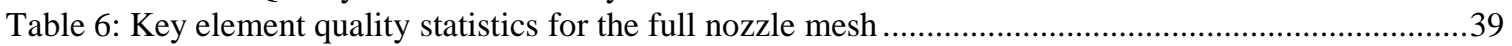

Table 7: Element Quality Data, simplified 3D sector model...............................................................55 


\section{LIST OF FIGURES}

Figure 1: Left: an annularly configured aerospike nozzle. Right: a linear aerospike nozzle. Images courtesy Garvey Spacecraft Corp. \& Lockheed Martin Corp.

Figure 2: Cross section drawing of the Cal Poly lab-scale hybrid rocket motor, shown here in the hollow single grain configuration. Image courtesy of Terry Cooke, NASA STTR Phase-1 Team. Figure 3: Cross section of the cooled throat nozzle used in the Cal Poly Mechanical Engineering Department with injectors and some thermocouple probes shown. All solid models courtesy of Jim Gerhardt, NASA STTR Phase-1 Team.

Figure 4: Section view of the throat and support ring of the hybrid rocket.

Figure 5: Combustion gas and Annulus fluid contact surfaces of the axisymmetric model.

Figure 6: Nodal locations where convergence studies were performed.

Figure 7: Convergence plot of the maximum temperature point shown in Figure 6.

Figure 8: Transient temperature data from the annulus side of the copper throat for an experimental rocket burn.

Figure 9: A contour plot of temperature at the end of the motor fire step with temperature in ${ }^{\circ} \mathrm{F}$. Nodes corresponding to thermocouple locations from experimental data are labeled.

Figure 10: Transient nodal temperature from the flange and annulus locations in the ABAQUS simulation.

Figure 11: Contour plot of plastic strain magnitude within the throat and support assembly after 5 fatigue cycles.

Figure 12: Contour plot of plastic strain magnitude within the throat and support assembly during the 5th cycle of steady state motor burn. These strains are summarized in Table 4.

Figure 13: Transient plot of plastic strain magnitude within the throat and support assembly during 5 fatigue cycles.

Figure 14: Comparison between transient data for the simplified thermal model and the Bartz equation thermal model.

Figure 15: The 2D axisymmetric full nozzle model, partitions included.

Figure 16: 2D full nozzle model mesh

Figure 17: Initial full nozzle model transient temperature data compared with Test Fire 57

thermocouple data

Figure 18: Parametric study transient temperature data. $\mathrm{h}_{\text {cold }}=0.01485-0.03485 \mathrm{~T}_{\text {cold }}=30 \mathrm{k}=0.005$

Figure 19: Parametric study transient temperature data. $\mathrm{h}_{\text {cold }}=0.03485 \mathrm{~T}_{\text {cold }}=30 \mathrm{k}=0.0005-10000$

Figure 20: Nodal locations for 2D Full Nozzle Convergence Study

Figure 21: Convergence plot at the copper/graphite junction location

Figure 22: Finalized full nozzle model transient temperature data, initial run

Figure 23: Transient temperature data for a parameter study of the graphite contact resistance

Figure 24: Rayleigh experiment throat insert with inlet/outlet barrier

Figure 25: The Rayleigh experiment nozzle assembly with additional instrumentation ports shown. 52 Figure 26: The initial 3D model, cut at the inlet/outlet barrier to increase the simplicity of the analysis. 54

Figure 27: Cut away view of the 3D sector model mesh

Figure 28: Temperature contour plot of the copper throat at $\mathrm{t}=23 \mathrm{~s}$, the end of the 'motor fire' step.

Temperature in ${ }^{\circ} \mathrm{F}$

Figure 29: Cutaway view of the 3D full nozzle model mesh

Figure 30: Temperature contour plot of the 3D full nozzle model at the end of motor fire. Temperatures shown in ${ }^{\circ} \mathrm{F}$.

Figure 31: Temperature contour of the copper throat at the end of motor fire predicted by the ideal gas simulation. Temperatures are shown in ${ }^{\circ} \mathrm{F}$.

Figure 32: Transient temperature data for the flange thermocouple location at three angular positions around the annulus in the ideal gas coolant simulation

Figure 33: Contour plot of maximum principle stress at the end of the 'Motor Fire' step of the simulation

Figure 34: Contour plot of maximum principle stress in the copper and stainless steel support ring at the end of the 'Motor Fire' step of the simulation 


\section{CHAPTER 1: INTRODUCTION}

Recently, the prospect of a single stage to orbit (SSTO) launch vehicle has become closer to a reality with new technology advances. The concept of SSTO is appetizing because of its theoretical low cost compared to multi stage rockets and its reliability. The main engineering problem is achieving the necessary ratio of propellant and structural mass to structural mass. According to Tsiolkovsky’s rocket equation, this ratio must be above about 10 to achieve orbit (1). In multi-stage rocket engines, the mass of the structure is constantly decreasing as stages are dropped during flight; however, in an SSTO vehicle, the entire structure is carried into space, thus making it harder to achieve the correct mass ratio. A number of advances in material technologies have decreased the weight of structures recently, but to carry a meaningful payload, other factors must be accounted for as well. Two of these are nozzle efficiency and motor efficiency. Two technologies which have gained some popularity in these fields are the aerospike nozzle and the hybrid rocket motor.

Hybrid rocket technology has existed for many years, but research in the field has recently resurfaced to explore use in SSTO launch vehicles. A hybrid rocket motor is typically characterized as a motor in which one propellant is stored in liquid or gaseous phase while the other is stored in solid phase, though some solid/solid, monopropellant, and ramjet motors have also been classified as hybrid because of the similarities between their combustion profiles and that of a traditional hybrid motor (2). The rise in popularity of this style of motor is due to its many benefits which, until recently, have apparently been outweighed by its disadvantages. The main advantages of using this type of motor are its high theoretical specific impulse, the safety of storage of its propulsion elements, which are inert when not placed together and combusted, and its start/stop/restart capabilities, which can be useful for long missions in which a single motor must be used, such as an SSTO launch, among other applications. Some disadvantages of hybrid 
motors are their relative complexity as compared with traditional motors and its varying specific impulse due to its varying fuel component mixture ratio. The mixture ratio varies because the surface area of the solid fuel grain exposed to the oxidizer is constantly changing.

A typical layout of a hybrid rocket motor consists of a hollow solid fuel grain whose center the gaseous oxidizer is injected through. Another configuration in an annular configuration in which there is a solid fuel grain surrounded by a small gap and then by a larger hollow fuel grain. In this configuration the oxidizer is injected into the annular combustion chamber between the two grains. Between the grain and the nozzle, there is generally a post-combustion chamber for the combustion gases to combine before being exhausted through the throat of the nozzle into the atmosphere.

Many different fuels and oxidizers can be employed in a hybrid rocket motor, creating a vast number of combinations that could be paired in any given application. Some oxidizers work better with some fuels, depending on various design criteria. Two common fuel grains are polymethly-methacrylate (Plexiglas $\left.{ }^{\circledR}\right)$ and hydroxyl-terminated polybutadiene (HTPB). A common oxidizer is $\mathrm{N}_{2} \mathrm{O}$, or nitrous oxide, but other fluids such as gaseous oxygen or hydrogen peroxide have been used as well. High energy metals such as aluminum have been added in powdered form to the fuel to achieve even greater specific impulse. For example, the winner of the Ansari X-Prize, a privately financed experimental space plane, used a HTPB/ $\mathrm{N}_{2} \mathrm{O}$ /Aluminum hybrid rocket motor to achieve two successive sub-orbital space flights.

Another rocket technology that has recently gained some popularity is the plug nozzle. A plug nozzle in its traditional form features an annular converging nozzle section with a circular plug or spike protruding from its center. In the original form of the plug nozzle, the spike tapers down to a sharp tip, a design known as the 'ideal' contour. Through research, the ideal curved contour 
was shown to be able to be shortened into a conical contour by as much as $30 \%$ with less than a $1 \%$ loss in efficiency. (3) Shortening the spike length would save valuable nozzle weight in the pursuit of the desired mass ratio. This configuration is known as an annular configuration, but there is another common configuration known as the linear configuration. In the linear configuration, the combustion chambers are all in a line and fire their hot gasses down a spike that has an identical cross section to the axisymmetric cross section of the annular spike.

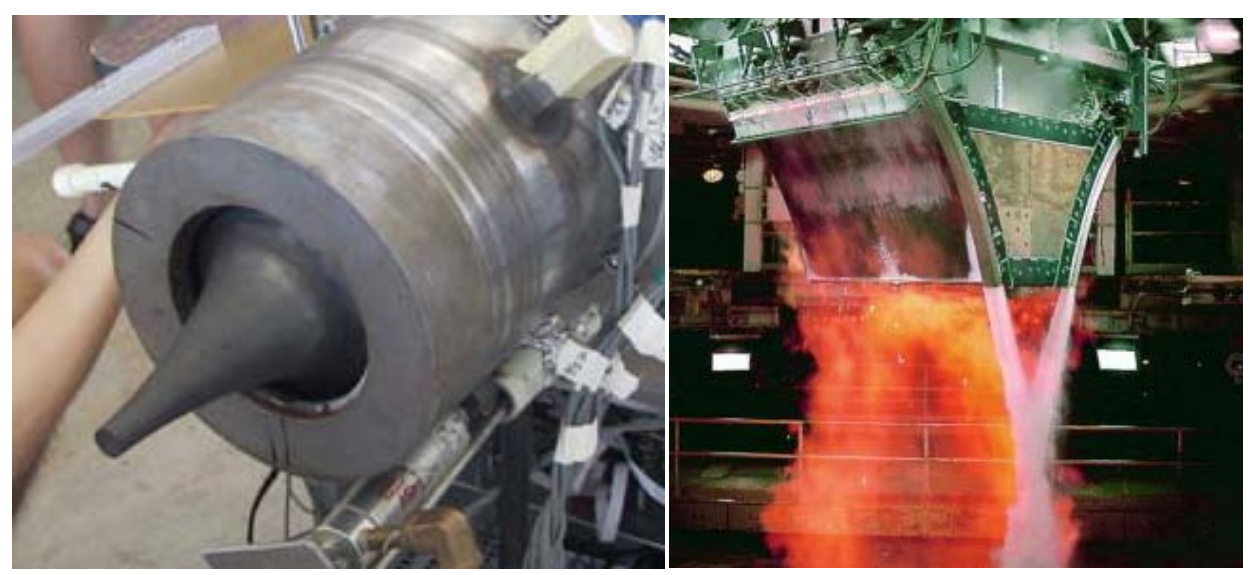

Figure 1: Left: an annularly configured aerospike nozzle. Right: a linear aerospike nozzle. Images courtesy Garvey Spacecraft Corp. \& Lockheed Martin Corp.

Plug type nozzles have a number of distinct advantages over traditional de Laval type nozzles. The main two are altitude compensation and throttling.

Traditional bell nozzles have a profile designed for a specific altitude (ambient pressure) and experience performance drops when the nozzle is not operating at that altitude. When the ambient pressure is lower than the design pressure, the exhaust gasses must continue expanding after exiting the end of the bell nozzle in order to equalize pressure with the atmosphere. This creates a loss of efficiency because some of the exhaust gas momentum is transferred into the transverse direction and provides no thrust. In this case the nozzle is said to be under-expanded. Conversely, when the ambient pressure is higher than the design pressure, the exhaust gasses 
separate from the nozzle wall and recompress to equalize in pressure. This causes a lost in thrust because the gasses are exerting pressure along a smaller area of the nozzle. A plug nozzle does not experience this effect because of inherent properties of the gas expansion around its profile. At high ambient pressure, the gasses compress against the upper portion of the spike as they are reoriented into the axial direction of thrust and never separate from the nozzle wall and thus do not experience over expansion. At low ambient pressure, shockwaves occur at the outer free stream boundary of the exhaust gasses and cause the flow to remain axially oriented and avoid experiencing under expansion. This increase in efficiency allows a decrease in the amount of fuel necessary to reach a given altitude, making a plug nozzle an excellent candidate for SSTO launch vehicles.

Plug nozzles also possess the advantage of throttling. In a rocket motor, throat area is designed around a specific chamber pressure at which the motor should theoretically burn consistently through its operation. In reality, the chamber pressure varies in an inconsistent manner, which makes it advantageous to change the throat area during the course of a burn. With an annularly configured plug nozzle this can be accomplished with a simple controller and an actuated plug which is adjusted fore or aft in the nozzle body, changing the throat area, based on instantaneous chamber pressure readings. This further increases the efficiency of the plug type nozzle.

A common adaptation to the plug nozzle is the aerospike nozzle, also known as a truncated spike nozzle. Because of how the exhaust gas pressure is applied to the spike contour, most of the pressure is applied along the upper portion of the spike and tapers down with axial progression along the spike contour. This allows a weight and length savings when designing an aerospike nozzle. There is a performance loss associated with the truncation of the spike; however, a large amount of study has been put into determining the percentage of the spike to be truncated, as well as additional modifications to increase the performance of a truncated spike. Most, if not all, 
aerospikes now feature a process called base bleed. In this process, the base of the truncated spike (where the cut was made) is perforated with many small holes through which a low pressure fluid flows during operation. The addition of this gas in the void behind the flat base of the aerospike increases the thrust of the aerospike back into the range of the thrust of a full length spike.

Despite their advantages, plug nozzles also possess a number of disadvantages. The major disadvantage of this type of nozzle is thermal loading because plug nozzles experience very high heat loads. The heat loads occur because the main portion of the nozzle is located within the hot gas stream which creates the problem of avoiding thermally induced failure and some sort of cooling system becomes necessary. Garvey, Besnard, and students from California State University at Long Beach used a graphite plug and nozzle body with no active cooling, relying completely on radiation cooling. Other plug type nozzles, such as the XRS-2200 linear aerospike engine use regenerative cooling. These and other various types of cooling will be discussed later in this section.

As of June 2009, no major launch vehicles have employed a plug or aerospike nozzle. The most recent attempt was Lockheed's X-33 SSTO reusable launch vehicle concept, which featured a large linear aerospike as its primary propulsion system. The aerospike underwent successful ground testing, but the X-33 project was cancelled and the engine never flown.

Like the aerospike, most rockets actually need cooling for their combustion chamber and throat regions and this cooling has been accomplished using a variety of methods. The simplest method allows the chamber and throat to heat up transiently until the material reaches a set temperature, at which point the engine is shut off. Usually the walls of the chamber are thick and designed to soak up as much heat as possible before reaching the design limit. The disadvantages of this 
method are apparent, and include short burn time and high thermal gradients which can produce yielding and deformation.

Similar to this method in simplicity is ablative cooling. Ablative cooling is accomplished by creating the chamber and throat from a composite material, usually consisting of fibers and matrix, and relying on the endothermic reaction of the material with the combustion gasses, pyrolysis of the matrix, charring, and localized melting. Essentially, gases seep out of the matrix material and form a relatively cool film between the material and the combustion gas, while the top layer of fibers and residues form a hard char that preserves the shape of the chamber and throat. In general, however, ablative cooling cannot be used under high chamber pressures, highly oxidative environments, or long duration firings.

Active cooling is commonly used in rocket combustion chambers and throats. The most well known is regenerative cooling, which gets its name from its similarity to regeneration steps in thermodynamic cycles. In this method, the combustion chamber is constructed with a jacket around it or, in some cases, a wall of tubes around it, through which passes the cool fuel or oxidizer. The cooling fluid absorbs heat and is then fed into the injectors of the combustion chamber and combusted. Because the fuel or oxidizer is hotter when it enters the combustion chamber than it would have been without passing through the cooling passages first, less energy is used to combust the products and the exhaust velocity of the products increases by a small percentage. This method is used on the main engine of the space shuttle. (4)

A second active cooling method is called film cooling. Film cooling functions by injecting a cool fluid against the chamber walls near fuel injectors which creates a film barrier between the walls and the combustion gasses. In general, this method is used in conjunction with another method of cooling such as regenerative cooling. Another method similar to this is transpiration cooling, 
where the cooling layer is formed by 'sweating' the cooling fluid through pores in the chamber and throat walls.

A third form of active cooling is called dump cooling. This is essentially regenerative cooling without recycling the coolant. This enables fluids other than the fuel or oxidizer to be used as a coolant if desired.

In the attempt to create a viable SSTO launch vehicle, efficiency and weight are two major considerations in the design process. This has led to the investigation of pairing an annularly configured aerospike nozzle with a hybrid rocket motor. The inherent efficiency advantages of each, paired together, could be the foundation for creating a lightweight solution to the SSTO problem. One of the immediately apparent advantages of this pairing is the use of the annularly configured two-part fuel grain as a method of insulating the stem of the spike from hot combustion gasses. This configuration leaves only the upper portion of the spike in contact with the hot gasses. With this in mind, California Polytechnic State University at San Luis Obispo (Cal Poly) has recently undertaken some projects to prove the feasibility of this hybrid motor/spike nozzle concept.

One of these projects performed a computational fluid dynamics (CFD) analysis of hot flow through an uncooled aerospike in conjunction with a sequentially coupled thermal/mechanical analysis of the spike to determine the life span of an uncooled spike (5). The scope of this project was too small to include any active or passive cooling, so it focused mostly on material selection and modeling process. Using the data from the CFD analysis, the thermal analysis used a 2D axisymmetric model to predict the transient temperature distribution through a lab-scale aerospike nozzle using various materials including Carbon-Silicon Carbide (C-SiC) and Columbium. This simulation predicted thermal failure within 4 seconds of ignition. The mechanical model, using 
the computed transient thermal gradients from the thermal model, predicted mechanical failure within 2 seconds of ignition. This led to the conclusion that some form of cooling would be necessary in this spike for feasibility of use.

Students at the California State University at Long Beach (CSULB) constructed, tested, and flew a liquid propellant aerospike nozzle whose major components were made from graphite (6). Graphite is a known high temperature material and, in this case, used no active cooling. The first static test that the graphite engine underwent ended in catastrophic failure of the graphite plug causing the combustion chamber to explode. After reinforcement of the spike with an internal titanium rod, the engine was successfully tested, mounted on a rocket and flown (7). A part of the nozzle liner experienced some thrust leakage which resulted in asymmetric thrust, causing the rocket to enter unstable flight. After recovery, the engine was rebuilt and flown again 3 months later for a total burn time of 8 seconds before successful parachute deployment, demonstrating the short duration effectiveness of an uncooled aerospike nozzle. Despite the success of this project, the nature of an uncooled nozzle and the results of the Cal Poly numerical study suggest that during a longer burn, the nozzle would overheat and fail. This necessitates the use of some sort of active cooling to cool the aerospike assembly for longer burns such as those occurring during SSTO launches.

With this in mind, the design process for a cooled aerospike began. The system under investigation consists of an annularly configured HTPB or Plexiglas and $\mathrm{N}_{2} \mathrm{O}$ hybrid rocket motor paired with an annular aerospike using $\mathrm{N}_{2} \mathrm{O}$ as the cooling fluid. The initial thought was to employ a concept that uses about $1 \%$ of the total flow as coolant base bleed through a truncated spike. A relatively simple solution to the design problem would be to guess the materials and geometry to use in the spike and its cooling system, fabricate it, and test it; however, this 'guess and check' method is flawed for a number of reasons. It was learned from the failure of the 
CSULB plug that there is a possibility of explosion that accompanies the failure of a spike. In an indoor laboratory test environment, as opposed to an outdoor desert test facility, this outcome is unacceptable because of the damage that could occur to the laboratory, other projects within the laboratory, and the test engineers. Additionally, a parametric study of different cooling designs is expensive and time consuming if each configuration must be manufactured. Instead, to properly design a cooled lab scale aerospike nozzle to be paired with a hybrid rocket motor, an accurate and reliable finite element model is necessary.

The goals which the model will help accomplish are:

1. Determine the expected maximum temperature and maximum thermal stresses within the aerospike and nozzle body based on a given cooling system.

2. Determine the reusability of the aerospike via a life cycle analysis.

To responsibly use the results from a computer model, the results must be validated against hand calculations and/or experimental data. In this case, this means creating an instrumentable rocket nozzle which uses a similar cooling method to the proposed aerospike, creating a computer model of the nozzle, and then matching the model to the experimental data gathered from firing the instrumented assembly. This led to the fabrication of a conventional converging/diverging nozzle with a circumferential cooling channel around the throat. This allowed the throat to be instrumented with thermocouples to follow the cooling fluid temperature and the throat temperature, which provided data with which to compare model predictions. In this case, the coolant flow is 2-phase and cannot be accurately modeled in a CFD program within the scope of this project, which leaves experimental data as the sole method by which to determine the film coefficient. 
This rocket nozzle uses the same hybrid motor as the proposed aerospike, and is constructed with a graphite converging section liner which connects to the copper throat section followed by a Hastelloy diverging section. The cooling annulus is formed between the copper throat and a stainless steel supporting ring, through which the cooling channel instrumentation is inserted via compression fittings. This converging/diverging nozzle rocket serves two purposes. The first is to provide data with which to create an accurate computer model. The second is to prove reusability of the cooled nozzle configuration to compare to what the computer model predicts as the life cycle of the nozzle.

The computer modeling for this step of the experiment will occur across multiple models. The first model is a simplified 2-D axisymmetric model with averaged coefficients. The results of this model can be compared with the results of the experimental rocket firings to see if the model is relatively accurate. The second model expands the simplified 2-D axisymmetric model to include more parts and variable combustion gas side film coefficients and sink temperatures to validate the simplification assumptions from the first model. Finally, a 3-D model with variable combustion gas and coolant film coefficients and sink temperatures will be created to fully validate the modeling procedure.

Once the modeling techniques and values have been proven accurate, a later analysis may undertake design of an aerospike and recommendations can be made for the fabrication of a cooled annular aerospike.

The Cal Poly rocket motor is a 6-inch diameter cylinder which is a little over 1 foot long. Inside the cylinder is a 1 foot long fuel grain and a small pre-combustion chamber into which the oxidizer is injected. The pre-combustion chamber allows the oxidizer to more evenly enter the combustion chamber, which, for the experiments discussed in this paper, is configured annularly. 


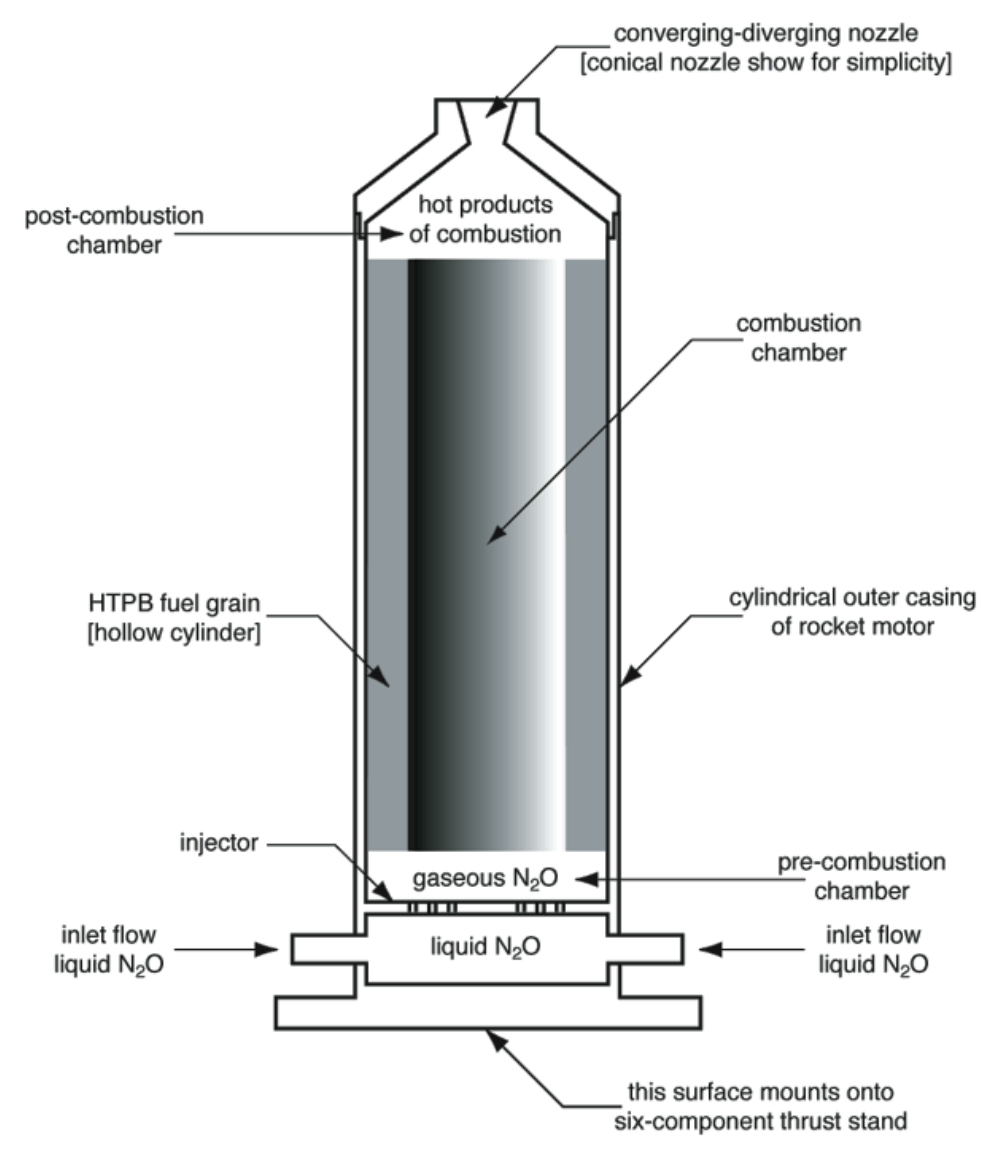

Figure 2: Cross section drawing of the Cal Poly lab-scale hybrid rocket motor, shown here in the hollow single grain configuration. Image courtesy of Terry Cooke, NASA STTR Phase-1 Team.

On top of the fuel grains is the converging nozzle section. This section consists of a converging graphite liner, which transitions to the cooled copper throat section, followed by a Haynes Hastelloy diverging section. Hastelloy is a proprietary high temperature alloy developed by Haynes International, Inc. Brazed to the throat is a stainless steel support ring, held in place by the Hastelloy and a stainless steel cap, through which fasteners run and thread into the main stainless steel nozzle body. In the Cal Poly laboratory, the motor is mounted to exhaust upwards into an exhaust hood. 


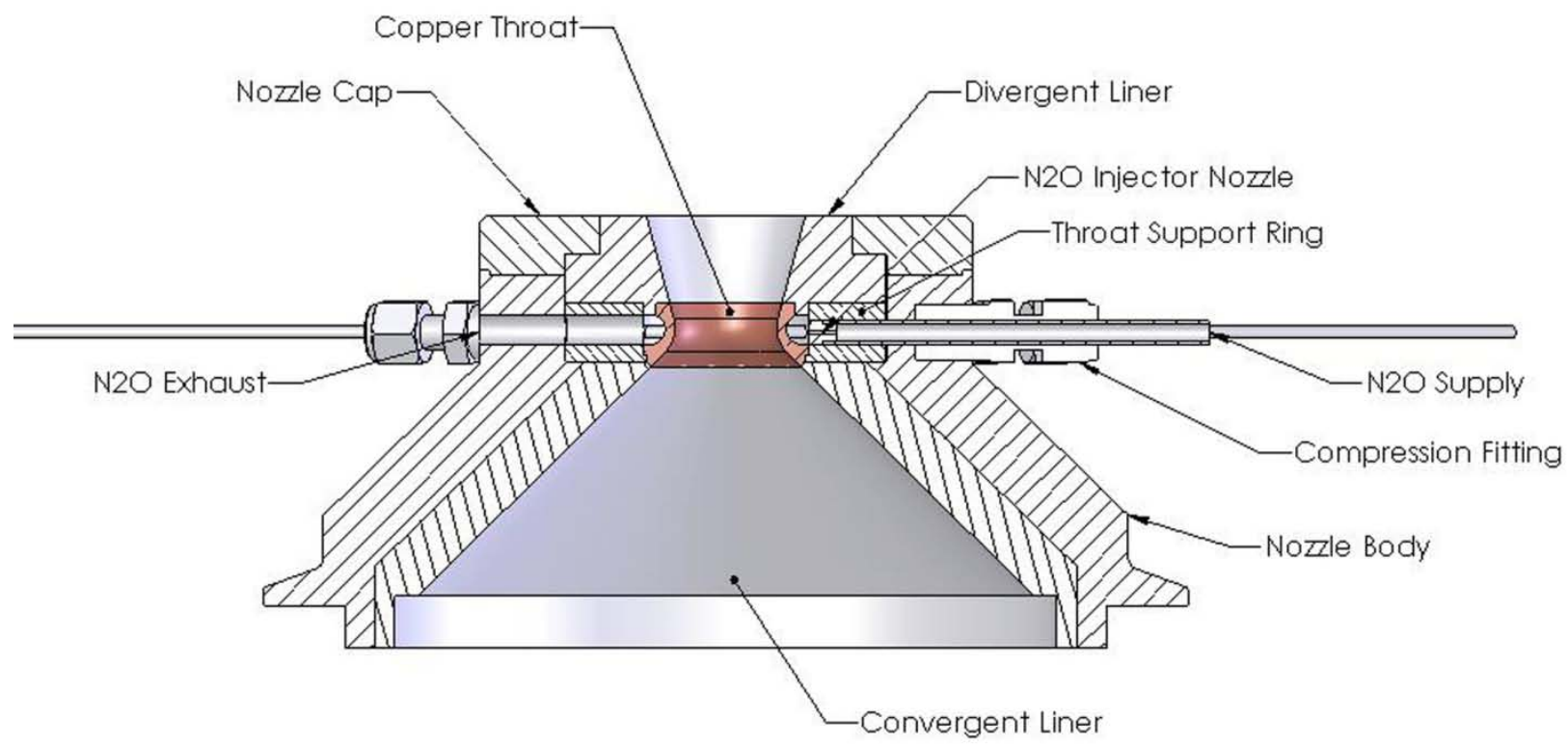

Figure 3: Cross section of the cooled throat nozzle used in the Cal Poly Mechanical Engineering Department with injectors and some thermocouple probes shown. All solid models courtesy of Jim Gerhardt, NASA STTR Phase-1 Team. 


\section{CHAPTER 2: SIMPLE MODEL}

\subsection{SIMPLIFIED THERMAL MODEL}

The nozzle from which experimental data was to be gathered was designed in SolidWorks and provided solid models as starting points for creating a finite element model in ABAQUS. The model consists of the copper throat joined with the stainless steel support ring, between which is the cooling annulus. A section view of the throat and support ring can be seen in Figure 4 .

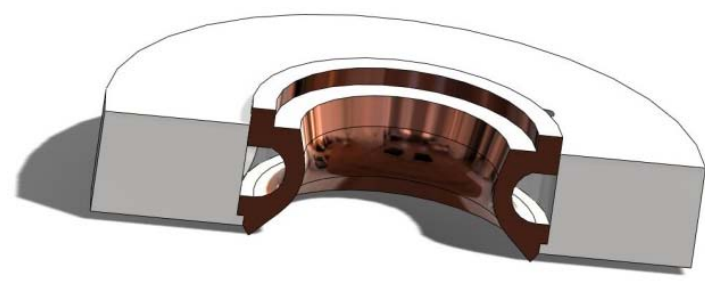

Figure 4: Section view of the throat and support ring of the hybrid rocket.

MODEL TYPE - The type of model used in this initial modeling attempt was a 2-D axisymmetric transient heat transfer model, the cross section of which can be seen in the section view of Figure 4. In this instance the cross-section on the right-hand side of Figure 4 was used.

LOADING STEPS - To model a typical motor burn, the model was created with 4 steps in addition to its initial state of room temperature throughout. In a typical burn the nozzle is exposed to 1) preliminary coolant flow (Coolant On), 2) firing the rocket (Motor Fire), 3) shutting off the rocket (Motor Shutdown), and 4) shutting off the coolant (Coolant Shutdown) and letting the nozzle body soak at room temperature with natural convection.

MATERIAL PROPERTIES - Over the temperature range to which the model was subjected, the properties of both the copper and the stainless steel vary non-linearly. Each of the materials was modeled with temperature dependent data gathered from experimental testing. Material data may be viewed in APPENDIX B: MATERIAL PROPERTIES. 
INTERACTIONS - There are three major interactions in the model and two minor ones. The first is the tie constraint between the copper throat and the stainless steel support ring. This models perfect conduction between the two materials and was used because of the lack of data on contact resistance between the copper, the stainless steel and the braze weld which joins them.

The two remaining major interactions are the film conditions and sink temperatures of the combustion gasses and the coolant applied to the respective surfaces shown in Figure 5. These values are averaged values calculated from the experimental data using an energy method and are shown in Table 1. The activation/inactivation of these interactions varies by step. In step 1, only the coolant film condition is active. In step 2 both the coolant and combustion gas film conditions are active. In step 3, only the coolant film condition is active, and in step 4, both of the film conditions are inactive.

\begin{tabular}{|ll|}
\hline Variable & Value \\
\hline $\mathrm{T}_{\text {hot }}$ & $2982^{\circ} \mathrm{F}$ \\
\hline $\mathrm{T}_{\text {cool }}$ & $70^{\circ} \mathrm{F}$ \\
\hline $\mathrm{h}_{\text {hot }}$ & $.0025 \mathrm{Btu} / \mathrm{in}^{2} \cdot \mathrm{sec}^{\circ}{ }^{\circ} \mathrm{R}$ \\
\hline $\mathrm{h}_{\text {cool }}$ & $.0195 \mathrm{Btu} / \mathrm{in}^{2} \cdot \mathrm{sec} \cdot{ }^{\circ} \mathrm{R}$ \\
\hline
\end{tabular}

Table 1: Cold and hot side fluid sink temperatures and film coefficients 


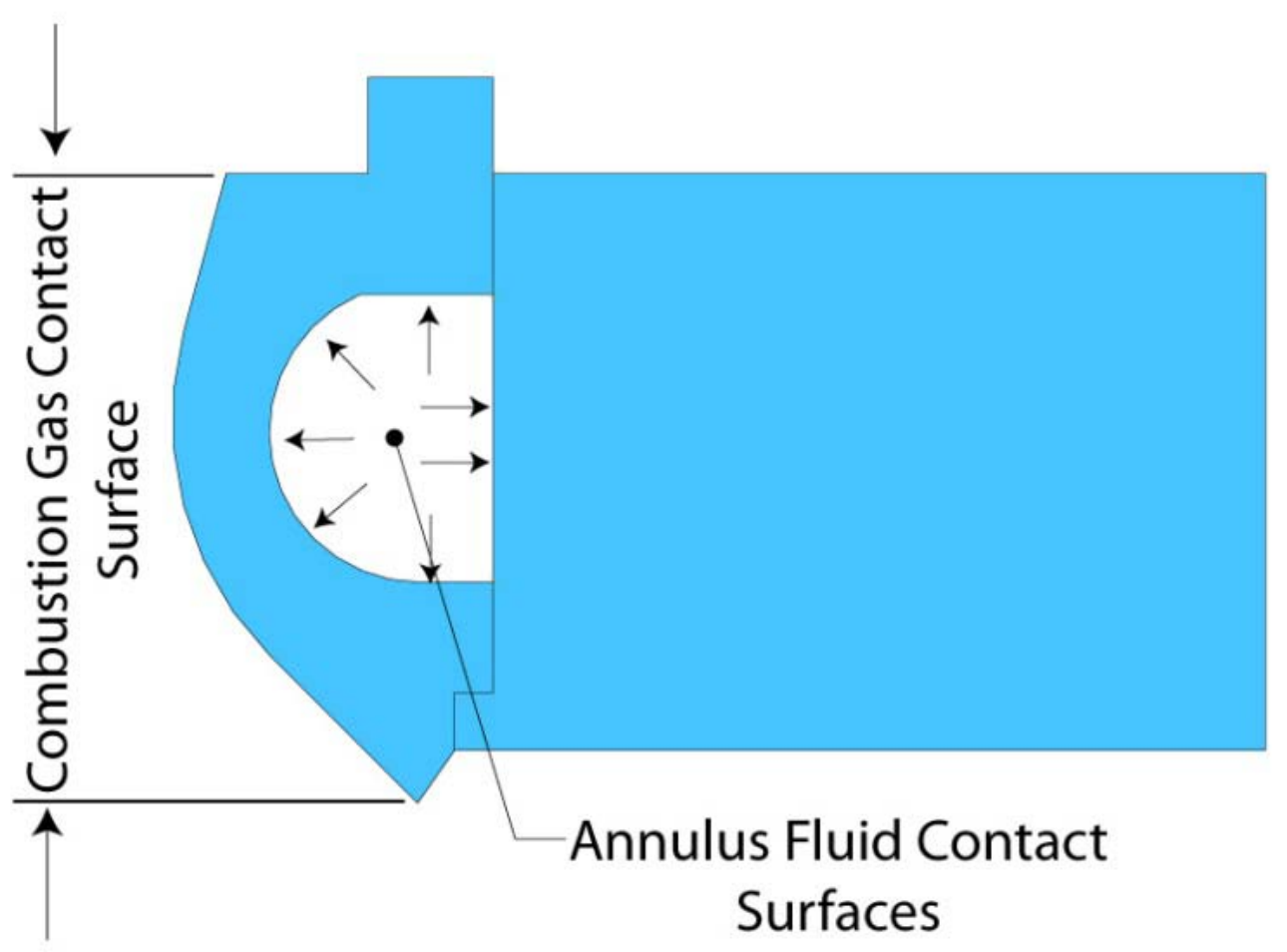

Figure 5: Combustion gas and Annulus fluid contact surfaces of the axisymmetric model.

The two minor interactions are natural convection film coefficients and sink temperatures which are applied whenever the two major film condition interactions discussed above are inactive.

It is important to note that all surfaces not in contact with the combustion gasses or the coolant fluid are modeled as adiabatic. This assumption was made because data on the heat flux out of the throat assembly is unavailable and can be assumed to be negligible upon inspection of preliminary trial runs and the radial nature of the heat transfer from the hot inner radius of ALL parts of the nozzle to the cool outer radius.

LOADING - The only prescribed load which the model undergoes is a model-wide initial temperature of $70^{\circ} \mathrm{F}$. 


\subsection{SIMPLIFIED MECHANICAL MODEL}

The mechanical model uses the same geometry and mesh as the thermal model, which makes it easier to map the nodal temperature data from the thermal model output into the mechanical model. Likewise, the mechanical model uses the same step sequence as the thermal model, however the mechanical model possesses some parameters that were not used in the thermal simulation.

MATERIAL PROPERTIES - The variation of material properties with temperature is not limited to thermal-related properties. Temperature dependent data was also used for coefficient of thermal expansion, elasticity and plasticity. The plasticity model used was a combined isotropic/kinematic hardening model. This model was chosen because of its accuracy in predicting low cycle fatigue plastic strain without the need for linearization around a point, and because the necessary experimentally determined hardening parameters were available (as opposed to being confined to a lower order model because of the lack of material data).

INTERACTIONS - The two parts were again connected to each other using a tie constraint to simulate the braze weld between them.

LOADING - Similar to the thermal model, the mechanical model was initialized with a predefined temperature field of $70^{\circ} \mathrm{F}$; however, this was followed by the read-in time dependent nodal temperatures from the thermal model. Additionally, during the steps where coolant was flowing, a pressure was applied to the inside of the annulus. Similarly, when the motor was firing, a pressure was applied to the throat surface. These pressure forces could produce negligible effects but were included to increase accuracy and because computational efficiency was not an issue for this portion of the simulation. 


\subsection{MESH DEVELOPMENT}

The meshing of the model was a critical step in creating an efficient model. The copper throat experienced most of the thermal loading, so a sufficiently refined mesh was necessary throughout the part and an initial size of 0.01 in. was chosen as a seed size to allow at least 5 elements across the thickness of the copper. The stainless steel mesh was then made to match the copper mesh in terms of global seed size. This level of refinement in the stainless steel mesh proved to be disadvantageous because the non-linear transient nature of the model combined with the overly refined mesh in the stainless steel caused the model to take up to an hour to run. 'Overly refined' in this case applies to the steel because the radially outermost portion of the steel undergoes almost no heat transfer and has a smaller thermal gradient as compared to the innermost portion which is in contact with the copper. The long run time led to a seed biasing scheme in the stainless so that the mesh would become less refined as it moved away from the copper. The biased mesh reduced the run time by about half and as will be seen in the convergence study later, affected the temperature negligibly.

The element type used throughout the model is 'linear heat transfer' (DCAX4/DCAX3). The full selection of meshing algorithms that ABAQUS has to offer was experimented with and a number of qualities of each were noted. The most effective for use in a convergence study proved to be a free mesh with the advancing front algorithm, quadrilateral elements in the support, and quadrilateral-dominated elements in the throat. This meshing scheme is effective because the advancing front mesh would always match node placement with seed placement when using a biased seeding scheme, which would allow the copper mesh to tie in exactly with the steel mesh. Also used was the 'medial axis' meshing algorithm. This algorithm yielded a cleaner and more structured mesh, however, it proved difficult to work with when using a biased mesh and an effective convergence study was more difficult to accomplish. This led to the convergence study being performed with the advancing front algorithm. Additionally, because a structured mesh 
produces better results in stress analysis FEA procedures, a thermal run was conducted with the medial axis mesh and used for the mechanical study. The thermal values using this mesh were compared with the values of the convergence study to ensure that the medial axis mesh was converged on acceptable values. The convergence study will be discussed in its own section of this paper. In the final mesh the thermal study featured 3633 degrees of freedom, and the mechanical model featured 6924. Key element quality numbers which verify the overall quality of the mesh are shown in Table 2.

\section{Table 2: Element quality data}

\begin{tabular}{|lll|}
\hline Quality Measure & Limit & $\%$ Elements Outside Limit \\
\hline Aspect Ratio & $<3: 1$ & $0.0 \%$ \\
\hline Min/Max Angle - Quadrilateral & $45^{\circ}<\theta<135^{\circ}$ & $0.2 \%$ \\
\hline Min/Max Angle - Triangle & $45^{\circ}<\theta<75^{\circ}$ & $0.2 \%$ \\
\hline
\end{tabular}

\subsection{ANALYSIS}

THERMAL ANALYSIS - The analysis performed was a simple transient heat transfer analysis with a quasi-Newton solver used for the ‘motor on’ step and a full Newton solver used for each other step. The quasi-Newton solver was used as opposed to a full Newton solver in order to be more computationally efficient due to the long simulation time for that step.

Two warnings were displayed during the thermal analysis. The first warning noted that small adjustments had been made in node positions along the tie constraint between the copper and the stainless steel. This is acceptable because the parts remain in contact throughout the simulation and the stainless steel was meshed so that the meshes would match along the line of contact. The second warning stated that severe discontinuity iteration (SDI) conversion is not available for heat transfer analyses in ABAQUS. This is also acceptable because the conversion of SDIs is a tool that is necessary in problems such as stick/slip or open/close contact problems where there is 
a difficulty in obtaining convergence over many increments of iteration. Without the availability of SDI conversion, the solver iterates until the SDI is sufficiently small or zero, which takes more time, but yields a more accurate iteration.

MECHANICAL ANALYSIS - The analysis performed was a general static analysis with transient steps. This analysis type meant that though the analysis was 'static' it actually occurred over a series of static steps, in this case these steps correspond to those read in from the thermal simulation. The mechanical model is run 5 times in sequence to show the plastic deformation fatigue performance of the assembly.

The only warning noted by ABAQUS stated that the strain measure 'LE' was not valid for some elements of the analysis, so the strain measure ' $\mathrm{E}$ ' was used instead. This is an acceptable condition. Logarithmic strain, 'LE', is the default strain measure for the simulation because it has been shown to yield accurate results for elastic-plastic deformations that correlate across tension, compression, and torsion. Integrated strain ' $\mathrm{E}$ ' is an integration of the strain rate, and has also been shown to be an acceptable measure for elastic-plastic deformations; however, the correlation between compression, tension, and torsion is not as distinct as 'LE'. In this case, torsion and compression can be considered to be negligible because the material is thermally expanding and in constant tension throughout, meaning that the use of integrated strain should yield accurate results.

\subsection{MESH CONVERGENCE}

An h-type mesh convergence was performed to determine the adequacy of the mesh. This began with a mesh that featured 162 degrees of freedom and finished with a mesh that featured 3506 degrees of freedom. The change in the number of degrees of freedom was accomplished by 
decreasing the global seed size in the copper part, and decreasing the edge seed size or increasing the number of biased seeds in the steel part. Figure 6 shows the nodal locations where convergence studies were made.

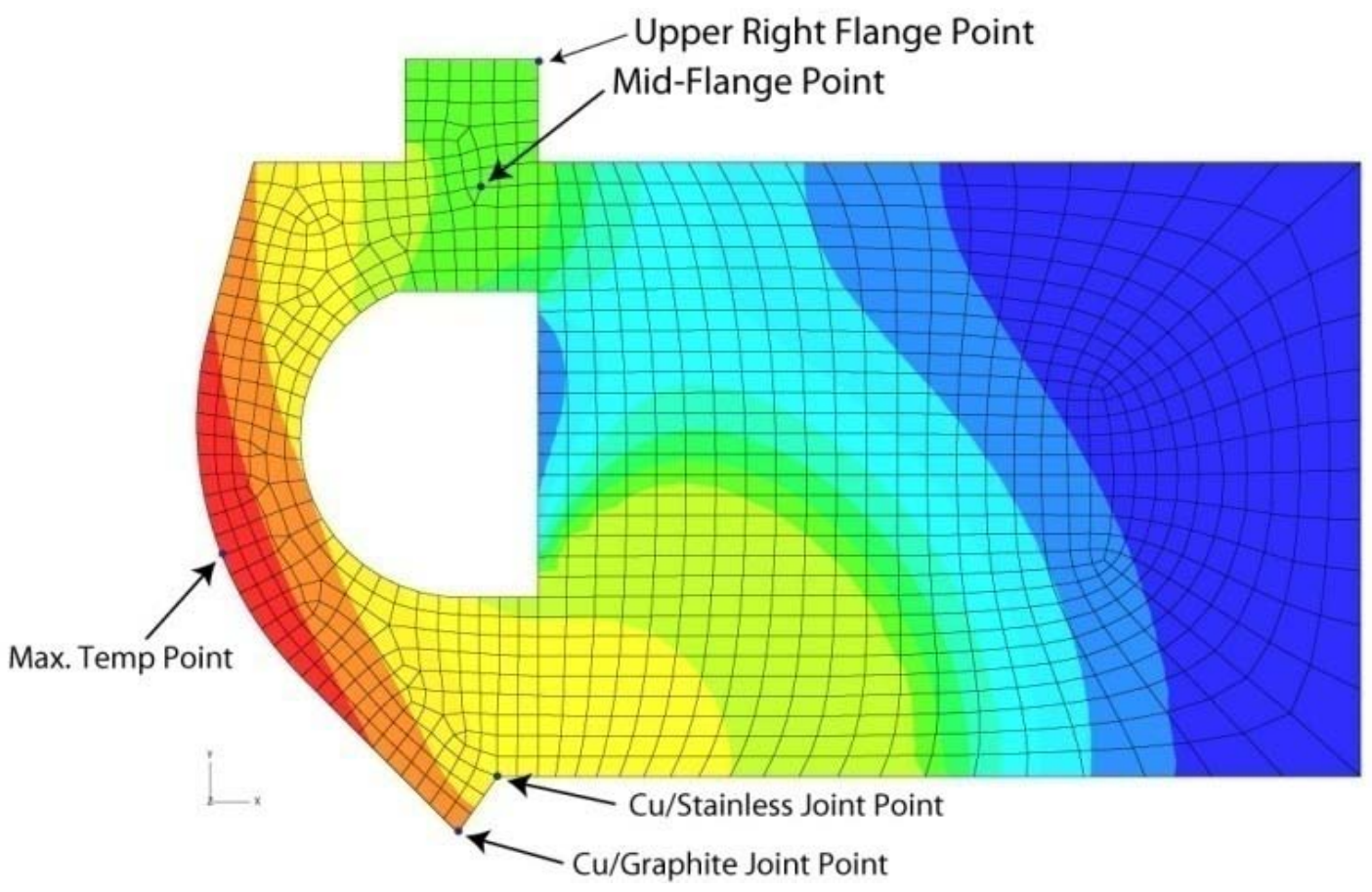

Figure 6: Nodal locations where convergence studies were performed.

A convergence plot of the maximum temperature point can be seen in Figure 7. The remaining convergence plots can be seen in APPENDIX A: CONVERGENCE GRAPHS. 


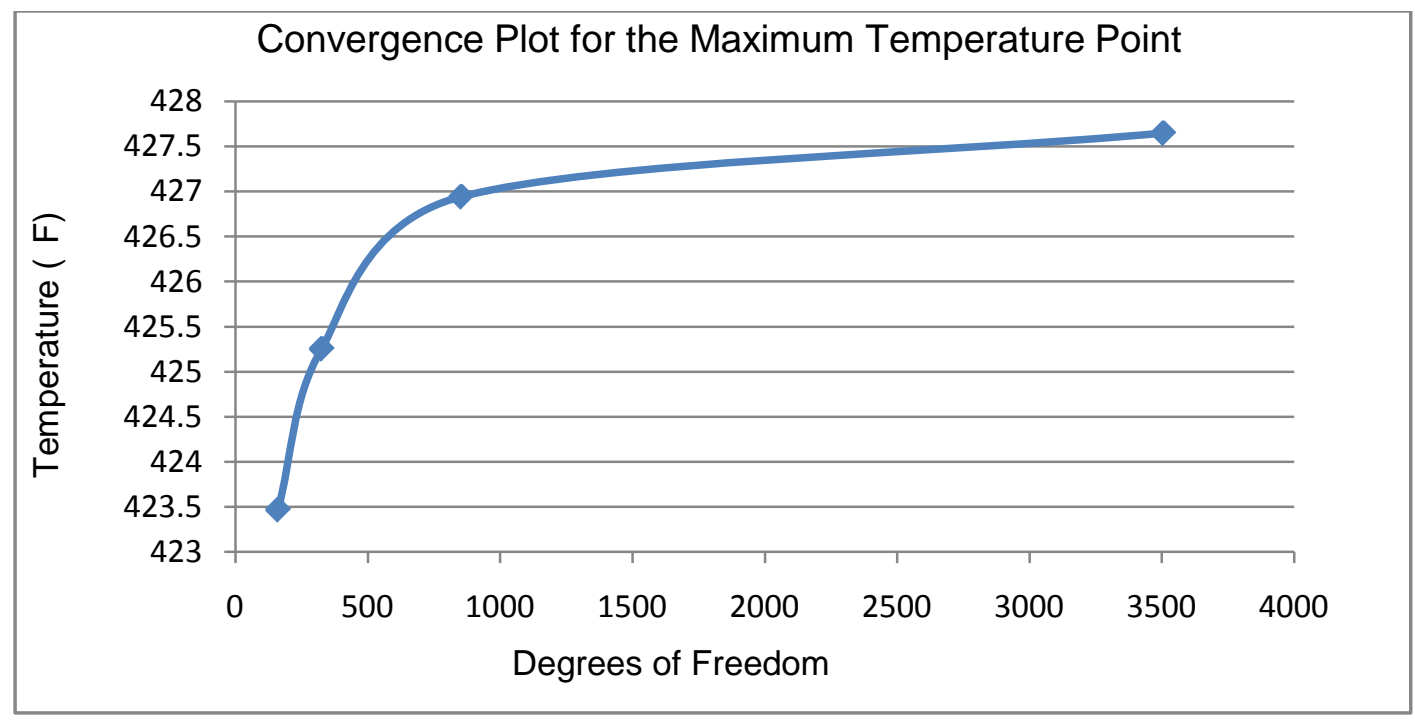

Figure 7: Convergence plot of the maximum temperature point shown in Figure 6.

A number of observations can be made about the results of the convergence study.

Firstly, the percent difference in nodal temperature values between each step was $1 \%$ or less in every refinement except one which changed by $2.3 \%$. This lends confidence to any inaccuracies of the study being unrelated to the mesh.

Secondly, the use of a free, advancing front mesh was non-ideal for a thermal study because of phenomena such as numerical diffusion. Because of the limitations encountered when using the meshing algorithms provided within ABAQUS, if a very high degree of accuracy was desired, a $3^{\text {rd }}$ party meshing program more capable of handling complex geometry and biasing would be desired.

Lastly, the necessity of such high accuracy is negated by the nature of the experimental results with which the data will be compared. The experimental data does not exhibit typical steady state or transient characteristics of a simple heat transfer problem, possibly due to the complexity of the two phase cooling flow within the annulus or anomalies of using an annularly configured hybrid rocket motor. The data with which the simulation will be compared are averaged values 
from the experimental data, and thus are representative of a range of temperatures read by the thermocouples in the experiment.

With these observations in mind, the mesh is considered fully converged, especially within the bounds of accuracy required for matching to the averaged experimental data.

\subsection{SIMPLIFIED MODEL RESULTS}

THERMAL SIMULATION - The thermal results matched well to the experimental test burn.

The data featured four thermocouples staked to the annulus side of the copper throat between the inlet and outlet of the coolant. The average of these four thermocouples was used as the comparison for this study. The transient data collected from these thermocouples is shown in Figure 8.

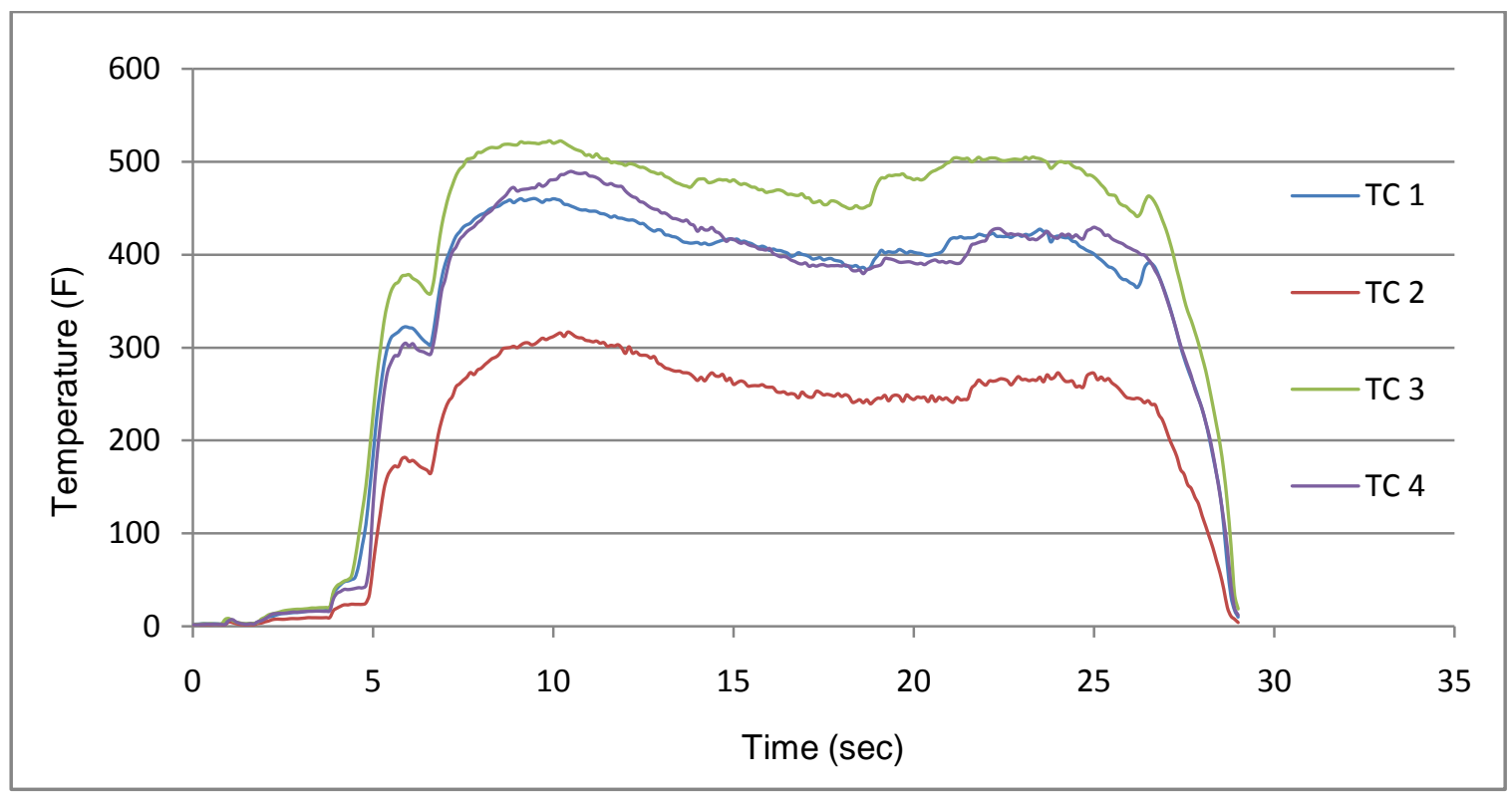

Figure 8: Transient temperature data from the annulus side of the copper throat for an experimental rocket burn.

In later experimental test firings, thermocouple data were also collected in the flange area of the copper via a drilled and staked thermocouple. These data cannot be used here because the 
averaged gas side conditions used in this simulation were calculated using data from a 185 psi chamber pressure test fire, and the flange thermocouple data was collected from a test fire at 250 psi chamber pressure, the comparison would be invalid and is not made. The flange thermocouple data will be used in a later model.

The nodes associated with the above thermocouple locations are shown below in Figure 9.

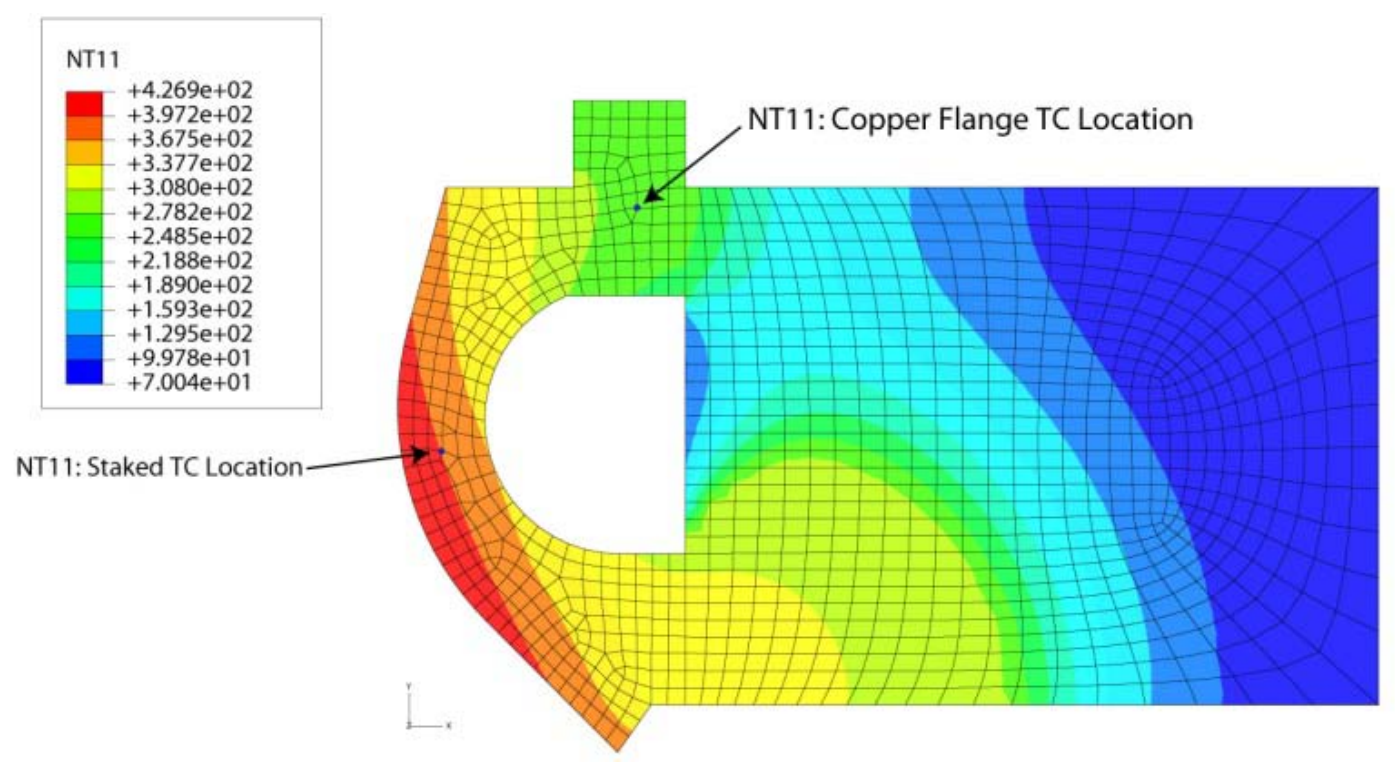

Figure 9: A contour plot of temperature at the end of the motor fire step with temperature in ${ }^{\circ} \mathrm{F}$. Nodes corresponding to thermocouple locations from experimental data are labeled.

The transient nodal temperatures from the simulation are shown in Figure 10. 


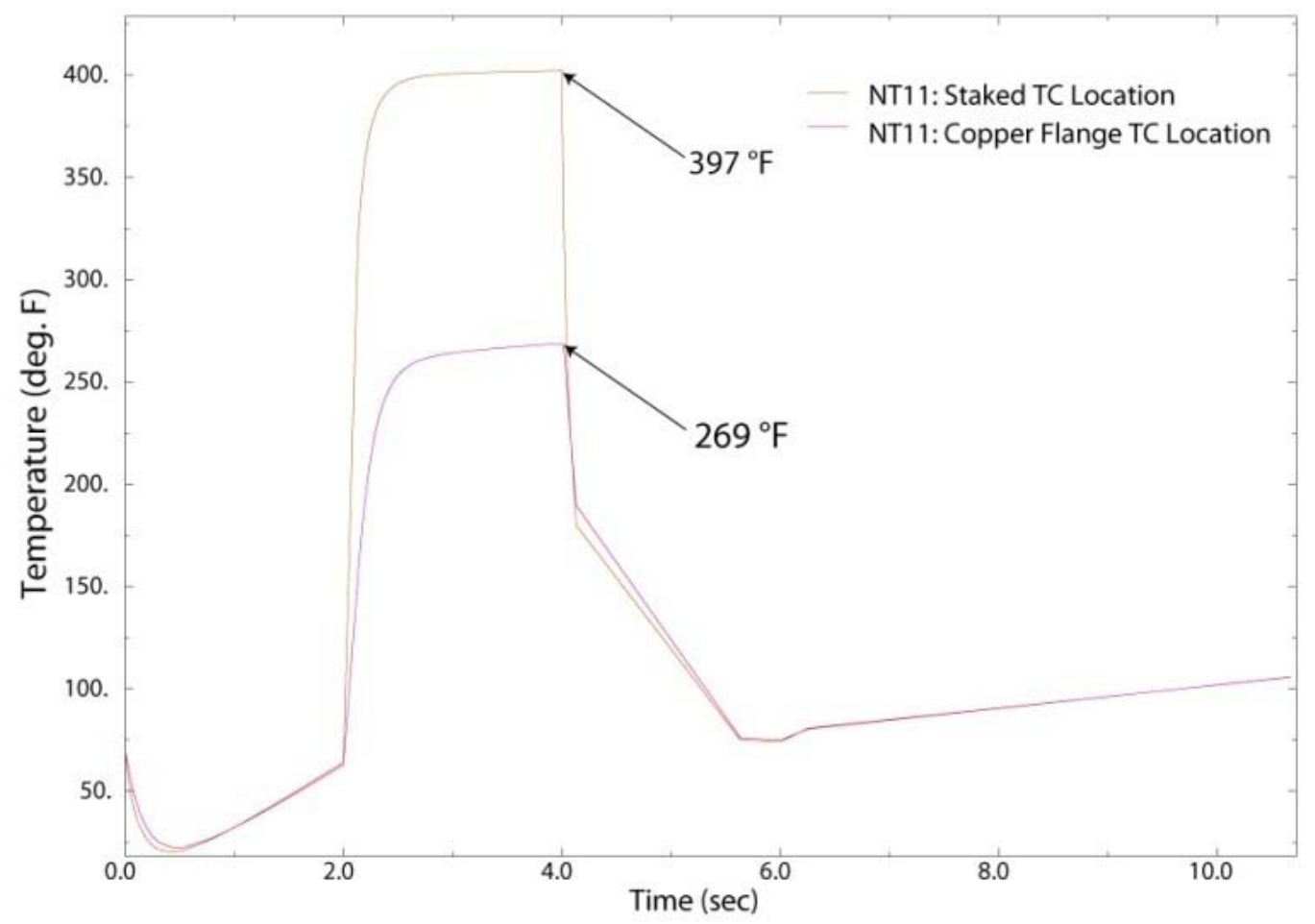

Figure 10: Transient nodal temperature from the flange and annulus locations in the ABAQUS simulation.

The averaged experimental and steady state simulated temperatures are compared in Table 3.

Table 3: Experimental and simulated average temperature data

\begin{tabular}{|llll|}
\hline $\begin{array}{l}\text { Data } \\
\text { Set }\end{array}$ & $\begin{array}{l}\text { Average Experimental } \\
\text { Temperature }\left({ }^{\circ} \mathrm{F}\right)\end{array}$ & $\begin{array}{l}\text { Steady State Simulation } \\
\text { Temperature }\left({ }^{\circ} \mathrm{F}\right)\end{array}$ & \% Difference \\
\hline 1 & $403^{\circ} \mathrm{F}$ & $397^{\circ} \mathrm{F}$ & $-1.49 \%$ \\
\hline 2 & $261^{\circ} \mathrm{F}$ & $269^{\circ} \mathrm{F}$ & $3.07 \%$ \\
\hline
\end{tabular}

As is apparent, the thermal simulation results match closely to the experimental results.

MECHANICAL SIMULATION - The mechanical simulation yielded results that matched intuitively with what is known about the melting point of copper and what had been theorized to occur within the copper during a rocket fire, which is that the copper will try to expand but is 
confined by the stainless steel which causes the copper to locally yield. This can be seen in a contour plot of the plastic strain magnitude shown in Figure 11.

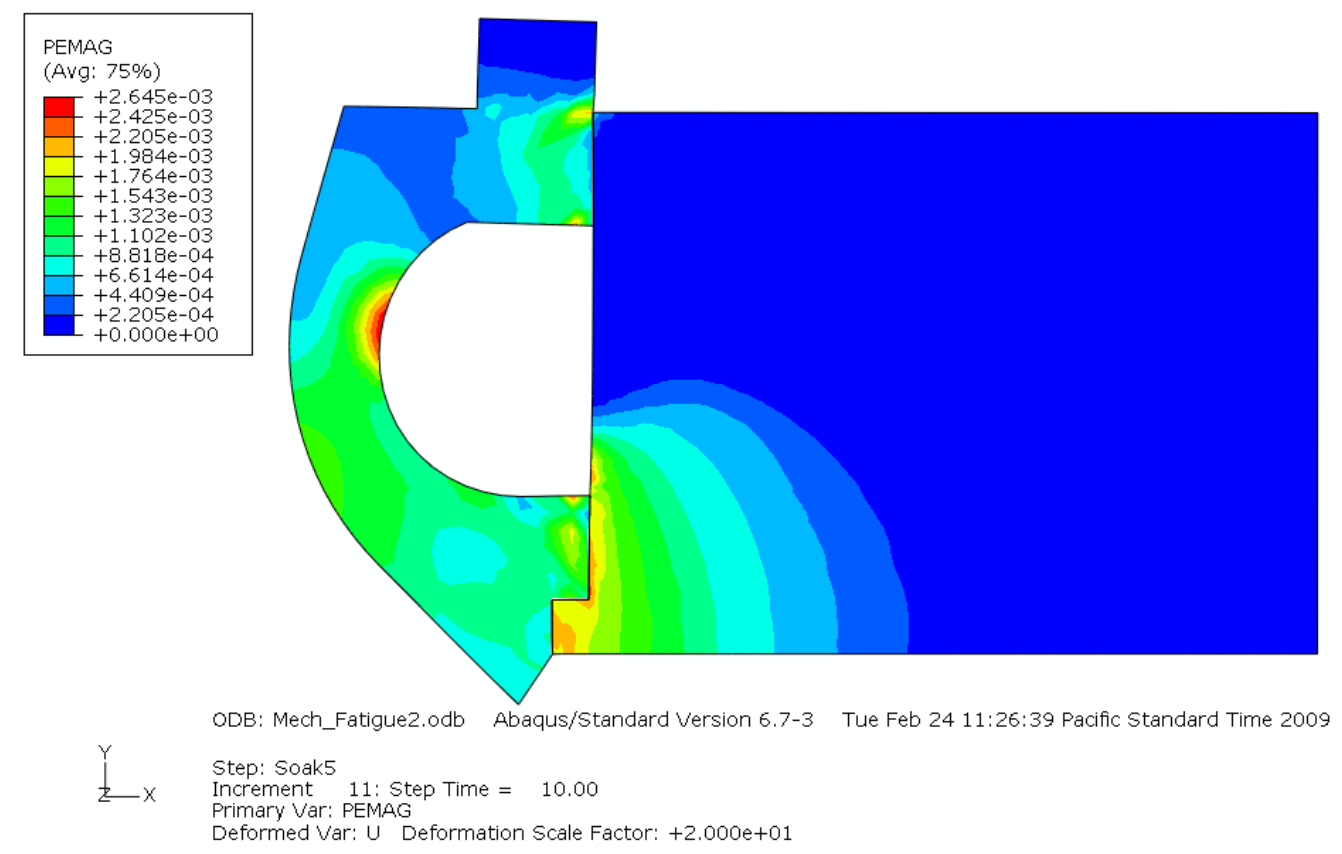

Figure 11: Contour plot of plastic strain magnitude within the throat and support assembly after 5 fatigue cycles.

Figure 11 shows the contour of the plastic strain magnitude after 5 fatigue cycles and clearly shows an area in the copper which undergoes the largest residual plastic strain. During motor fire, the area with the largest thermal gradient undergoes a significant amount more plastic strain than elsewhere, and can be seen in Figure 12. 


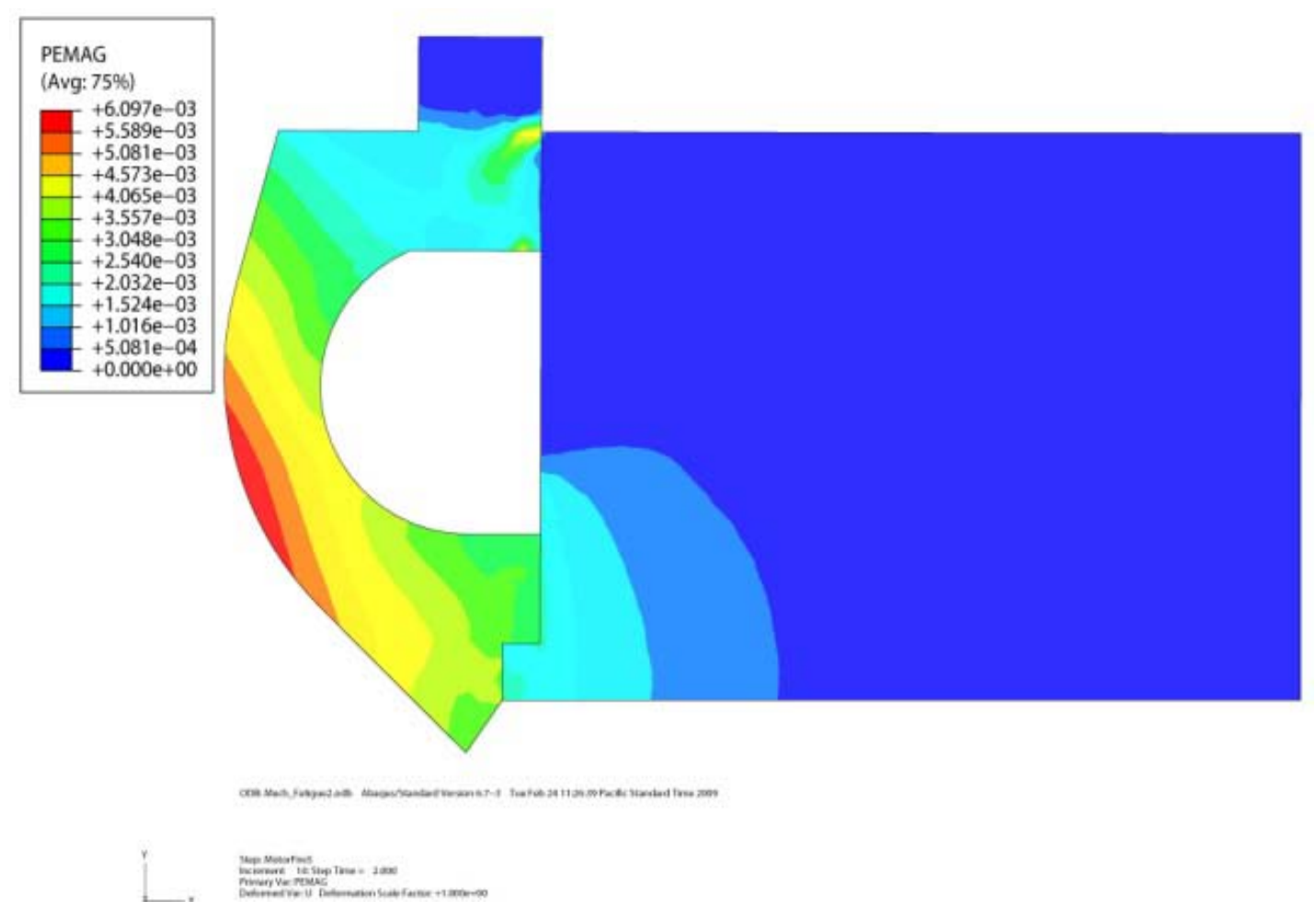

Figure 12: Contour plot of plastic strain magnitude within the throat and support assembly during the 5 th cycle of steady state motor burn. These strains are summarized in Table 4.

Table 4: Location, time, and magnitude of key plastic strains shown in Figure 11 \& Figure 12.

\begin{tabular}{|lll|}
\hline Location of Strain & Time during cycle & Magnitude \\
\hline Combustion gas side of throat & End of motor fire & $6.097 \cdot 10^{-3} \mathrm{in} / \mathrm{in}$ \\
\hline Annulus side of throat & End of cycle & $2.645 \cdot 10^{-3} \mathrm{in} / \mathrm{in}$ \\
\hline
\end{tabular}

A transient plot of the plastic strain in both of these regions is shown in Figure 13. 


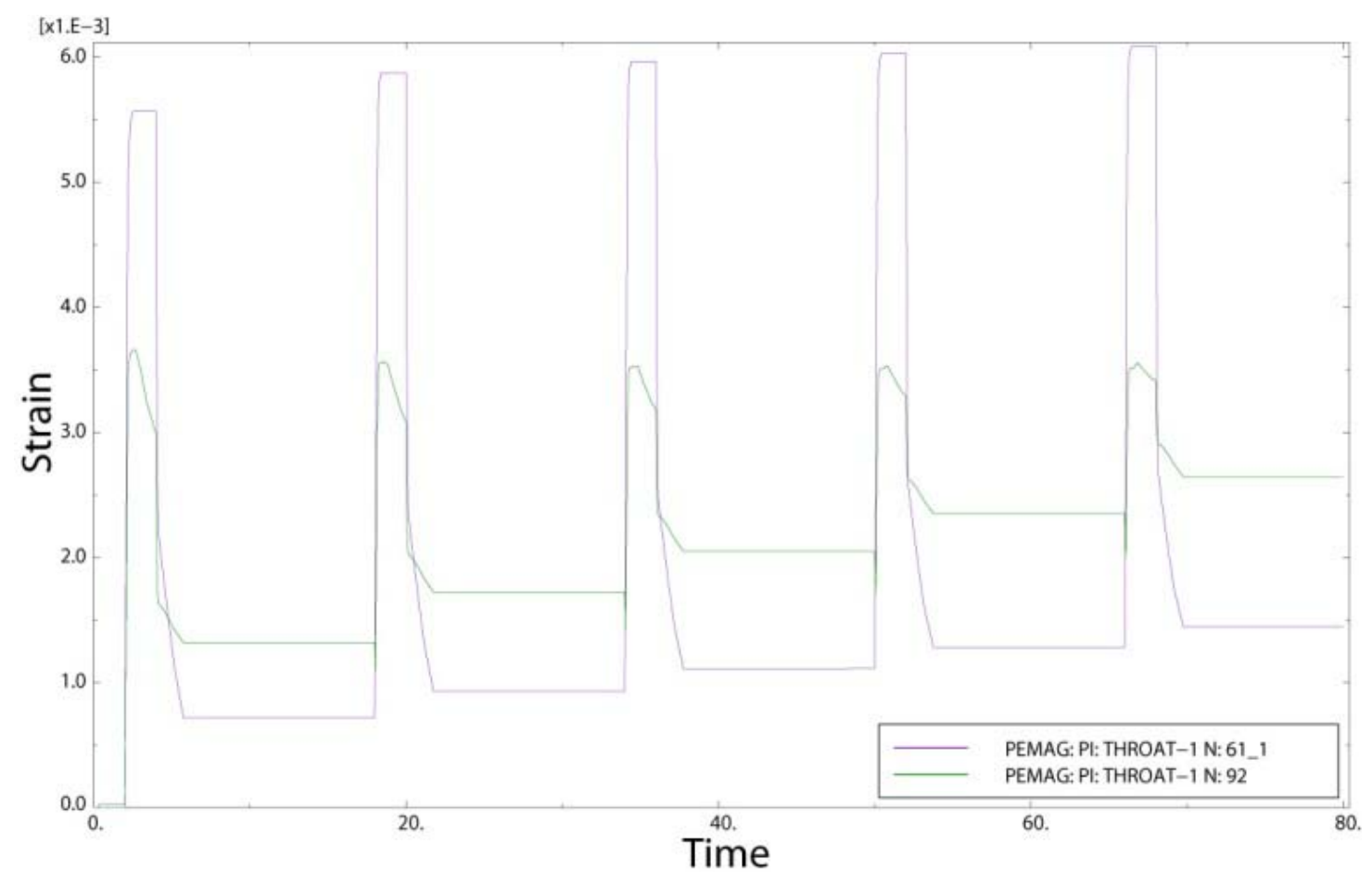

Figure 13: Transient plot of plastic strain magnitude within the throat and support assembly during 5 fatigue cycles.

These data were used in conjunction with the Manson-Halford fatigue life model to predict the number of burns the nozzle will be able to undergo before failure. This yielded a conservative estimate of 300 burn cycles.

\subsection{SIMPLIFIED MODEL DISCUSSION}

The thermal results show an excellent correlation between the data and the finite element model.

This is somewhat expected because the film coefficients are experimentally determined.

The fatigue life analysis was done using a Mason-Halford fatigue life curve and the equation:

$$
\left(\frac{n}{N_{\varepsilon}}+\frac{n e_{r}}{e_{u}}\right)=1.0
$$

Where: 
- $\quad n$ is the estimated number of cycles.

- $\quad N_{\varepsilon}$ is the allowable number of cycles for the strain range, in this case 500 (From OFHC Annealed copper life cycle curve for a strain range of 0.006 in/in).

- $e_{u}$ is the elongation at failure for the given temperature, in this case $0.39 \mathrm{in} / \mathrm{in}$.

- $e_{r}$ is the ratchet strain for the given temperature, is this case is $0.0003 \mathrm{in} / \mathrm{in}$

This predicts upwards of 350 cycles before failure, but a more conservative estimate of 300 motor fire cycles before failure is used for convenience, which still satisfies the reusability criteria of the nozzle. 


\section{CHAPTER 3: EXPANDED THERMAL MODELING METHODOLOGY}

In the above model, assumptions were made about the nature of the heat transfer in the throat and support ring, the foremost of which being the adiabatic boundary condition on the top and bottom of the model. The physical motor has additional material located above, outwards of and below the throat section. The Hastelloy diverging section of the nozzle which sits above the ring and throat could serve has a heat sink as well as a heat source because it is in contact with exhaust gasses. These effects are also true of the graphite below the throat. To verify that the results obtained from the initial model are not a lucky coincidence of assumed conditions, an expanded model that includes the Hastelloy is necessary. In this model, graphite and other stainless steel parts of the upper nozzle were omitted from the expanded model for simplicity.

The simplified model uses a single user-defined film coefficient and sink temperature to represent the heat transfer into the throat occurring from the hot combustion gasses. This method of approximating this heat transfer is no longer viable as the model moves axially away from the center of the throat (the point of inflection between the converging and diverging sections of the nozzle) because both the film coefficient and the sink temperature decrease significantly as combustion gasses expand through the nozzle. The addition of film conditions to the Hastelloy surface necessitated variable values for these parameters as a function of axial distance along the throat. To accomplish the application of a variable film condition, an implementation of the Bartz equation was used.

The Bartz equation is a semi-empirically determined equation used to determine heat transfer film coefficient and free stream temperatures based on a number of geometric and heat transfer parameters. The values determined by the equation are estimates and can be assumed to be close 


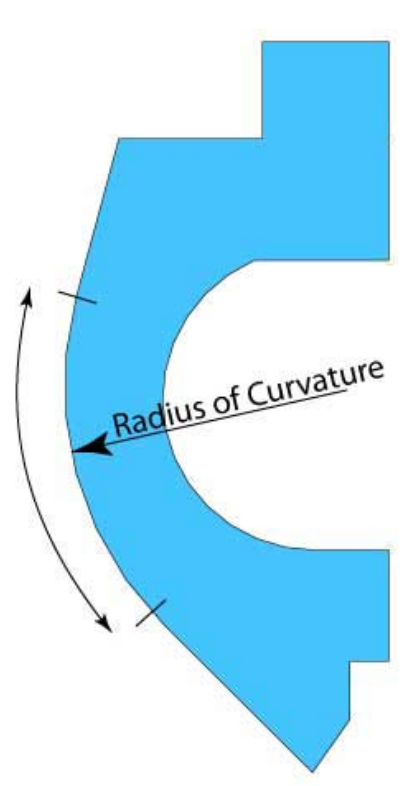

to the actual values, especially around the smallest diameter of the throat. The equation uses the radius of curvature of the throat in the axial direction as one of the determining parameters, however, in the case of this nozzle, the throat only curves for a small portion of the area where applicable heat transfer is occurring; the remaining portions of the converging and diverging sections are cross sections of a cone and thus flat. To apply the equation and obtain approximate values a radius of curvature of ten times that of the maximum radius of curvature in the throat is used for these sections. The overall coefficient and temperature vs. axial position curves match the expected shape of the curve which led to the conclusion that they are sufficiently accurate for this simulation.

Using this equation, values were found at the top edge of the throat, the narrowest section of the throat, and the bottom edge of the throat. These values, along with corresponding sink temperature values were placed in an array in a FORTRAN subroutine file using the *SFILM condition in ABAQUS. Also placed in an array were the axial (Y-direction) coordinate associated with each Bartz film coefficient and temperature. Each node on the gas side surface calls the subroutine file and passes to it coordinates, time, and other unused parameters. Using the axial coordinate value passed to the file (variable coords(2)) combined with the axial position array mentioned above, a film coefficient is linearly interpolated from the Bartz calculated values in the aforementioned coefficient array and passed back to into ABAQUS as the value of the film coefficient. An identical method is used for sink temperature. All FORTRAN code can be viewed in 


\section{APPENDIX C: FORTRAN SUBROUTINES.}

\subsection{SIMPLIFIED MODEL WITH VARIABLE FILM COEFFICIENTS}

To determine if any anomalies in the expanded model were due to the model expansion or to the application of the variable film coefficients a simplified model that used variable film coefficients was necessary. The simplified model combustion side film interaction was switched to the variable scheme file and tested. Once this verified the relative accuracy of the Bartz values in a comparison with an identical model or conversely, identified what type of results could be expected from the model based on the addition of the Bartz equation coefficients and temperatures, the variable values could be applied to the expanded model and any differences could be attributed to the expansion of the model or interpreted based on the differences observed between the simple models. A results comparison between the simple model and the Bartz model can be seen in Figure 14. 


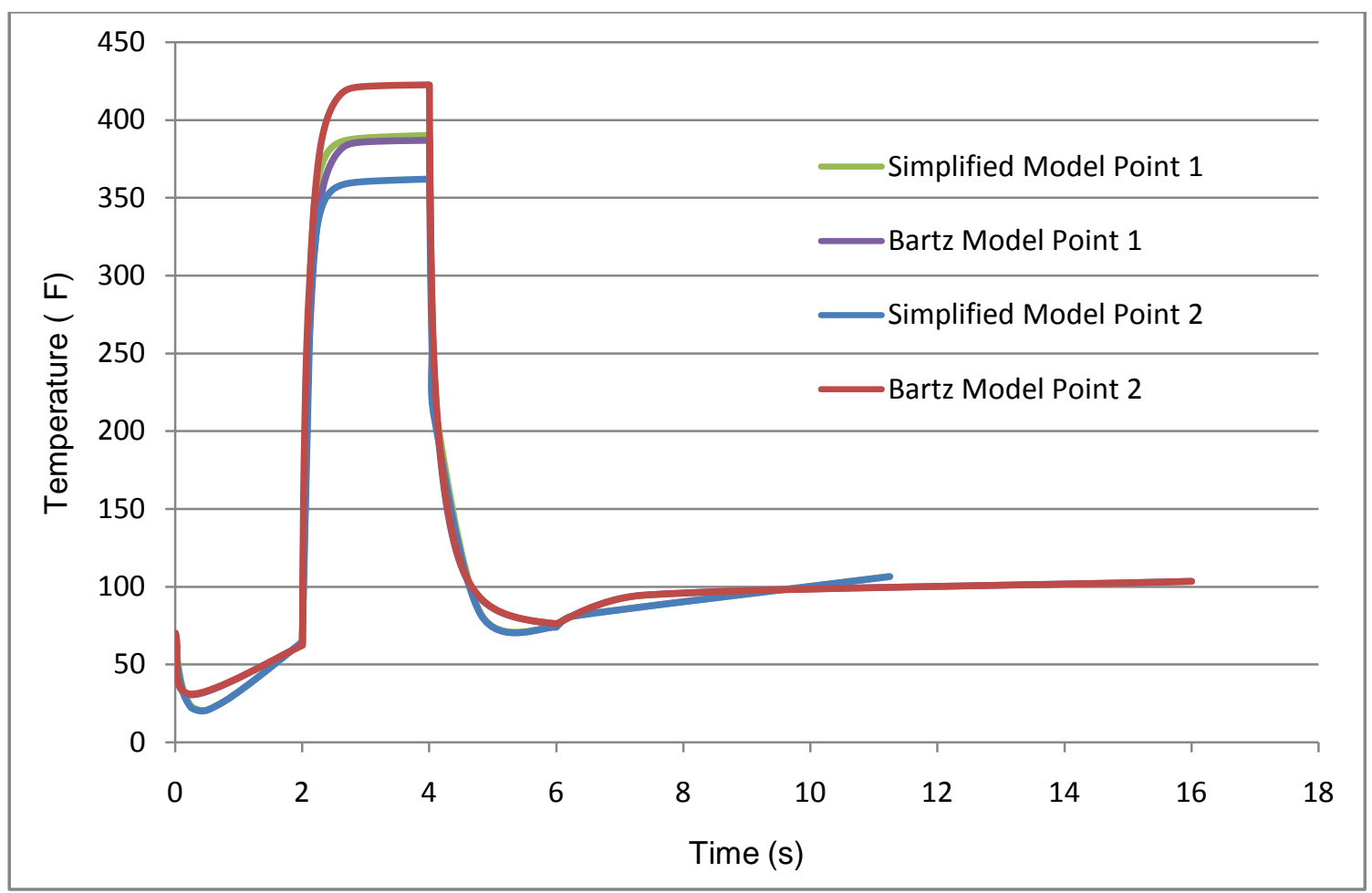

Figure 14: Comparison between transient data for the simplified thermal model and the Bartz equation thermal model.

Point 2 is located at the throat thermocouple location. It is clear that the Bartz equation model is hotter than the simplified model by about $60^{\circ} \mathrm{F}$. Point 1 is located on the surface of the cooling annulus, so it is understandable that the temperatures are the same. This comparison establishes a baseline that proves the Bartz equations yielded results on the correct order of magnitude and the model expansion may proceed.

\subsection{HASTELLOY MODEL}

\subsubsection{REVISION 1}

Because a 3-D solid model of the Hastelloy part already existed, it was simple to create the axisymmetric representation and incorporate its section into the simplified model. All settings from the simplified model were used in the expanded model with the addition of temperature dependent thermal material properties for the Hastelloy and a revision of the hot gas interaction. 


\subsubsection{REVISION 2}

In the simplified model, a tie constraint was used to fix the copper and stainless steel together, which for simulation purposes meant that the nodes which the two materials shared also shared temperatures, and for practical purposes meant that perfect conduction between the two materials was being modeled. The results from the simplified model suggested that this assumption was valid, but with the addition of heat flux occurring from the Hastelloy down into the copper and stainless steel, thermal contact resistances were considered as well. There is no method of determining exact thermal contact resistance without empirical data, so generalized values based on ranges given in literature were used (8).

\subsection{HASTELLOY MESH DEVELOPMENT}

The geometry of the Hastelloy created difficulties when attempting to create a legitimate mesh. It would be undergoing relatively high thermal gradients towards its inner radius and almost no thermal gradients towards its outer radius. Also, because of the variable film coefficients, the largest heat flux is located at the end in contact with the copper and the smallest heat flux is at its free end. These facts suggest a seed biasing scheme that is clustered around the copper and becoming sparser moving away from the copper in both axial and radial directions.

Initial inspection of the mesh generated using this technique provided some confidence that the model would work, however, this initial simulation diverged and failed during the 'Motor Shutdown' step. The initial step size was decreased and the simulation run again, however the same problem occurred, and after several other parameter adjustments, no headway was made. It was determined that the Hastelloy needed re-meshing because the results from the 'Motor Fire' step showed that there was a high thermal gradient along the entire edge of the Hastelloy that was in contact with the combustion gasses. It was surmised that the larger elements towards the free tip of the Hastelloy were experiencing thermal gradients that were too large and combined with 
the abrupt change in boundary conditions between the 'Motor Fire' and 'Motor Shutdown' steps, produced a divergent solution.

A scheme of partitioning and re-meshing was then undertaken. The new mesh was created using a combination of structured and free meshing algorithms, depending on the partition being meshed. A seed size of 0.01 in. was chosen along the walls in contact with the copper or combustion gasses. Elsewhere, a seed size of 0.015 in., 0.02 in. or a biased scheme was used to help maximize simulation efficiency and enhance nodal matching between the steel and Hastelloy so that the tie or contact resistance constraints would not be affected by nodal shifting or confused by nodal mismatches. After a number of attempts at different partitioning schemes with different meshing algorithms, a final mesh was found. Key mesh parameters can be viewed in the Table 5 .

\section{Table 5: Element Quality Data for Hastelloy mesh}

\begin{tabular}{|lll|}
\hline Quality Measure & Limit & $\%$ Elements Outside \\
\hline Aspect Ratio & $<3: 1$ & $0.0 \%$ \\
\hline Min/Max Angle - Quadrilateral & $45^{\circ}<\theta<135^{\circ}$ & $0.11 \%$ \\
\hline Min/Max Angle - Triangle & $45^{\circ}<\theta<75^{\circ}$ & $0.33 \%$ \\
\hline
\end{tabular}

\subsection{ANALYSIS}

Similar to the simplified analysis, a transient thermal analysis was used to run this simulation. Unlike the simplified analysis, a quasi-Newton solver was used for 'Motor Fire', 'Motor Shutdown’ and ‘Coolant Shutdown’ steps because both steps required a large amount of computation time.

ABAQUS displayed a number of warnings upon running either of the simulations. The first stated that small adjustments to node positions were not printed in the warning dialog. When the data file was inspected to determine the amount that any nodes were adjusted, the distances were 
on the order of $10^{-6}$ in. and judged to be inconsequential. The second warning stated that SDI conversion was not available for thermal analyses, and as discussed with the simplified model, this was not a problem. The third warning warned of two distorted elements whose parameters were outside the recommended limits. The limits that ABAQUS imposes are the same as or less conservative than those discussed in the mesh development sections of this paper and it was discovered that the elements in question possessed a minimum angle of $44.8^{\circ}$ and $44.4^{\circ}$. These angles are acceptable because they are extremely close to the $45^{\circ}$ limit and the elements of which they are a part of are a small percentage of the overall number of elements.

\subsection{EXPANDED THERMAL MODEL RESULTS}

The revision 1 model yielded mixed results. At the throat thermocouple location, the temperature reached steady state and matched well to the previous simulation as well as to the experimental data. At the flange thermocouple location, the data did not match either the simplified simulation or the experimental data and differed by about $100^{\circ} \mathrm{F}$. The revision 2 model temperature matched at the throat location and yielded better results in terms of final temperature in the flange. Of more concern is that the slope of the thermocouple temperature as a function of time does not match the slope of the simulation temperature at that location as a function of time. This discrepancy means that there are unseen heat transfer dynamics which are not being modeled, such as time varying film coefficients in the cooling annulus, or the model itself is not large enough to fully capture the heat transfer dynamics of the system.

A variable film coefficient could be modeled in two ways. The first would be to create a film coefficient that would vary with time, and the second would be to create one that would vary with temperature. A time varying coefficient could be made to tailor the output of the simulation to that of the experiment; however, other than producing transient plots that matched, this method would not provide useful data towards the end goal of the project, which is to create a model that 
can be applied to an aerospike model. The second method of creating a temperature varying coefficient immediately appears to have more of a connection to the physical phenomena occurring within the system, however, on closer inspection of the experimental data, the cooling fluid temperature remains fairly constant throughout the burn, which means this method may not have the potential to affect the data.

A simpler method of testing whether or not the film coefficient is the cause of the transient data mismatch is to increase the model size by adding in the remaining portions of the nozzle body and inspect the subsequent transient data. 


\section{CHAPTER 4: FULL UPPER NOZZLE MODELING}

With the shortcomings of the expanded model in mind, a model of the full upper section of the nozzle was created to more effectively model the transient heat transfer dynamics of the system. This model would be able to take into account the heat transfer from the graphite liner of the converging nozzle section as well as heat capacitance effects of the outer stainless steel nozzle body and cap.

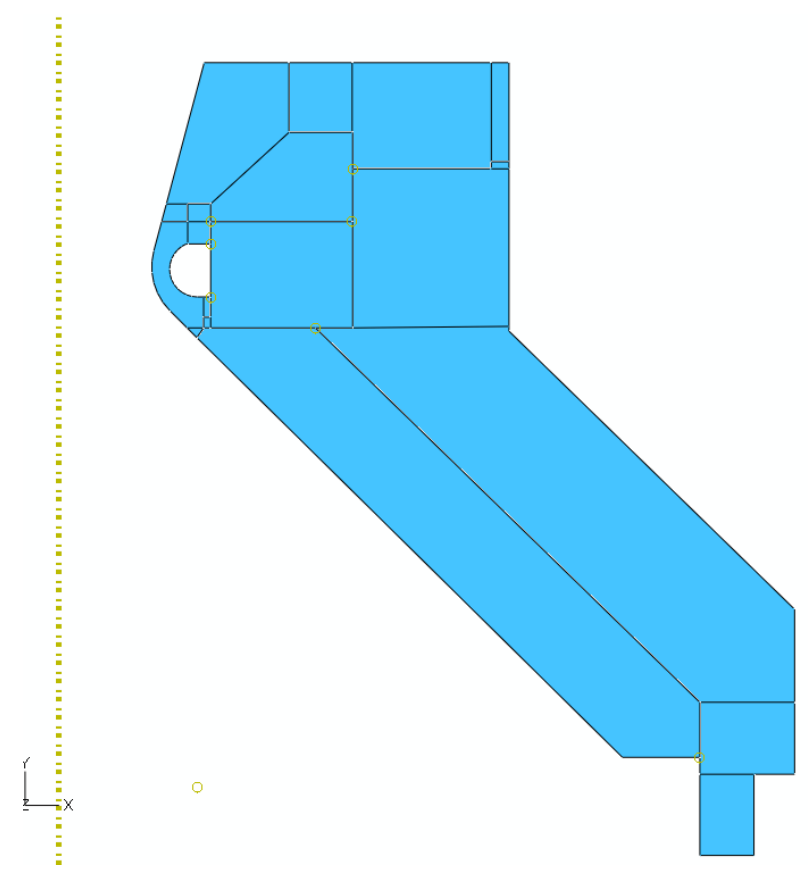

Figure 15: The 2D axisymmetric full nozzle model, partitions included.

Again, the full nozzle model was based around the framework that had been created starting with the simplified thermal model and expanded thermal model. To properly understand what effects the additional parts of the model would have on the performance of the simulation, the first step would be to create the model and run it using identical conditions as the expanded model. The main difference between the models is that the Bartz equation would be used to calculate the sink temperatures and film conditions along the wall of the converging nozzle section. Additionally, contact resistances would also need to be added to the newly created part junctions. The contact resistance between steel is a fairly well documented parameter, and mostly varies with contact 
pressure. In this case a pressure of $10 \mathrm{psi}$ was assumed as a baseline to start the modeling. The contact resistance between graphite and steel is not as well documented; however, the small amount of data available indicates that it is within the range of the steel/steel contact resistances found above. Because both of these values depend heavily on contact pressure, which is unknown in this scenario, they are approximations and can be adjusted within bounds of reasonable contact pressure. The initial value started at $1 /\left(0.006 \mathrm{BTU} / \mathrm{s} \cdot \mathrm{in} .{ }^{\circ} \mathrm{R}\right)$.

The cap and outer nozzle body are both stainless steel, and thus could use the stainless steel material data from the previous models. The converging liner is made of graphite, so new material properties needed to be input. In this case, no temperature dependent data could be found, so graphite properties at $212^{\circ} \mathrm{F}$ were used.

\subsection{MESH DEVELOPMENT}

The development of the mesh for the remainder of the model followed a similar methodology as the Hastelloy mesh used. The graphite used 0.01 in. seeds along the surface in contact with the combustion gasses, as well as seeds matched to the seeds in the throat and support ring to promote effective mathematical contact. The seeds along the opposite edge were 0.03 in. The stainless steel nozzle body and cap all used a global seed size of 0.03 in. and were partitioned to maximize the amount of structured mesh that could be used throughout. The mesh along with key mesh quality parameters can be seen in Figure 16 \& Table 6 . 


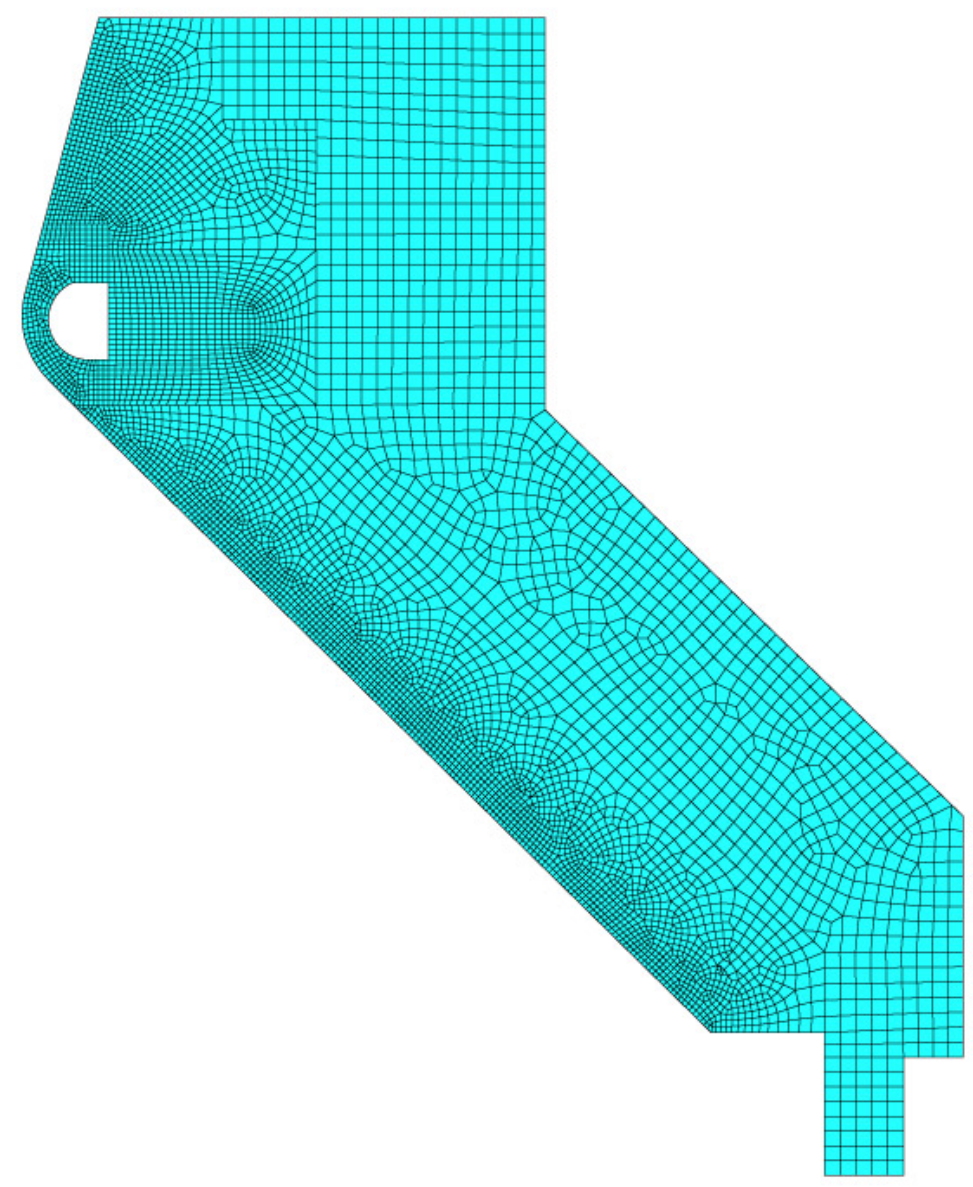

Figure 16: 2D full nozzle model mesh

Table 6: Key element quality statistics for the full nozzle mesh

\begin{tabular}{|lll|}
\hline Quality Measure & Limit & $\%$ Elements Outside Limit \\
\hline Aspect Ratio & $<3: 1$ & $0.08 \%$ \\
\hline Min/Max Angle - Quadrilateral & $45^{\circ}<\theta<135^{\circ}$ & $0.27 \%$ \\
\hline Min/Max Angle - Triangle & $45^{\circ}<\theta<75^{\circ}$ & $0.43 \%$ \\
\hline
\end{tabular}




\subsection{INITIAL FULL MODEL - RESULTS \& DISCUSSION}

The initial full model results exhibited interesting phenomena occurring at the thermocouple location and showing up in the transient temperature plot. Initially, the plot follows the same path as the expanded model: a very fast temperature rise which sharply levels out and continues to increase slowly. At about 15 seconds, however, the temperature plot then increase slope, indicating a faster increase in temperature. Upon inspection of a transient movie of the heat flux vectors in the model superimposed on a temperature contour plot, a wave of high temperature and heat flux can be seen propagating up from the graphite into the support ring and subsequently into the flange of the copper. It took approximately 15 seconds for this 'heat wave' to reach the thermocouple location. The slope of the plot during the 15-24 second range was much closer to the slope of the experimental data. These results provided a number of insights with which the model could begin to be refined.

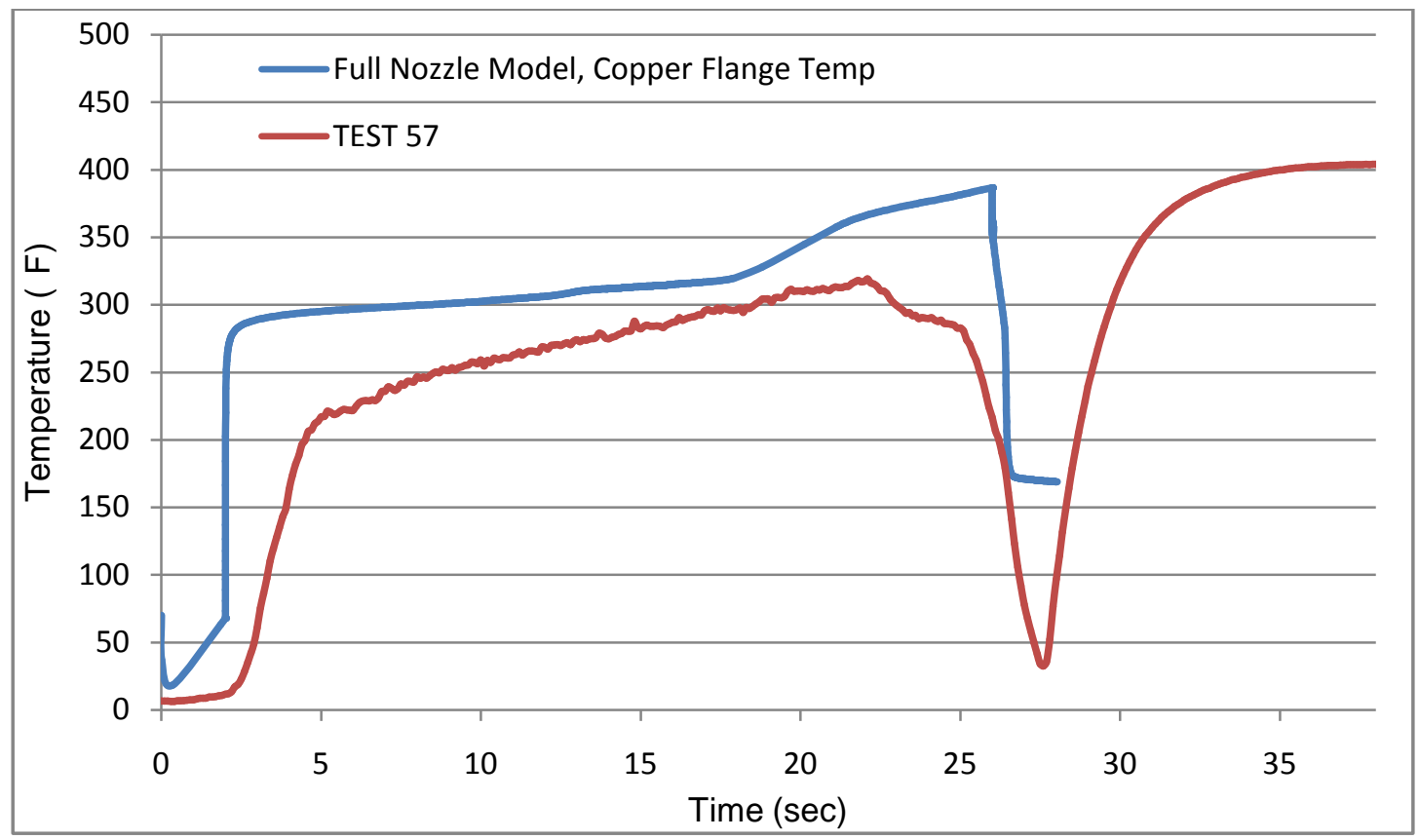

Figure 17: Initial full nozzle model transient temperature data compared with Test Fire 57 thermocouple data 
As can be seen in Figure 17, the temperature in the flange is dramatically higher than that of the experiment. This prompted a second look at the experimental data to determine if the hot and cold side properties in use were acceptable.

The hot side properties were still the Bartz values calculated at a 200 psia chamber pressure, which means updating them to match the chamber pressure in the experimental run would increase the simulation temperature seen at the flange location. These values were corrected, but were not the cause of the elevated flange temperature in the simulation. In addition to correcting these values, a two second linear ramp up at the beginning of the motor fire, and a three second ramp down at the end of motor fire were applied to the hot gas sink temperature and film coefficient to account for motor startup and shutdown.

The cold side properties were values calculated using a 1D finite difference energy method by a professor working on the project. When the temperature of the fluid in the simulation was compared to the temperature of the fluid in the experimental data, it became clear that the $T_{\text {cold }}$ value of $70{ }^{\circ} \mathrm{F}$ was between $40^{\circ} \mathrm{F}$ and $50^{\circ} \mathrm{F}$ too high. Additionally, the $\mathrm{h}_{\text {cold }}$ value being used had been averaged from four thermocouple readings in a previous experimental run which all read somewhat differently. This discrepancy in the thermocouple temperatures created some doubt as to the exact $\mathrm{h}_{\text {cold }}$ value which should be used, prompting the need for a parametric study of this value. The addition of these changes would decrease the flange temperature significantly. 


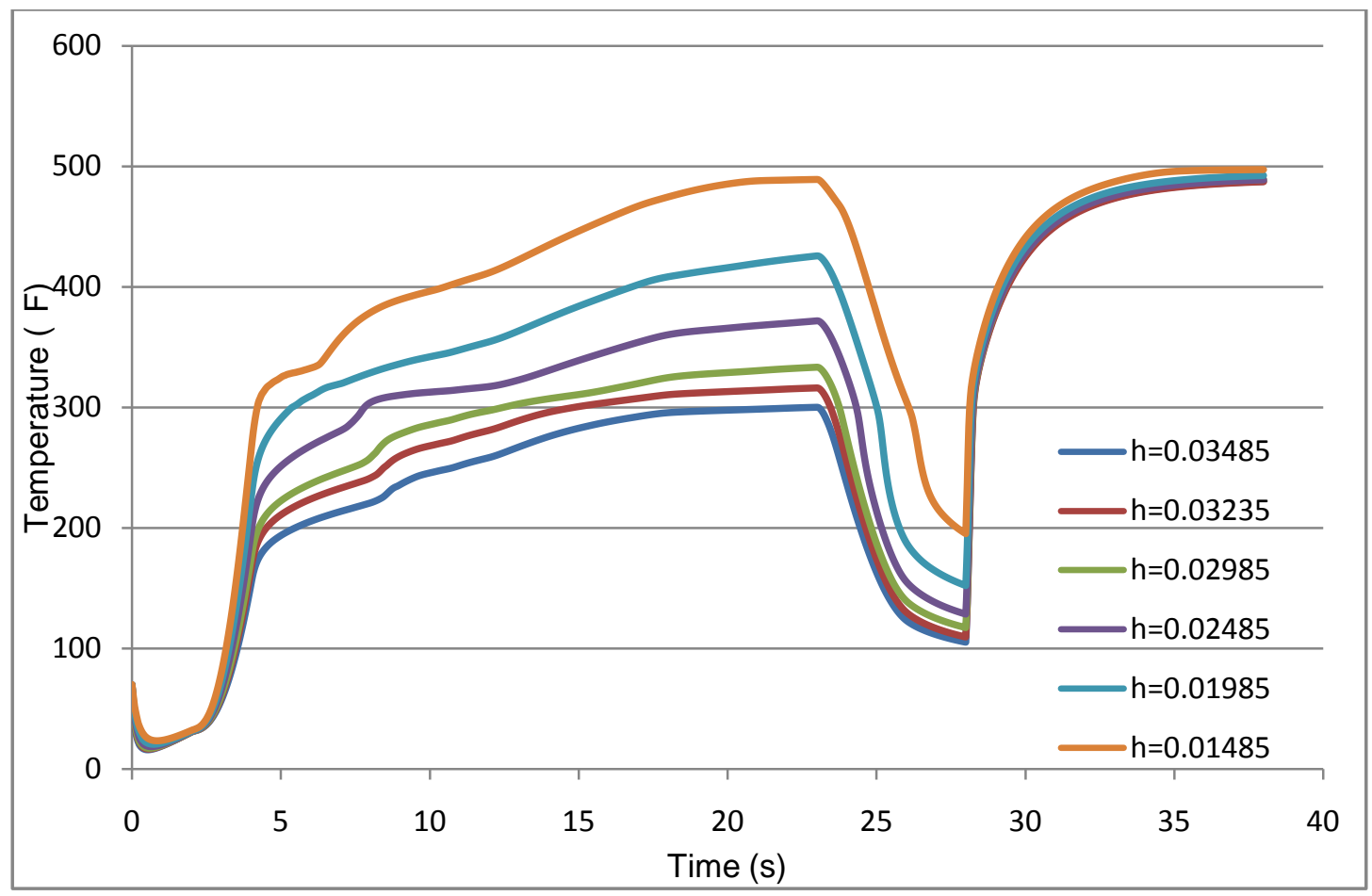

Figure 18: Parametric study transient temperature data. $h_{\text {cold }}=0.01485-0.03485 T_{\text {cold }}=30 k=0.005$

As can be seen in Figure 18, $\mathrm{h}_{\text {cold }}$ has an effect on the transient nature and overall magnitude of the flange temperature. The film coefficient was varied from $0.01485 \mathrm{BTU} / \mathrm{s} \cdot \mathrm{in}^{2} \cdot{ }^{\circ} \mathrm{R}$ to 0.03485 $\mathrm{BTU} / \mathrm{s} \cdot \mathrm{in}^{2} \cdot{ }^{\circ} \mathrm{R}$ by increments of 0.005 . What is also noticeable is the absence of the 'heat wave' slope change of the data. Because the thermal contact resistance could play a significant role in the transient shape of the data, a parametric study of thermal resistance magnitudes was also undertaken.

The first hypothesis for refining the contact resistance model was that the contact resistance between the Hastelloy and the copper throat and stainless steel support ring was too high. With a slightly lower resistance, the temperature in the flange would increase more quickly and possibly exhibit a steeper slope in the initial seconds of the 'Motor Fire' step of the simulation.

The second hypothesis involved decreasing the resistance between the graphite, throat, and other stainless parts. This would decrease the time it would take for the secondary 'heat wave' to reach 
the thermocouple location and continue increasing the thermocouple temperature. Both hypotheses were tested during the parametric study.

The contact conductance (the parameter used in ABAQUS, the inverse of the contact resistance) was started at $10000 \mathrm{BTU} / \mathrm{s} \cdot \mathrm{in} \cdot{ }^{\circ} \mathrm{R}$ and the simulation was run. The simulation was then run with values of $1,0.15,0.015$, and 0.005 , essentially varying the value from almost perfect conduction to about what the initially assumed conductance was. The comparison of these data can be seen in Figure 19.

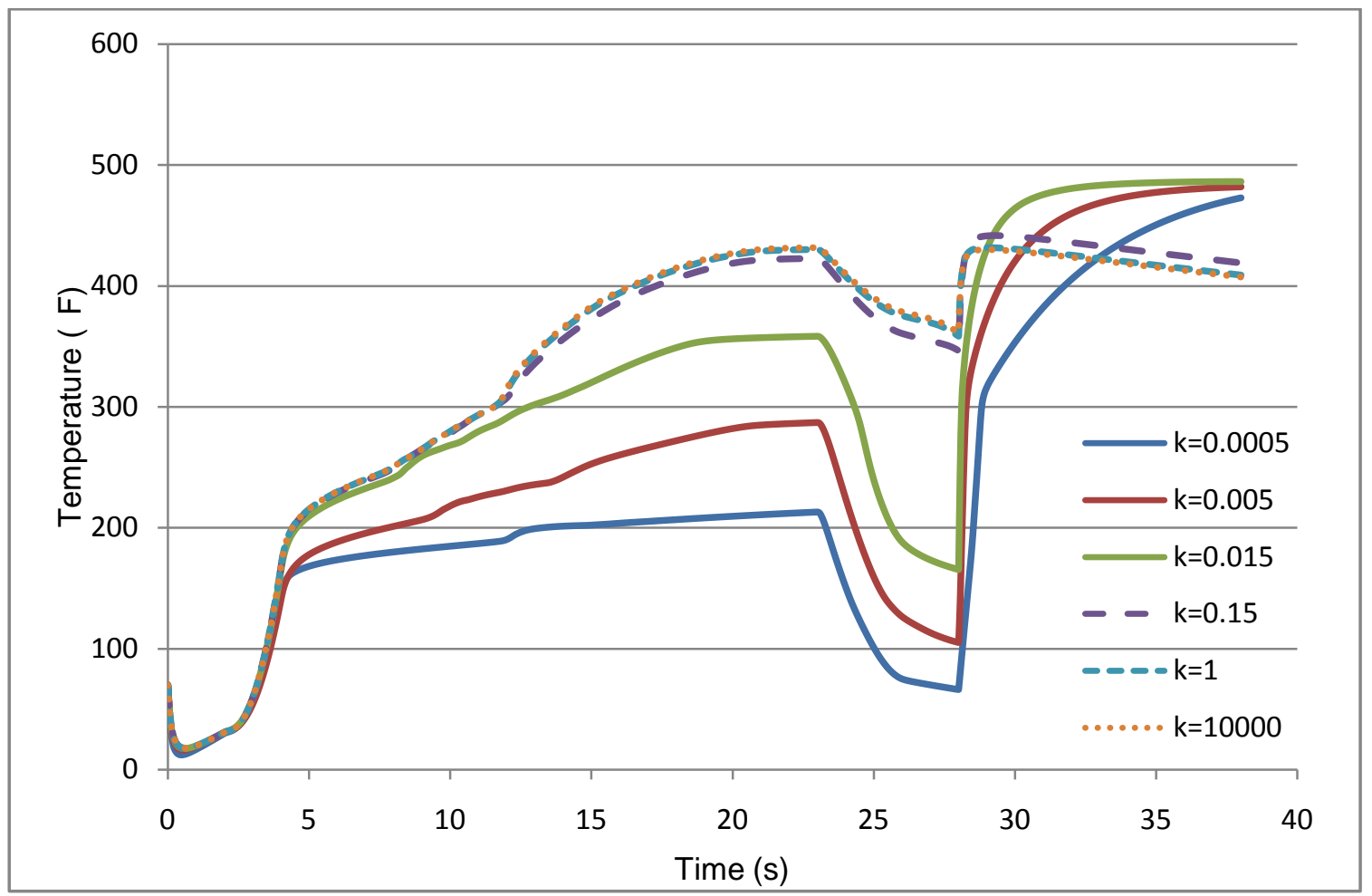

Figure 19: Parametric study transient temperature data. $h_{\text {cold }}=0.03485 T_{\text {cold }}=30 k=0.0005-10000$

One key aspect of the study is that during the 'motor off' step, not even the smallest contact conductance used allowed the temperature in the flange to drop as much as the temperature in the experimental data. This discrepancy between simulation result and experimental data suggests that the contact conductance of $0.005 \mathrm{BTU} / \mathrm{s} \cdot \mathrm{in} .{ }^{\circ} \mathrm{R}$ was closest to the conductance of the physical 
system, however, further decrease of the contact conductance to $0.0005 \mathrm{BTU} / \mathrm{s} \cdot \mathrm{in} .{ }^{\circ} \mathrm{R}$ yields data whose transient path appears similar to the adiabatic simplified model, and yet during the 'motor off' step the temperature never reaches the low value that is shown in the experimental data. It is then concluded that the low temperature reached by the flange thermocouple in the experiment is due to effects that are not being modeled. There are a number of effects which could be causing this phenomenon, the foremost being a variable contact pressure between the motor parts due to thermal gradients causing material expansion which in turn introduces a variable thermal resistance. A variable contact pressure could account for transient effects seen in the higher resistance cases, and still include the lower temperature reached in the 'motor off' step seen in the experimental data. To account for this effect, a fully coupled thermal/mechanical model would need to be run with data relating contact resistance to contact pressure. While this is possible, it is outside the limited scope of this analysis. Other less prominent effects could be a higher natural convection coefficient due to air movement caused by the plume, or heat conduction into the unmodeled portion of the motor body - a relatively large amount of metal that can act as a heat sink/diffuser into the air. Also, radiation effects are not considered and could play a part in diffusing heat away from the flange area during the motor fire.

\subsection{MESH CONVERGENCE}

To validate the mesh of the full nozzle model, an h-type mesh refinement convergence study was performed. The number of degrees of freedom was varied from 677 to 6102 . The variable chosen for the study was nodal temperature. The locations at which the convergence study was performed are shown in Figure 20. 


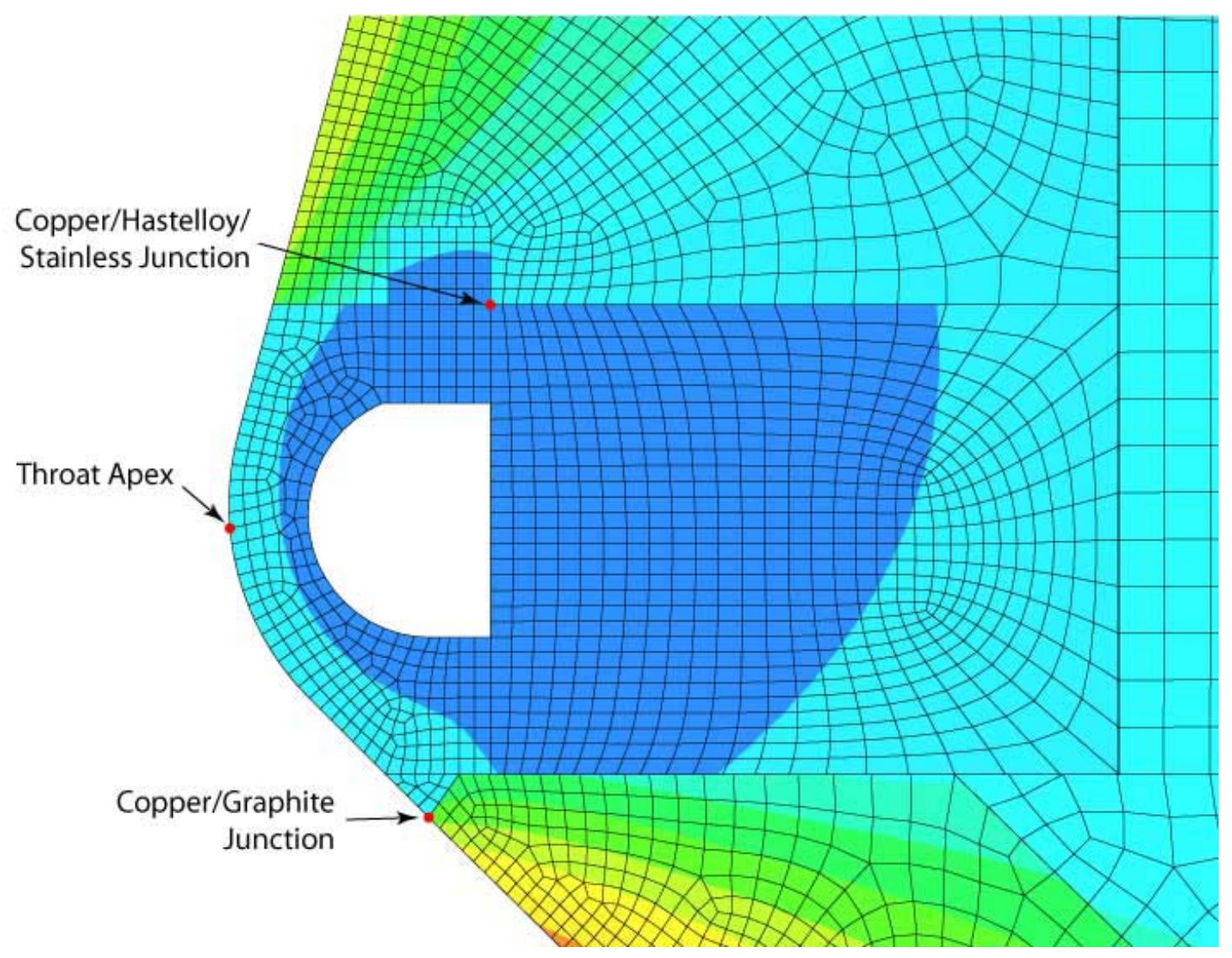

Figure 20: Nodal locations for 2D Full Nozzle Convergence Study

The convergence plot for the Copper/Graphite Junction can be seen in Figure 21. The remaining two plots may be seen in APPENDIX A: CONVERGENCE GRAPHS. 


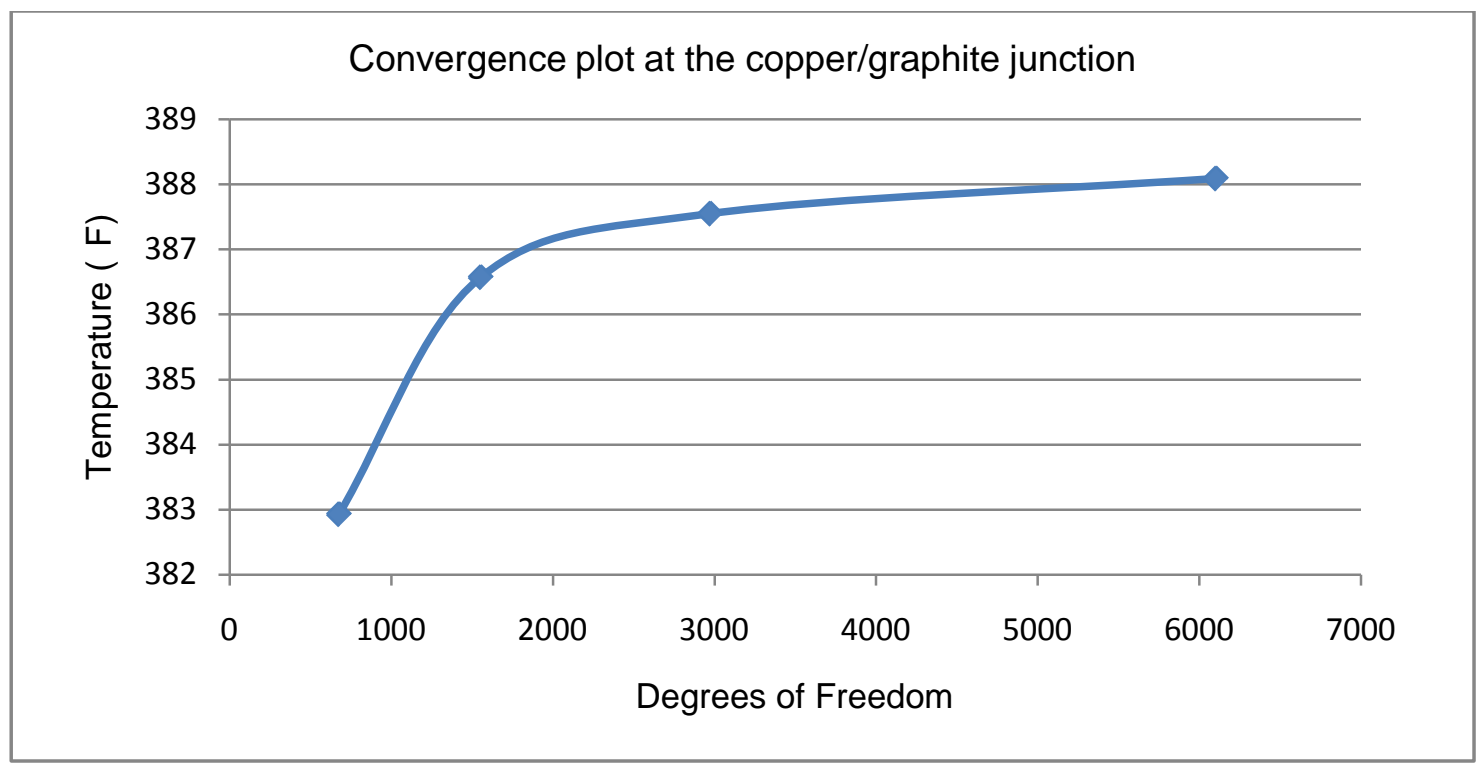

Figure 21: Convergence plot at the copper/graphite junction location

As can be seen in the graph, the mesh is almost completely converged by the second point, and is converged by the final point. This was the case at both of the other convergence locations as well, and for the purpose of this experiment, the mesh was considered converged.

\subsection{FINALIZED FULL NOZZLE - MODEL PARAMETERS AND RESULTS}

The final full model used information gathered during the two parameter studies to determine the correct contact resistance and $\mathrm{h}_{\text {cold }}$ values to use. The values obtained were $\mathrm{k}=0.005 \mathrm{BTU} / \mathrm{s} \cdot \mathrm{in} .{ }^{\circ} \mathrm{R}$ and $\mathrm{h}_{\text {cold }}=0.03235 \mathrm{BTU} / \mathrm{s} \cdot \mathrm{in} .{ }^{2}{ }^{\circ} \mathrm{R}$. The results seen from this transient data plot very nearly match the experimental data. As can be seen in the plot shown in Figure 22, the data matches well during the initial seconds of the burn, but increases to above the data range after about 6 seconds of motor fire, or 8 seconds of total simulation and then levels out and drops back into the range of the data towards the end of the burn. 


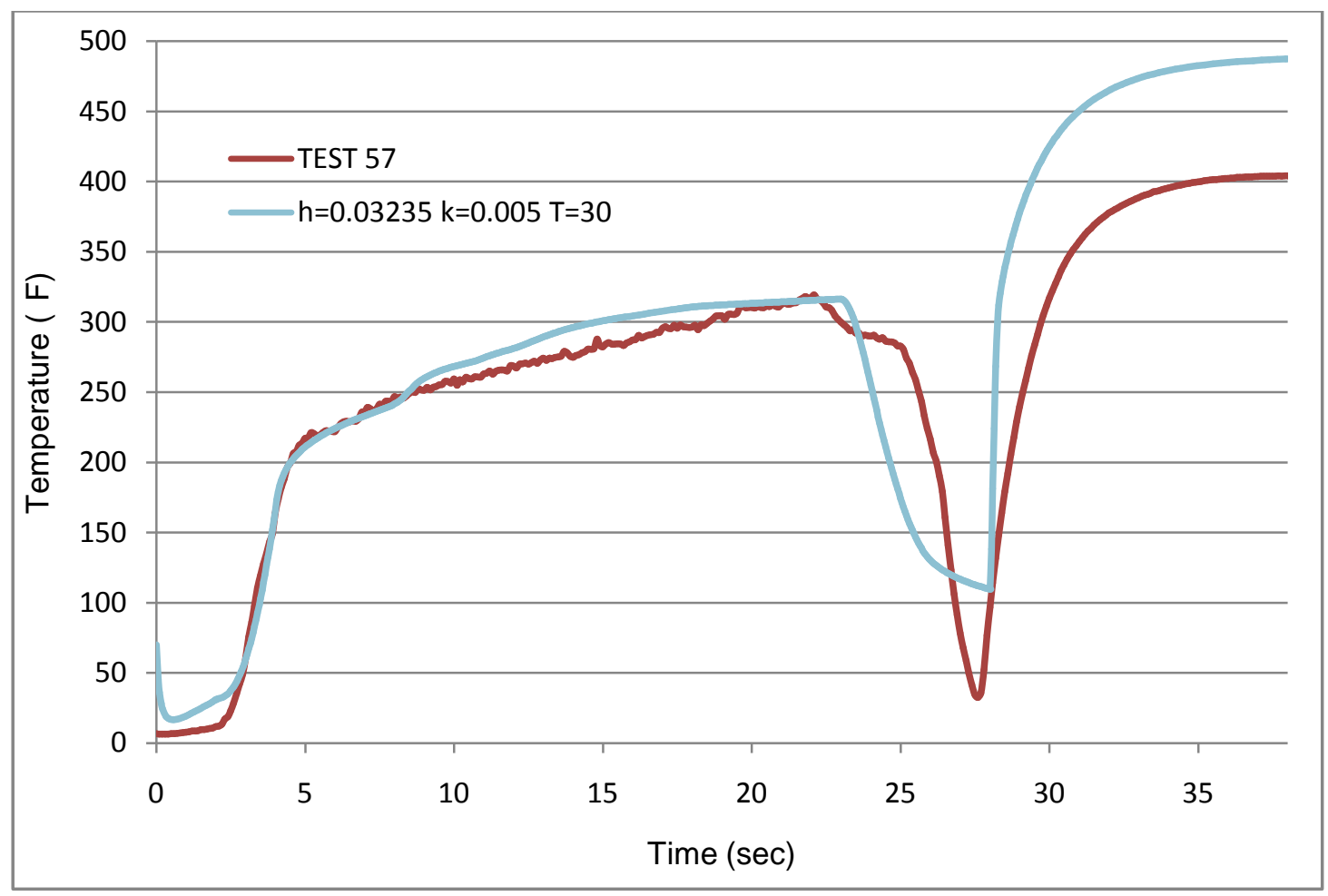

Figure 22: Finalized full nozzle model transient temperature data, initial run

After inspecting a transient movie of heat flux vectors superimposed on a temperature contour plot, it was evident that the 'heat wave' mentioned above was the cause of this temperature increase. It was then theorized that because the graphite liner was not bolted together like the stainless parts of the nozzle, that it may have a higher average contact resistance than the stainless parts. It would then make sense that the 'heat wave' would not propagate through the material as fast, due to the lower heat flux from the graphite, and the temperature would not increase as significantly at the 8 second mark. This phenomenon prompted a quasi-parameter study.

A separate contact resistance was created for the junctions between the graphite and any other part. The first iteration decreased the conductance value, $k$, by an order of magnitude to 0.0005 BTU/s·in. ${ }^{\circ} \mathrm{R}$. This proved to flatten the curve too much after the 8 second mark, so the next iteration featured a values of $\mathrm{k}=0.001 \mathrm{BTU} / \mathrm{s} \cdot \mathrm{in} .{ }^{\circ} \mathrm{R}$. As can be seen in the comparison plot in 
Figure 23, this moved the curve to a position in between the previous two scenarios. The curves matched acceptably and the result was considered final.

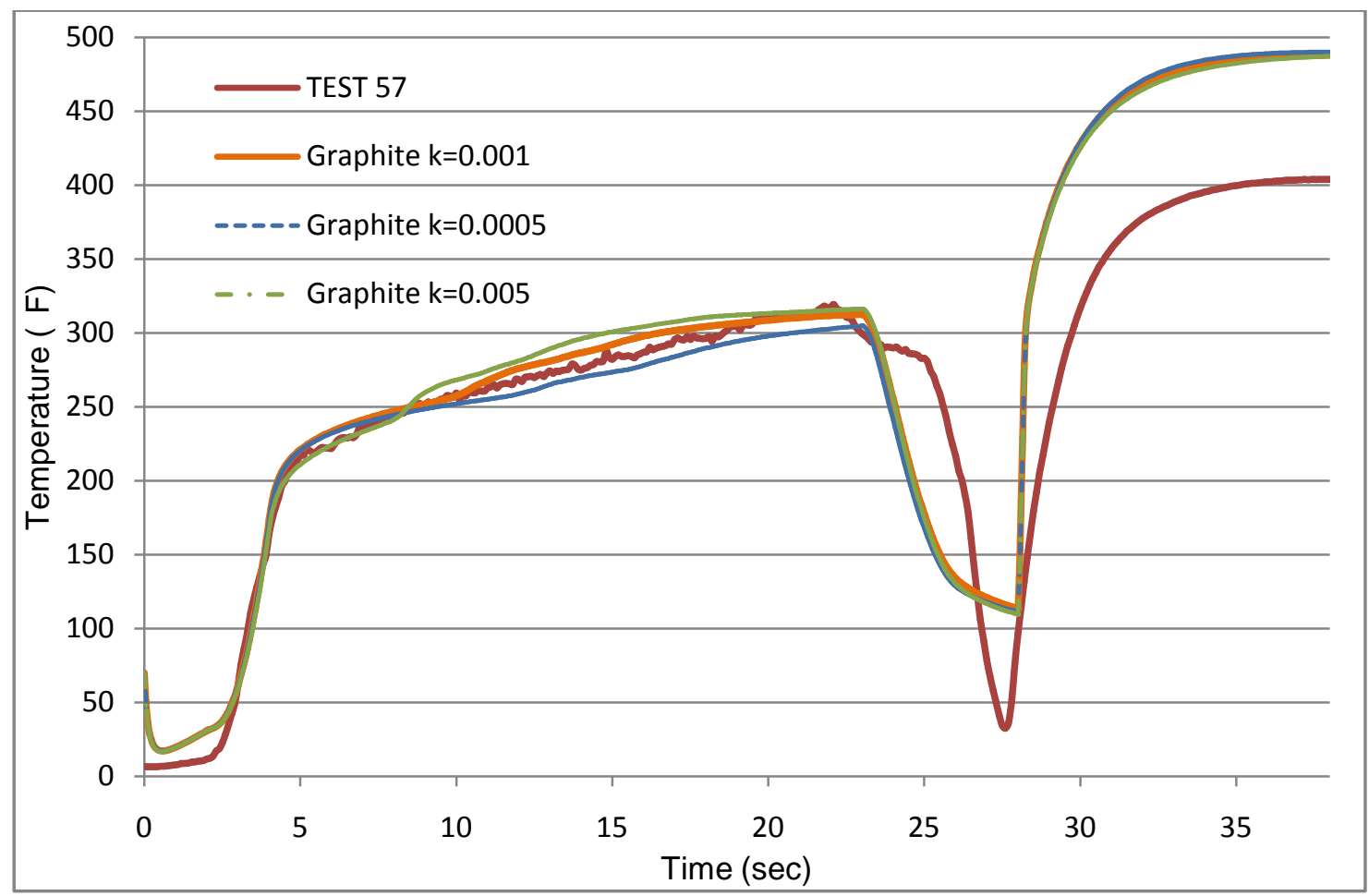

Figure 23: Transient temperature data for a parameter study of the graphite contact resistance

\subsection{FINALIZED FULL NOZZLE - DISCUSSION}

The final transient plot matches the experimental data well. Some key differences are a decrease in slope towards the end of the 'motor fire' step, a difference in 'motor off' curve shape and equilibrium temperature, and a difference in final temperature.

The decrease in slope towards the end of the 'motor fire' step has to do with a mismatch between coolant gas temperature and film coefficient as well as contact resistance. As can be seen in the results of the parameter re-evaluation as well as the subsequent parameter studies from earlier in this paper, a change in any of these values can affect this shape as well as the shape of other parts of this curve. It is possible that the slope could be made to match even more exactly, but 
considering that these values were loosely derived from experimental data and then adjusted within the range of acceptability to attempt to accurately characterize the system, the additional parameter adjustment required to achieve this more exact match will not benefit the design of a cooled aerospike.

The difference in the curve shapes between the experimental and simulation data in the 'motor off' step is simply a programming simplification. During the experimental motor fire, the oxidizer supply to the motor is turned off at approximately 22 seconds, however, because of fluid inertia in the supply lines, as well as the diffusion of the remaining oxidizer in the pre-combustion chamber, the motor continues to burn at a lower chamber pressure and temperature, causing both the sink temperature and film coefficient to decrease slowly, before a complete stop of heat flux into the nozzle. This stage of the motor burn in between full-on and full-off causes the mismatch; however, it was not necessary to model this.

The mismatch in equilibrium temperature for the 'motor off' step was discussed above. To reiterate, it is most likely because of variable contact pressure between materials in the nozzle, especially the hot graphite.

The mismatch in equilibrium temperature in the 'soak' step could have happened for a number of reasons. The first is the same as the 'motor off' step mismatch. The difference in final temperatures between the experimental and simulation data for both steps is approximately the same. If it is possible to additionally decrease the temperature in the flange during the 'motor off' step while the coolant is still flowing, then it makes sense that it will also have a lower equilibrium temperature during the 'soak' step. Also, if the convection from the rocket to the atmosphere is higher because of plume effects, then the temperature should also be lower, though by how much is unknown. 
The results are very satisfactory. Considering the averaged nature of everything about this model other than its cross-sectional shape, it matches the experimental data very closely. That being said, there are many things a further exploration of the subject could do to increase the accuracy of the model in terms of its applicability to aerospike modeling.

Firstly, there are equations that relate thermal contact resistance to contact pressure. These equations provide rough data at best; however, if used as a baseline with experimental contact pressure data, a pressure-contact resistance correlation could be established and used in a fully coupled thermal/mechanical model to gain some additional accuracy in the model.

Secondly, though it is unknown how it would be done, a study could be performed on the relation between coolant temperature, cooling annulus material temperature and film coefficient. If a relationship between these values could be established, a more effective film coefficient model which uses material temperature and coolant temperature as its independent variables could be formulated.

These two additions to the model would take much of the guess work out of using a computer model to determine aerospike feasibility.

As part of this process, it is useful to characterize annulus sink temperature as a function of how far around the cooling annulus the fluid has traveled and use this data to characterize the film coefficient as a function of annulus fluid temperature and pressure. This would necessitate the fabrication of a new, more heavily instrumented rocket nozzle as well as the expansion of the current model from two dimensions into 3 dimensions. 


\section{CHAPTER 5: SIMPLIFIED 3D NOZZLE MODEL}

To gain a further understanding of how the oxidizer cooling varies with longer exposure to heat, a new, more heavily instrumented nozzle was created. The newly instrumented nozzle differs from the previous nozzle in a number of ways. Firstly, the coolant enters and exits at approximately the same spot in the annulus. This necessitated a barrier between the inlet and exit ports. The reason behind this revision was to increase the total amount of cooling done by the fluid to get more data on the effect of prolonged exposure to a hot rocket throat, thus enabling the creation of a more accurate model for use in aerospike design. The new throat with the inlet/outlet barrier is shown in Figure 24.

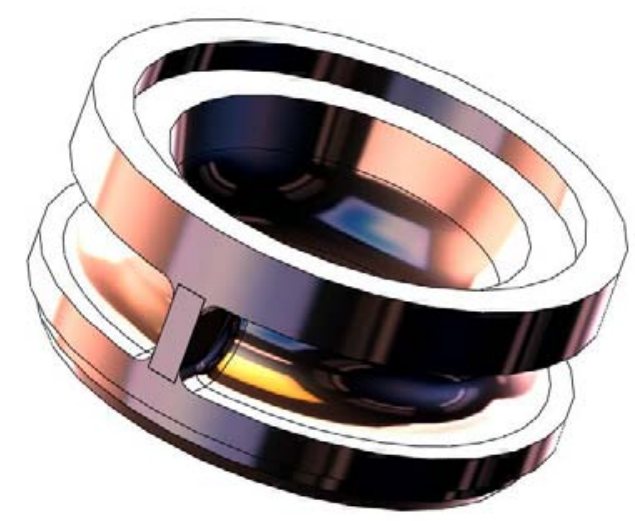

Figure 24: Rayleigh experiment throat insert with inlet/outlet barrier

Secondly, to be able to get the necessary data from 8 separate locations around the cooling annulus, the nozzle body itself needed to bet expanded to accommodate the fittings for the instrumentation causing it to have slightly more mass than the previous nozzle. The new nozzle configuration can be seen in Figure 25. 


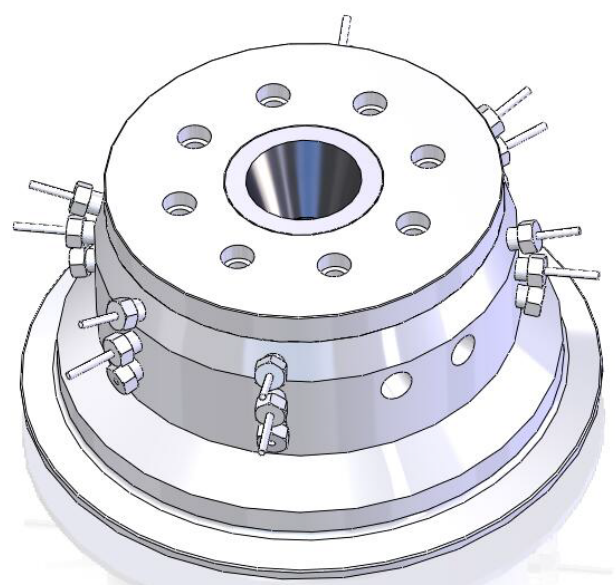

Figure 25: The Rayleigh experiment nozzle assembly with additional instrumentation ports shown.

In this configuration, coolant temperature and pressure, as well as copper flange temperature is able to be measured at each angular location.

These parts were then used to create a 3-dimensional model from the ground up. Each part was created in SolidWorks for the purpose of part fabrication, so most of them needed to be defeatured for modeling. This included removing holes and fillets, shifting a notch in the cap/nozzle junction to improve mesh quality, and cutting out excess material at the bottom of the nozzle body to simplify the shape.

The removal of holes and fillets is acceptable for this experiment because it is a heat conduction experiment. There are no stress concentrations to be examined or fluid dynamics to be affected. The amount of material removed or added because of the alterations is a small portion of the overall amount of material, and will not appreciably, if at all, affect the heat capacity of the nozzle as a whole. 
The shift of material between the nozzle and cap will not affect the simulation at all. There is no net change in the amount of material in the model; the only alteration is a shift of boundary by less than 0.01 inches in a region far from the region of interest. Similarly, the bottom region of the nozzle body only acts as a heat sink and is in a region which joins to the remainder of the motor body in the physical system. The local results for this region will not model the physical system at all. Since this leaves its only effect on the system to be as a heat capacitance device, the lack of a small flange in a region far from the region of interest will not affect the results.

\subsection{D MODELING METHODOLOGY}

This model used the same material properties and loading steps as the 2D axisymmetric model. The hot gas side film coefficients and sink temperatures are all applied in the same manner as the 2D model; however, the coolant film condition was applied variably around the annulus.

Additionally, because of the large amount of nodal data output at each time increment, the output data was restricted to the copper throat because no experimental data would be gathered from the stainless steel support ring.

The annulus film coefficient values were calculated by using a simplified 2D finite difference approach to calculate approximate coefficients at each data point from an earlier experimental test fire. These values were then plotted against angular position around the annulus and curve fitted. Because the data was calculated from a one inlet/one outlet run, the curve fit was used to extrapolate the data out to approximately $2 \pi$ radians around the annulus. This allowed separate film coefficient values to be calculated for any position around the annulus. A uniform, reliable change in temperature as a function of angular position around the annulus was not seen in any of the test data, so the average temperature of $40^{\circ} \mathrm{F}$ from the curve fit experimental data was used around the entire annulus. 
Similar to the 2D model progression, the 3D model would start simple in order to debug the model and compare values, and would then move to a full nozzle model if computational power allowed. During the initial debugging phase, the copper and steel rings would be cut along the inlet/outlet barrier to prevent interaction between hot and cold areas over a small distance, thus creating large gradients. This 'sector' model can be seen in Figure 26. Once this model was successful, the physical system would then be modeled.

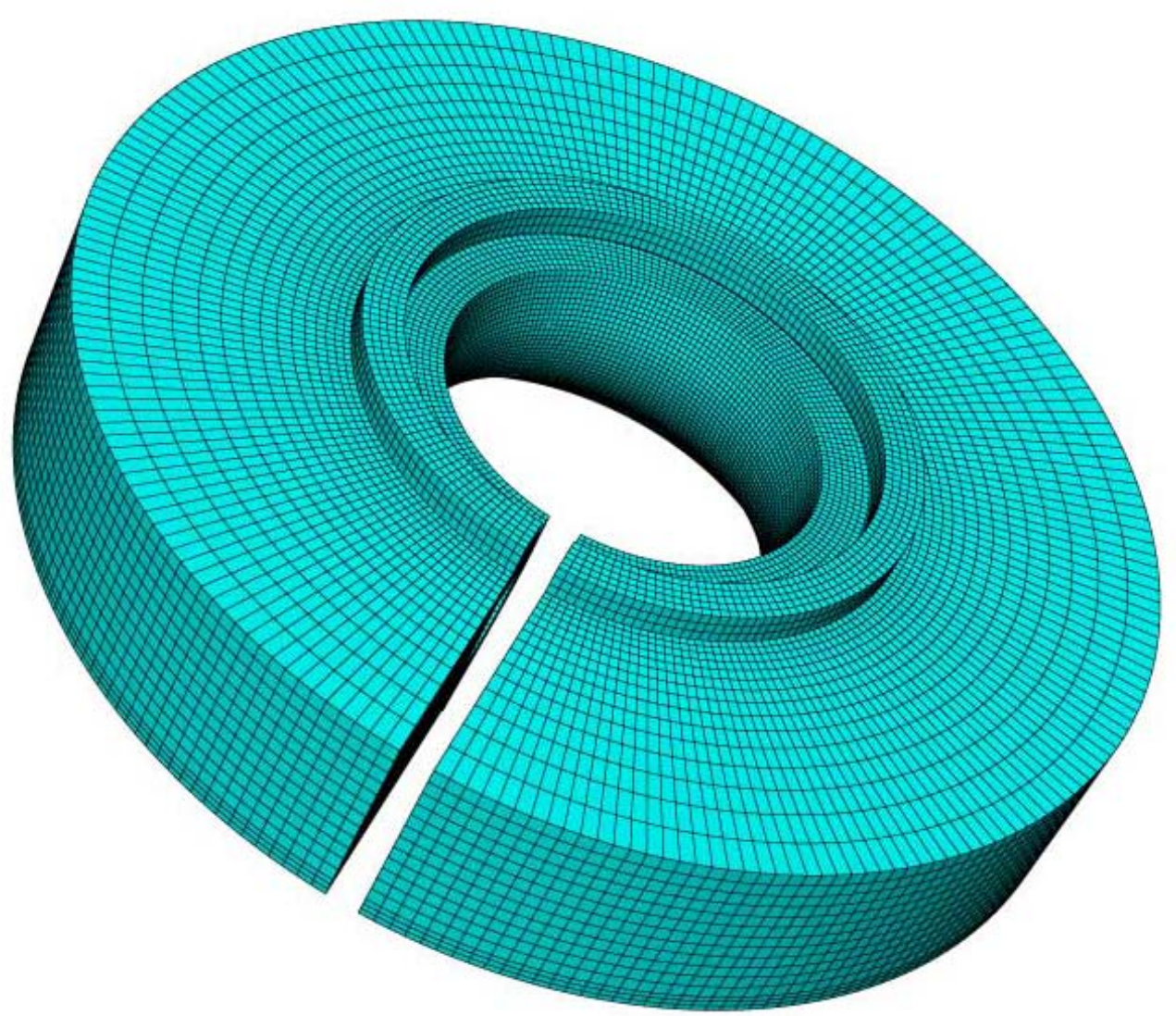

Figure 26: The initial 3D model, cut at the inlet/outlet barrier to increase the simplicity of the analysis.

\subsection{MESH DEVELOPMENT}

To create an acceptable 3D mesh in ABAQUS, the approximate seed size from the 2D axisymmetric model was used as a starting point. The first parts to be meshed would be the 
copper throat and stainless steel support ring. The lessons learned while creating the 2D model were applied to the 3D model mesh generation. The copper started with a $0.01 \mathrm{in}$. seed size, and the steel used a 0.01 in. contact seed size and a biasing scheme to decrease the density of the mesh as it moved away from the copper. A cutaway view of this mesh can be seen in Figure 27.

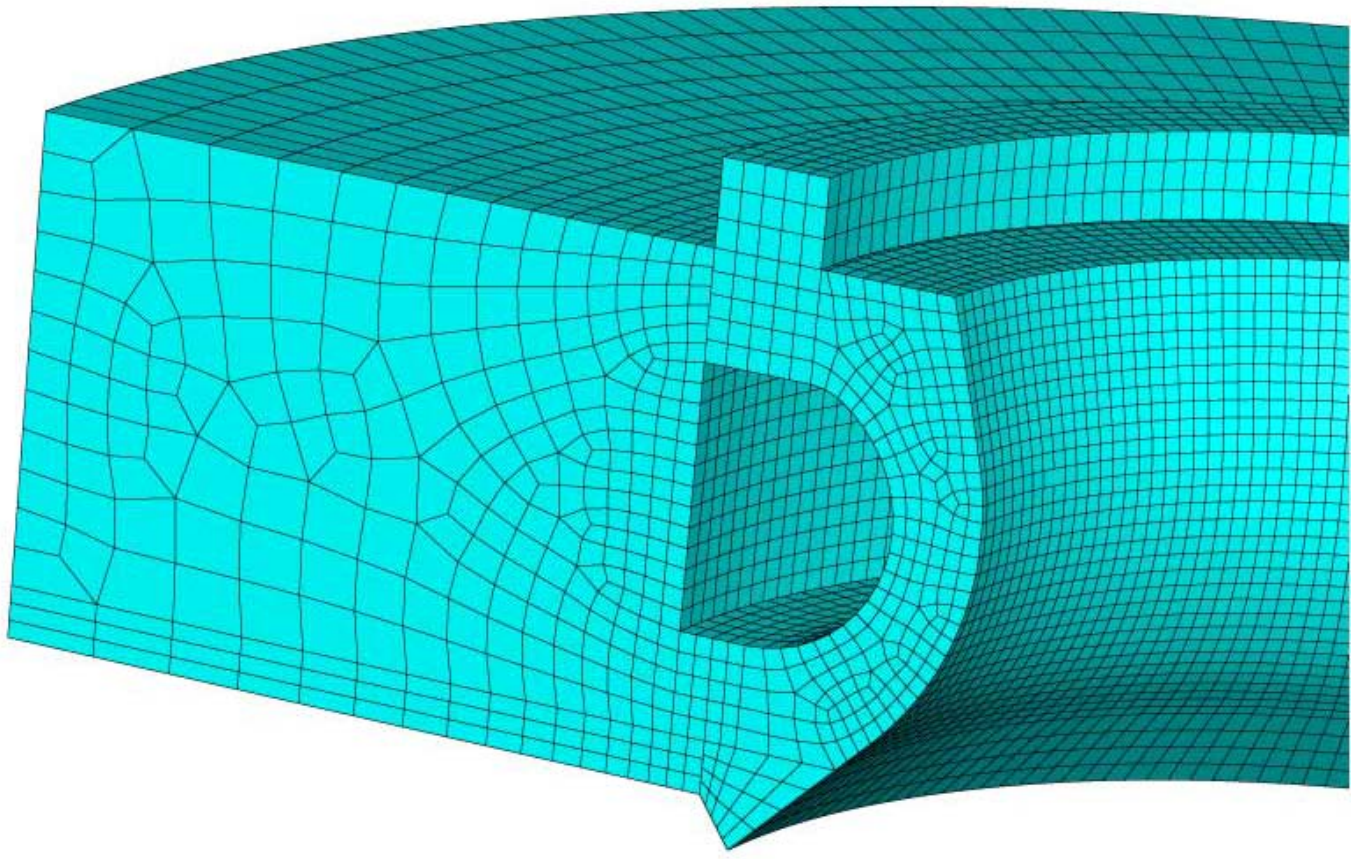

Figure 27: Cut away view of the 3D sector model mesh

The type of elements used were DC3D8: '8 Node Linear Heat Transfer Bricks.’ Key element quality numbers can be seen in Table 7. It is important to note that 3:1 is the desirable maximum aspect ratio, but $5: 1$ is acceptable.

Table 7: Element Quality Data, simplified 3D sector model

\begin{tabular}{|llll|}
\hline Quality Measure & Limit & \% Elements Outside Limit & Worst Element \\
\hline Aspect Ratio & $<3: 1$ & $2.79 \%$ & $5.31: 1$ \\
\hline Min/Max Angle - Hexahedron & $45^{\circ}<\theta<135^{\circ}$ & $0.50 \%$ & $42^{\circ} / 145^{\circ}$ \\
\hline
\end{tabular}


As can be seen from this data, most of the model features acceptable element quality. The distorted elements were mostly concentrated in rings of the model. For example, 190 of the elements that did not satisfy the angle criteria in the throat portion of the model were in the small angular flange at the bottom of the copper and formed a ring of elements in the flange. Almost all of the elements that did not satisfy the aspect ratio criteria were the elements in the bottom of the steel ring that can be seen in Figure 27.

\subsection{ANALYSIS}

During initial runs of the model, it became clear that using the quasi-Newton solver during the motor fire step was proving computationally inefficient because of the number of times that the Jacobian matrix needed to be reformed. This led to the 'motor fire' step being switched to the Full Newton solver, which has a faster convergence rate than the quasi-Newton solver, but takes more computational time in most cases. The initial, minimum and maximum time step data were carried over from the $2 \mathrm{D}$ analysis.

Three types of warnings were displayed after running the model. The first stated that SDI conversion was not available in heat transfer analysis. The ramifications of this warning have previously been discussed. The second stated that small nodal adjustments were not printed. This has also been previously discussed. All of the distances adjusted that were printed were on the order of $3 \cdot 10^{-5}$ inches and were judged inconsequential. Finally, the last warning stated that 188 elements were distorted. Because the element quality checks performed in the mesh development section of this chapter are stricter that those performed by ABAQUS, the elements which it refers to have already been examined and recorded in Table 7. 


\subsection{SIMPLIFIED 3D SECTOR MODEL RESULTS}

The sector model results are as expected. In a movie of a temperature contour plot over time, the variable coolant film coefficient is visible as the temperature changes as a function of angular position. During motor fire, the throat behaves as expected, as it does during cool down and soak as well. A temperature contour plot of the copper ring at the end of the motor fire step can be seen in Figure 28.

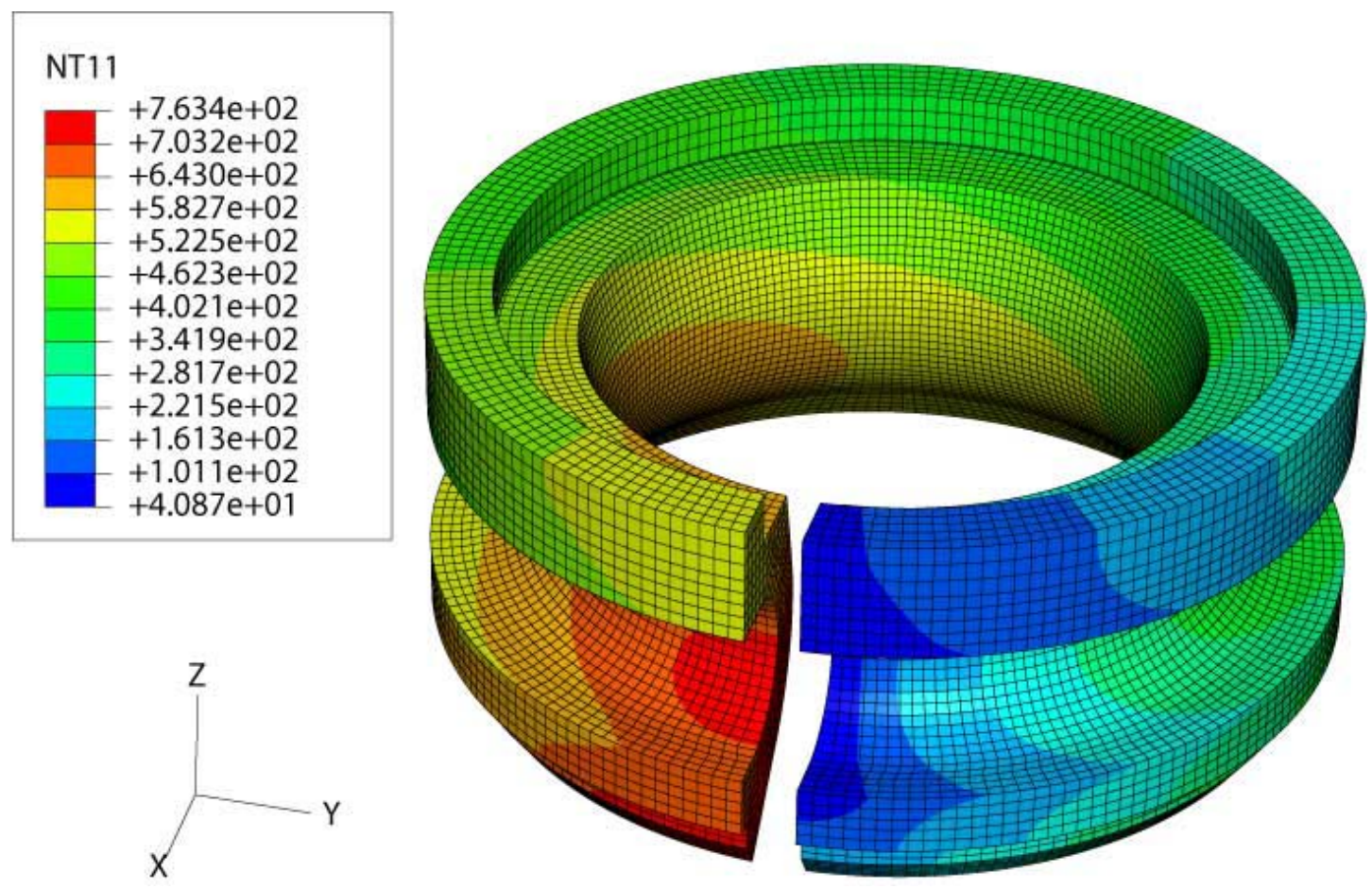

Figure 28: Temperature contour plot of the copper throat at $t=23 \mathrm{~s}$, the end of the 'motor fire' step. Temperature in ${ }^{\circ} \mathrm{F}$

Because the model is behaving as expected, it may be expanded to the full non-sector throat model to obtain data that will more accurately match the transient data of an experimental test fire. 


\section{CHAPTER 6: FULL 3D NOZZLE MODEL}

\subsection{MODELING METHODOLOGY}

The same process could be followed for expanding the simplified 3D sector model into the full 3D nozzle model as was followed during the expansion of the 2D model from its simplified form into the full 2D nozzle model. The additional material properties were added, the junctions were given the same thermal contact conductance as the 2D full model, and the same Bartz coefficients and locations were used in applying the hot gas side conditions. Also, the output data was again restricted to only the copper ring. The only parameter difference between the parameters of the 3D full nozzle model and the 2D axisymmetric full nozzle model, as mentioned previously, is the addition of the variable cool side fluid parameters that vary with angular position around the annulus. In terms of the physical model, the inlet/outlet barrier and the overall size increase due to the additional instrumentation were the only changes.

\subsection{MESH DEVELOPMENT}

The mesh seed sizing used on the sector model was again used on the stainless steel support ring and copper throat. Meshing the copper throat with the inlet/outlet barrier as part of the throat was difficult at best, so to decrease the difficulty of meshing, the barrier was modeled as its own part and connected to the copper using a tie constraint. Numerically, this is identical to the barrier and throat being modeled as a single piece. This allowed for better partioning of the copper throat and better mesh quality overall. Having discovered in the 2D model convergence study that a slightly less dense mesh could be used in the Hastelloy and graphite, a less dense mesh was used in these areas of the 3D nozzle as well in order to save on computing time. Finally, the meshes in the nozzle body and cap used seed sizes of 0.04 in. A cutaway view of the meshed part can be seen in Figure 29. 


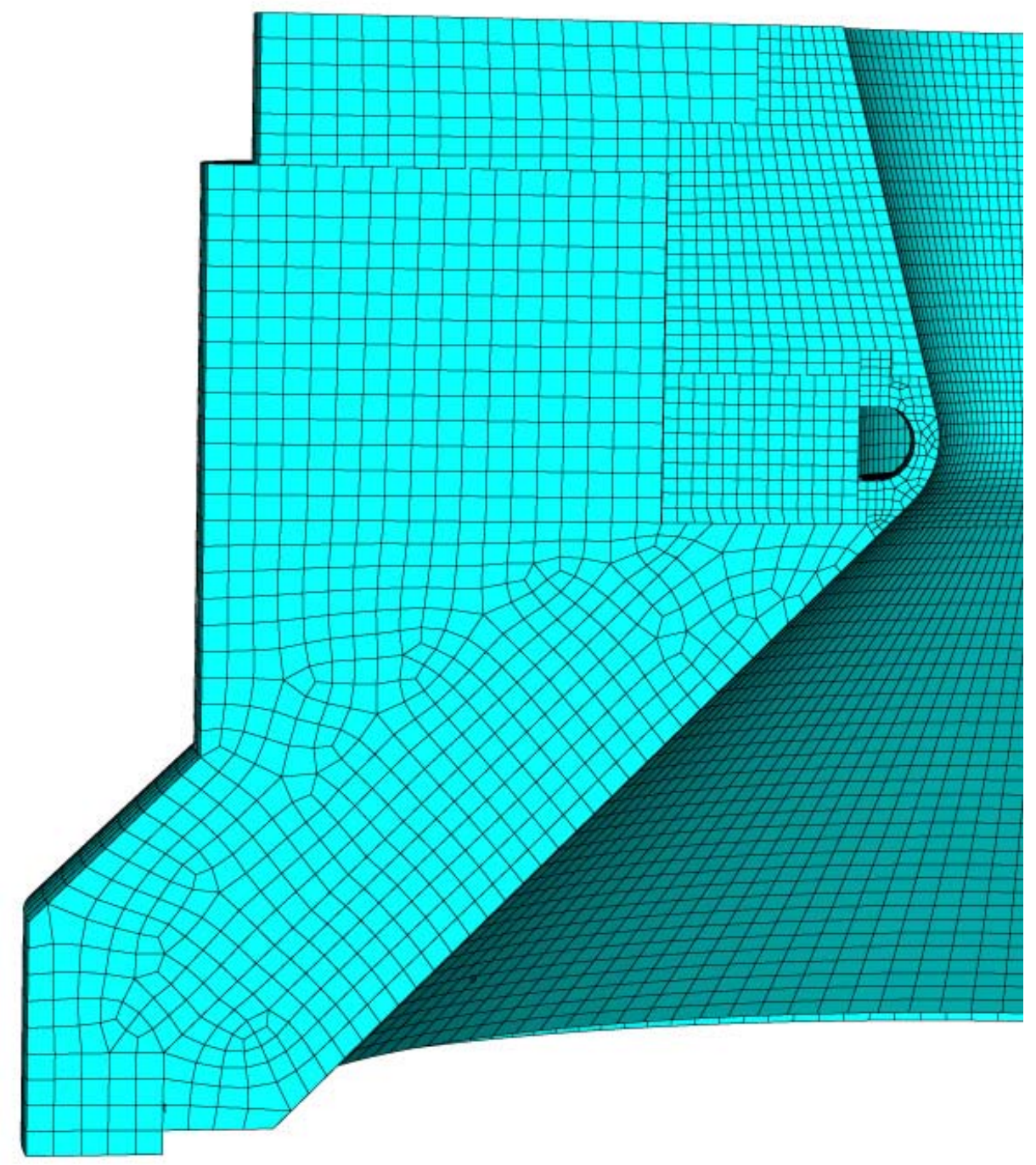

Figure 29: Cutaway view of the 3D full nozzle model mesh

\subsection{ANALYSIS}

An identical analysis technique was used for the full nozzle model as was used for the simplified sector nozzle. A number of warnings were displayed when the model was initially run. The only warning which had not been seen before warned of nodes having incorrect normal definitions. The others warned of distorted elements, that absence of SDI conversion in a heat transfer analysis, and node adjustments. The node adjustments were all on the order of $10^{-4} \mathrm{in}$. or smaller. For a heat transfer analysis, this level of adjustment is fine. There were a total of 140 distorted 
elements, all of which were in the converging liner. These made up less than $0.01 \%$ of the total elements in the model and were not in a critical location, additionally, they, along with other less distorted elements, were discussed in the mesh development section of this chapter. Finally, to address the elements with incorrect normal definitions, this warning does not apply to a heat transfer analysis because it only affects finite sliding contact. Because the contact interaction is being used solely for its contact resistance property, and not for any physical contact or sliding modeling, the warning may be ignored.

\subsection{RESULTS}

As a preliminary run, before the Rayleigh nozzle had actually been fired, the results looked favorable. The data can be loosely compared with the experimental test fire \#50 from which the cold side gas conditions were calculated. A temperature contour plot at the end of the 'motor fire’ step can be seen in Figure 30. 

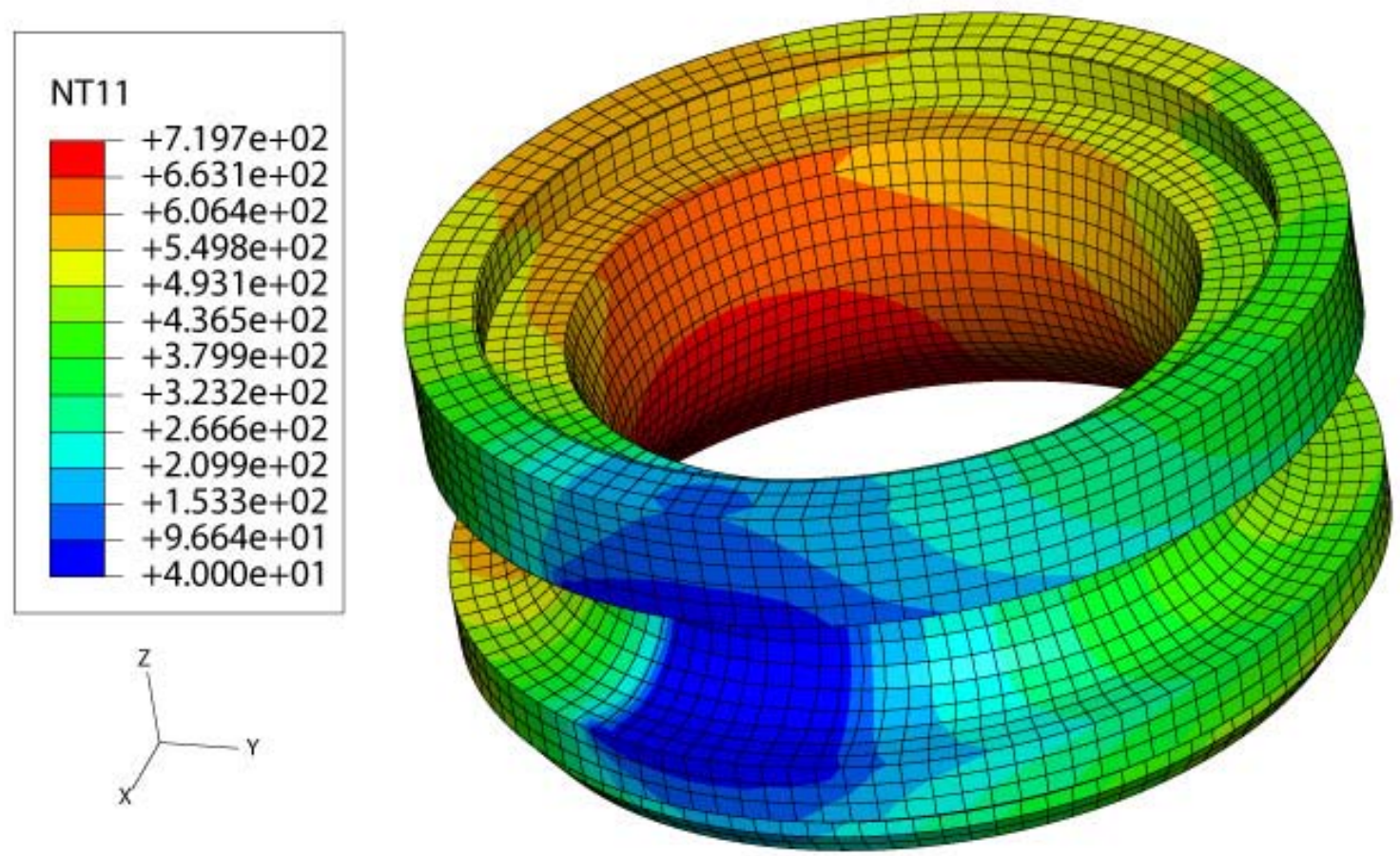

Figure 30: Temperature contour plot of the 3D full nozzle model at the end of motor fire. Temperatures shown in ${ }^{\circ} \mathrm{F}$.

Test run \#50 was a one inlet/one outlet experiment, which means that the data available from it was dispersed around a $180^{\circ}$ portion of the throat and in this case was throat location temperatures. The simulation yielded temperatures that were about $100^{\circ} \mathrm{F}$ or more lower than the experimental data at the experimental thermocouple locations. The discrepancy in the data could mean a number of things. The first is that the estimated film coefficients were incorrect; the second is that the averaged cold side sink temperatures were too low. As stated in Section 5.1 the average sink temperature from run \#50 was used because the fluid temperature thermocouple data varied widely from $29^{\circ} \mathrm{F}$ to $155^{\circ} \mathrm{F}$, but not in ascending order from inlet to outlet; the coldest reading was recorded at the location closest to the outlet. Because the fluid is changing phase throughout its course through the cooling annulus, it was possible that there were phenomena occurring within the annulus that cannot be predicted using the four thermocouple readings in the experiment. To attempt a more accurate simulation run, another run was 
conducted taking the average between the adjacent $155^{\circ} \mathrm{F}$ and $29^{\circ} \mathrm{F}$ thermocouple readings, combined with the other two thermocouple readings of $43^{\circ} \mathrm{F}$ and $53^{\circ} \mathrm{F}$ to create a variable mapped temperature scheme around the first half of the annulus. This simulation yielded results that were still $50^{\circ} \mathrm{F}$ to $100^{\circ} \mathrm{F}$ lower than the experimental data. The logical conclusion that can be drawn from this is that the 2D finite difference approximation used to calculated the $\mathrm{h}_{\text {cold }}$ values was not accurate enough. The next step was then to model a simulation run using completely theoretically determined values for $\mathrm{h}_{\text {cold }}$ and $\mathrm{T}_{\text {cold }}$. This meant that a fluid in a single phase would be necessary in the annulus.

\subsection{INERT GAS MODEL}

To set up an experiment whose results could be predicted by a model using theoretically determined coefficients, an ideal gas was a prime candidate for the cooling fluid. The use of such a fluid would allow the assembly to be cooled by a single phase fluid of which the properties are well known and documented. Helium was chosen by the thermal/fluids team working on the project and a uniform $\mathrm{h}_{\text {cold }}$ value of $0.01034 \mathrm{BTU} / \mathrm{s} \cdot \mathrm{in} .{ }^{2} \cdot{ }^{\circ} \mathrm{R}$ was determined along with a $\mathrm{T}_{\text {cold }}$ value that varied from $69^{\circ} \mathrm{F}$ to $82^{\circ} \mathrm{F}$ around the annulus. These values were based on a $500 \mathrm{psi}$ annulus pressure. Once the values from above were placed into the FORTRAN subroutine, the model was then run.

\subsection{INERT GAS MODEL THERMAL RESULTS}

The results for the inert gas model yielded promising results. The maximum temperature of 461 ${ }^{\circ} \mathrm{F}$ reached by the copper during the simulated test fire with helium as the coolant is shown in Figure 31. It can also be seen in Figure 32 that the maximum overall temperature in the copper is about $600{ }^{\circ} \mathrm{F}$, well within the thermal limit of the material. This is on the order of temperatures in the previous models and is much lower than some experimental thermocouple readings. With 
this in mind, we can safely conclude that using ideal gas as a coolant is an acceptable experiment to validate this model.

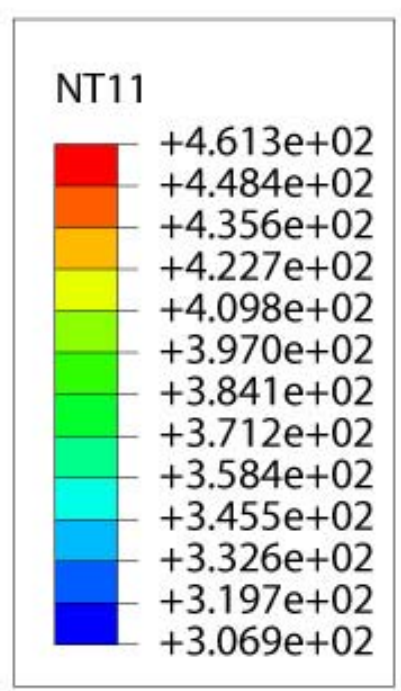

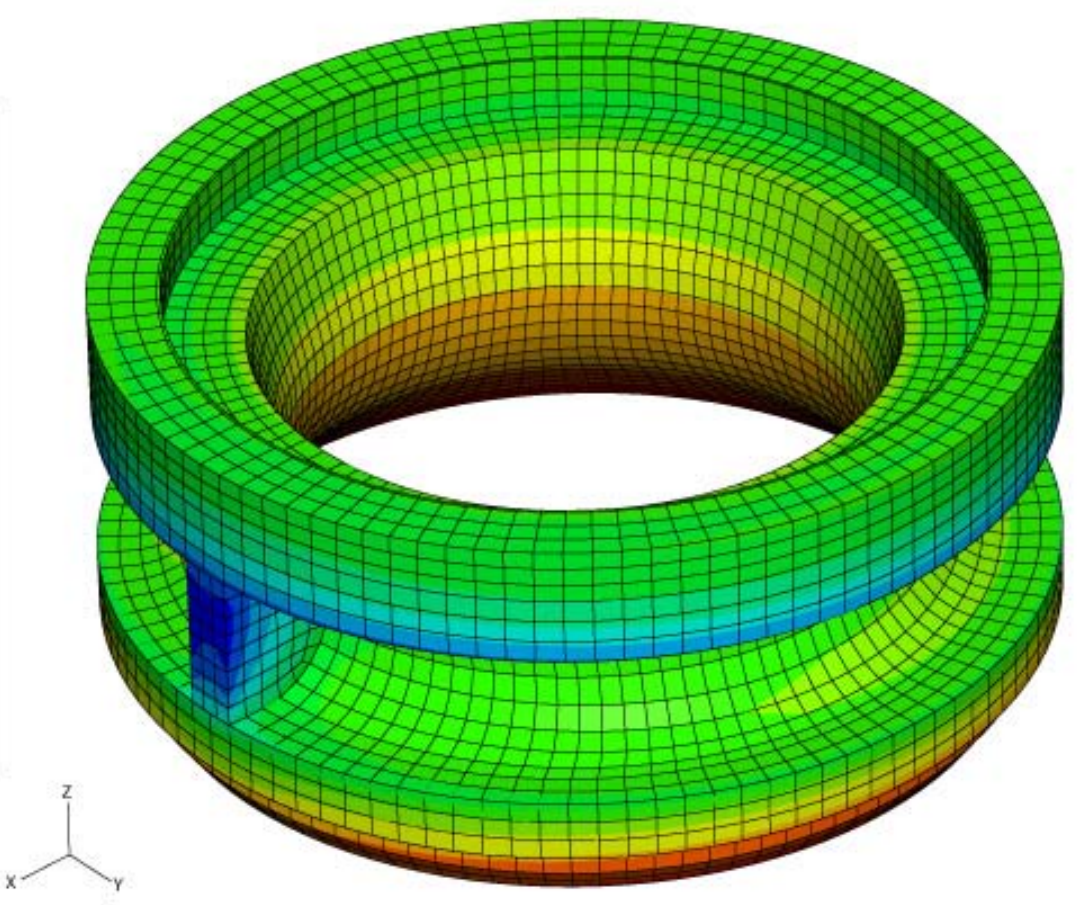

Figure 31: Temperature contour of the copper throat at the end of motor fire predicted by the ideal gas simulation. Temperatures are shown in ${ }^{\circ} \mathrm{F}$.

Transient plots of the flange thermocouple location near the inlet, outlet, and middle of the path around the annulus can be seen in Figure 32. It can be seen that because the heat transfer coefficient is uniform and the temperature of the coolant varies little, the curves are very close together. 


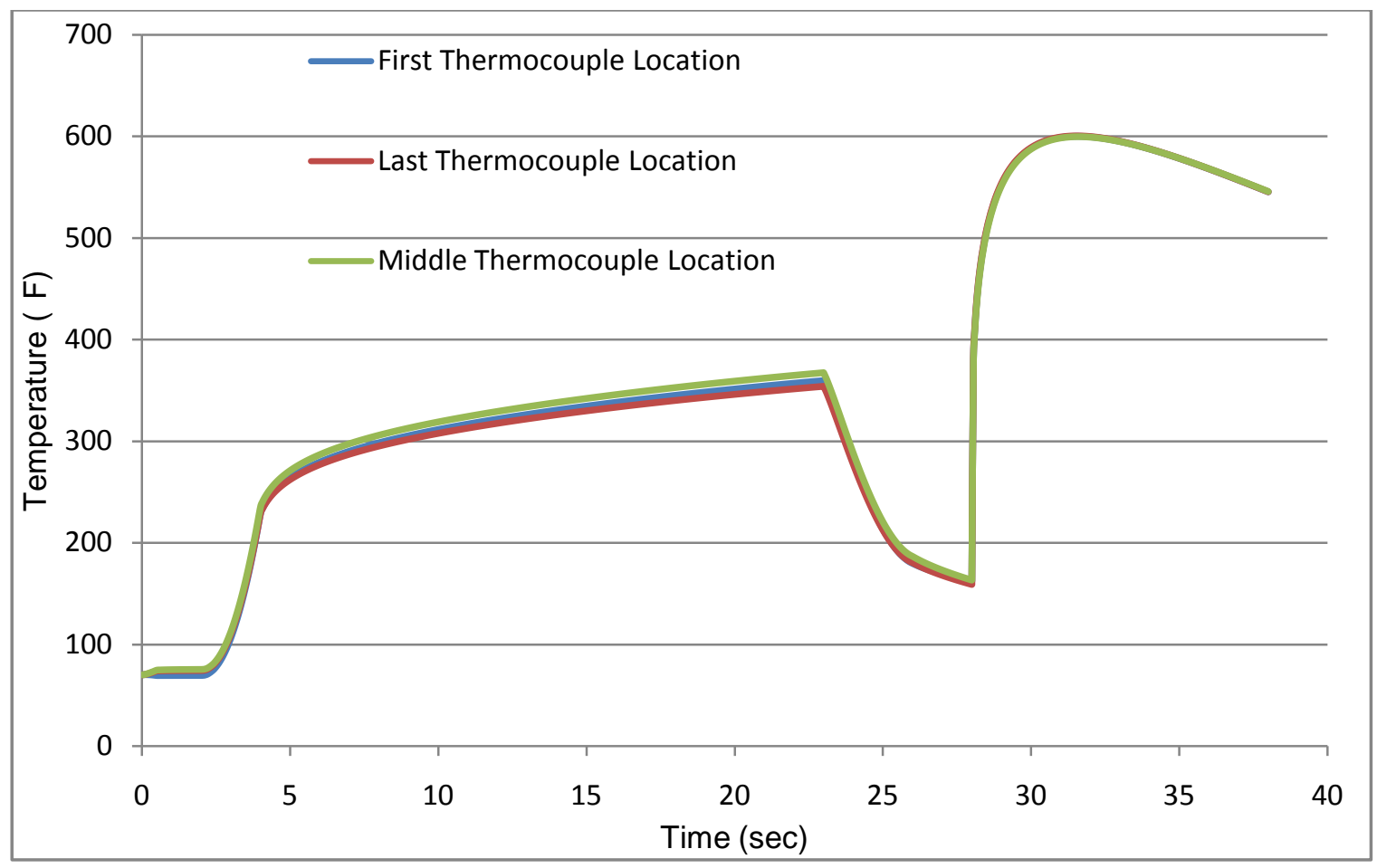

Figure 32: Transient temperature data for the flange thermocouple location at three angular positions around the annulus in the ideal gas coolant simulation

\subsection{INERT GAS MODEL MECHANICAL RESULTS}

Finally, it is useful to perform a mechanical analysis of the inert gas experiment to determine if any abnormal effects occur that are related to the change in thermal gradients as compared with the previous models. Because the temperature of the copper as a function of angular position around the annulus varies by such a small amount ('small amount' in this case is about $5^{\circ} \mathrm{F}$, much less than the previous experimental test fires), a 2D axisymmetric model could be used for the analysis.

It can be seen in Figure 33 \& the magnified detail section in Figure 34 that the mechanical model maximum principle stress values in the critical area of the copper are well within the ultimate strength of the material, in this case the conservative value of $31000 \mathrm{psi}\left(3.1 \cdot 10^{4} \mathrm{psi}\right)$ was used for the copper. The results from this model, as well as the thermal model, suggest that the material in 
the inert gas nozzle will remain intact and the nozzle is safe to fire and subsequently obtain data from.

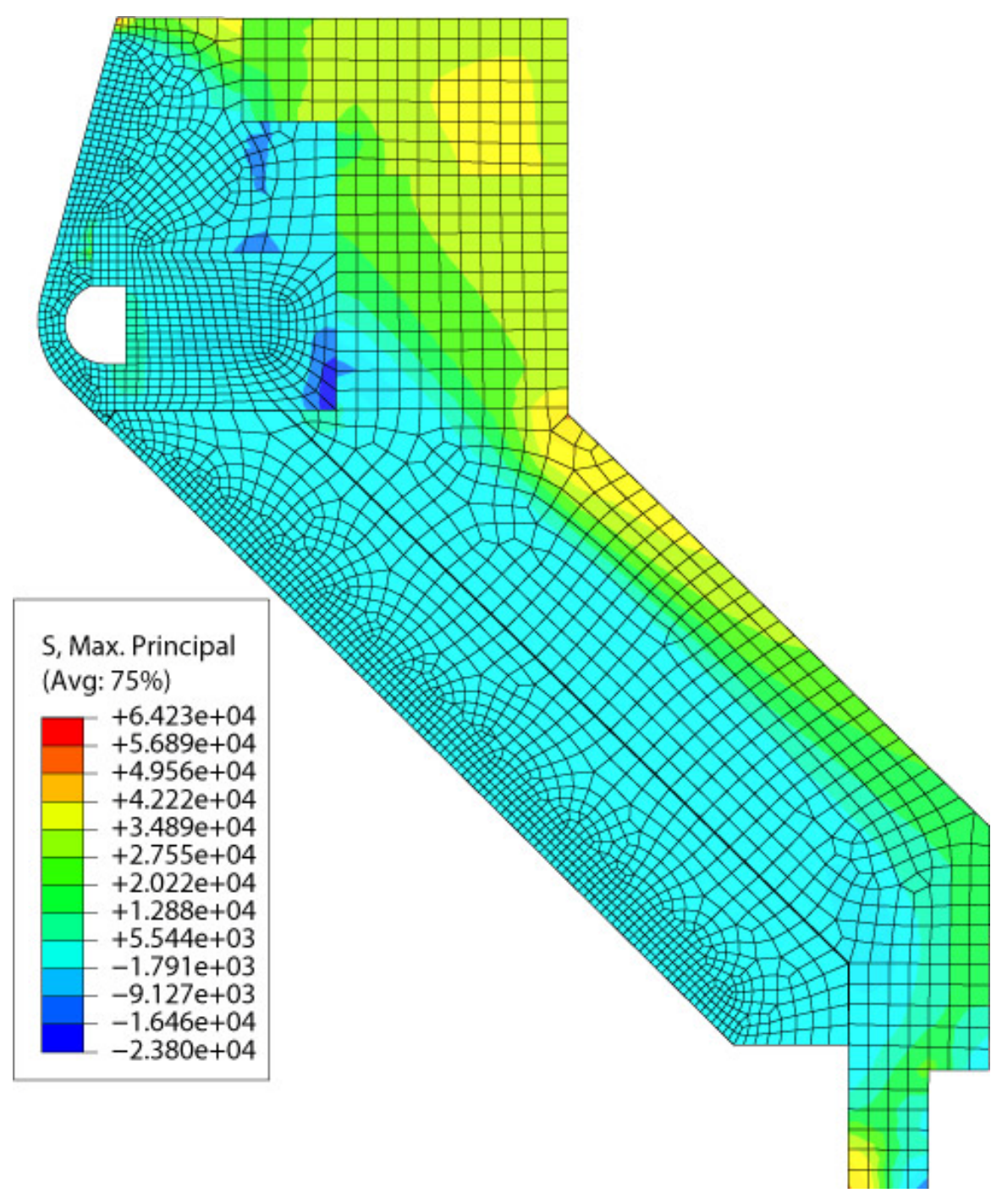

Figure 33: Contour plot of maximum principle stress at the end of the 'Motor Fire' step of the simulation 

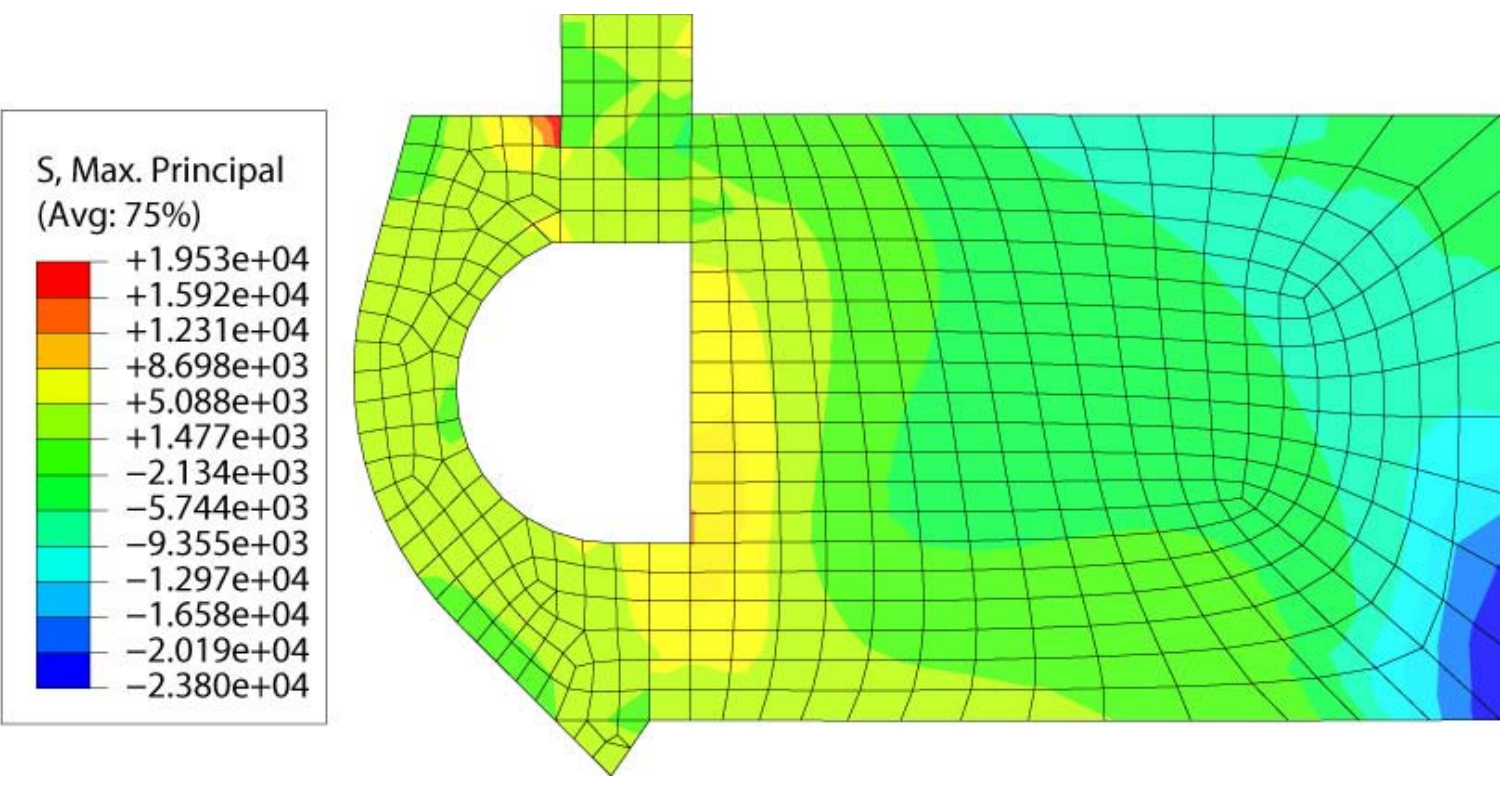

Figure 34: Contour plot of maximum principle stress in the copper and stainless steel support ring at the end of the 'Motor Fire' step of the simulation

\subsection{INERT GAS MODEL DISCUSSION}

The next step in finalizing this model as a design tool is to fire the motor using helium as the coolant and compare the results. If the theory behind the helium matches reality, the model should accurately predict the temperatures in the nozzle, and the results should be satisfactory, finally showing that this model can be used with theory as a predictive tool. 


\section{CHAPTER 7: CONCLUSION}

A series of finite element models of a converging/diverging rocket nozzle with an oxidizer cooled throat were created using ABAQUS. The end goal of the models was to establish a modeling methodology which could then be applied to the design of an actively cooled aerospike nozzle. The first model created was a simplified 2D axisymmetric model consisting of the copper throat and stainless steel support ring. This model yielded acceptable results and was then expanded to include the Hastelloy diverging liner of the nozzle. When this model yielded only partially accurate results, the model was expanded to include all parts of the nozzle including the cap, body, and graphite converging liner. The expanded and full 2D nozzle models used the Bartz equation to calculate variable film conditions for the combustion side of the nozzle and mapped them onto the model using a FORTRAN subroutine. The full nozzle model yielded interesting results and prompted a parameter reevaluation and three parametric studies. These studies provided the data that was used to modify the model parameters and obtain accurate results. Once the 2D axisymmetric full nozzle model obtained accurate results, a 3D model with variable coolant side film conditions was created. The first 3D model featured only the copper and stainless steel support ring portions of the nozzle, and was cut along the newly added barrier between coolant inlet and outlet. This created a sector model with which it was possible to investigate the performance of the newly applied coolant film conditions. Once the FORTRAN subroutine used to apply these coefficients was validated, the model was then expanded to include all parts of the nozzle. This model yielded acceptable results with respect to the methods with which the parameters were calculated and a more accurate way of calculating the cold side film conditions was investigated. This method involved using an ideal gas as the coolant so as to keep the coolant in a single phase. A separate graduate project calculated the ideal gas film conditions as a function of angular position around the cooling annulus. These values were then input into the model using the FORTRAN subroutine and the model was run. The results yielded 
data that indicates that the nozzle will not fail. Transient curves at the thermocouple locations in the nozzle were generated and will be compared to the experimental data upon firing of the ideal gas cooled nozzle.

Overall, the project was a success. The groundwork and much of the structure of a legitimate predictive tool that can be used in the design of a cooled aerospike nozzle has been created. 


\section{BIBLIOGRAPHY}

1. Turner, Martin J. L. Spacecraft Propulsion Principles, Practices and New Developments 2nd Edition. s.l. : Springer.

2. Sutton, Paul and Biblarz, Oscar. Rocket Propulsion Elements 7th Edition. s.l. : John Wiley \& Sons, 2000.

3. Berman, K. and Crimp, F.W. Performance of Plug-Type Rocket Exhaust Nozzles. s.l. : ARS Journal, 1961. Vol. 31.

4. NASA. NSTS 1988 News Reference Manual. s.l. : NASA, 1988.

5. Browning, William R. Preliminary Design Study of an Un-cooled Annular Aerospike Nozzle. San Luis Obsipo : Cal Poly San Luis Obispo, 2007.

6. Besnard, Eric and Garvey, John. Student Development and Test of a Gimbaled Annular Aerospike Nozzle. Indianapolis : AIAA, 2002.

7. Besnard, Eric and Garvey, John.. Aerospike Engines for Nanosat and Small Launch Vehicles (NLV/SLV). San Diego : AIAA, 2004.

8. Incropera, Frank and DeWitt, David P. Introduction to Heat Transfer, 4th Edition. s.l. : John Wiley \& Sons, 2002.

9. Simulia Inc. ABAQUS CAE \& Analysis User's Manual, Theory Manual. s.l. : Simulia Inc., 2007.

10. Madhusudana, C.V. Thermal Contact Conductance. New York : Springer, 1996.

11. Huzel, Hieter K., Huang, David H. and Arbit, Harry. Modern Engineering for Design of Liquid-Propellant Rocket Engines. s.l. : AIAA, 1992. 


\section{APPENDIX A: CONVERGENCE GRAPHS}

\section{SIMPLIFIED 2D AXISYMMETRIC MODEL}
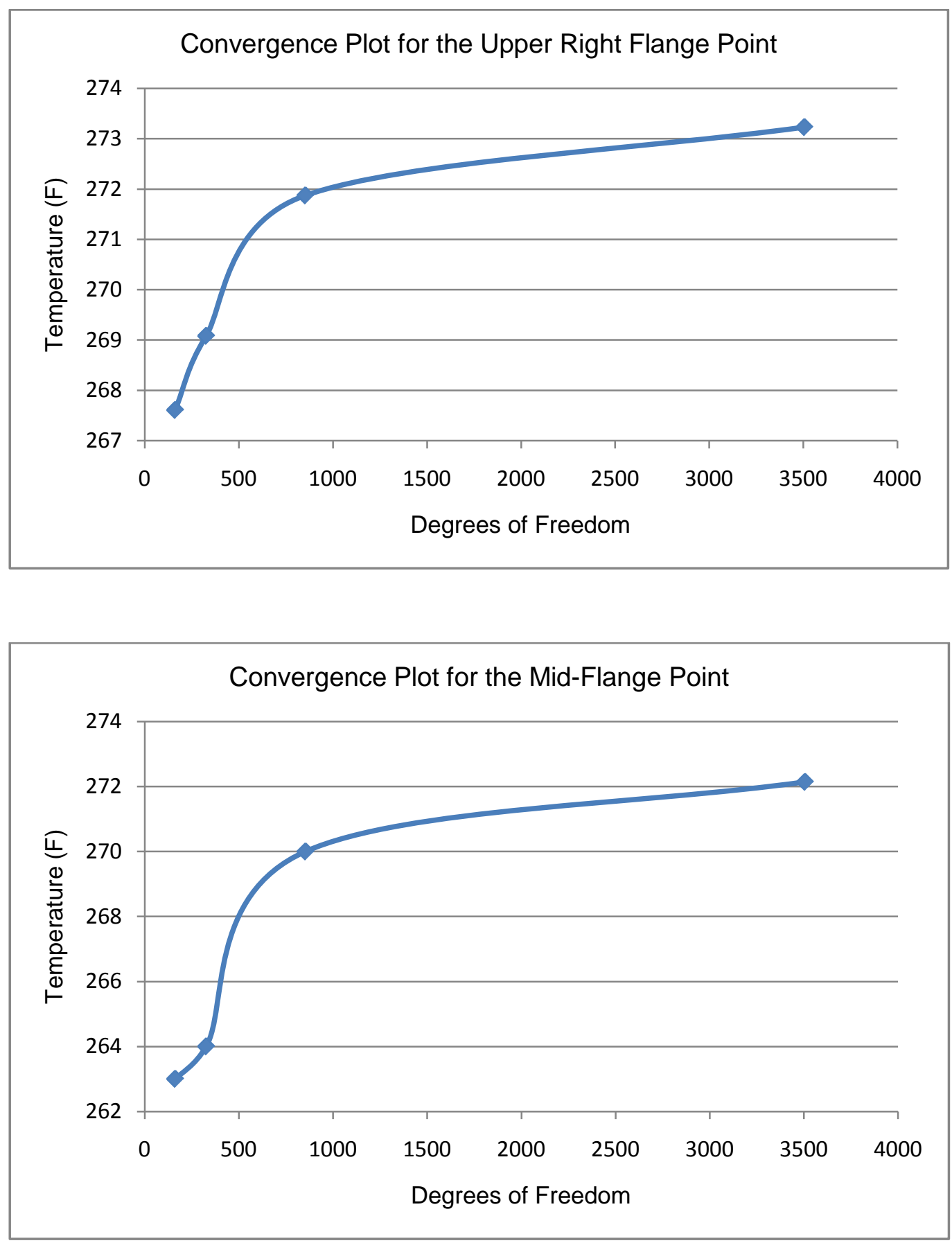

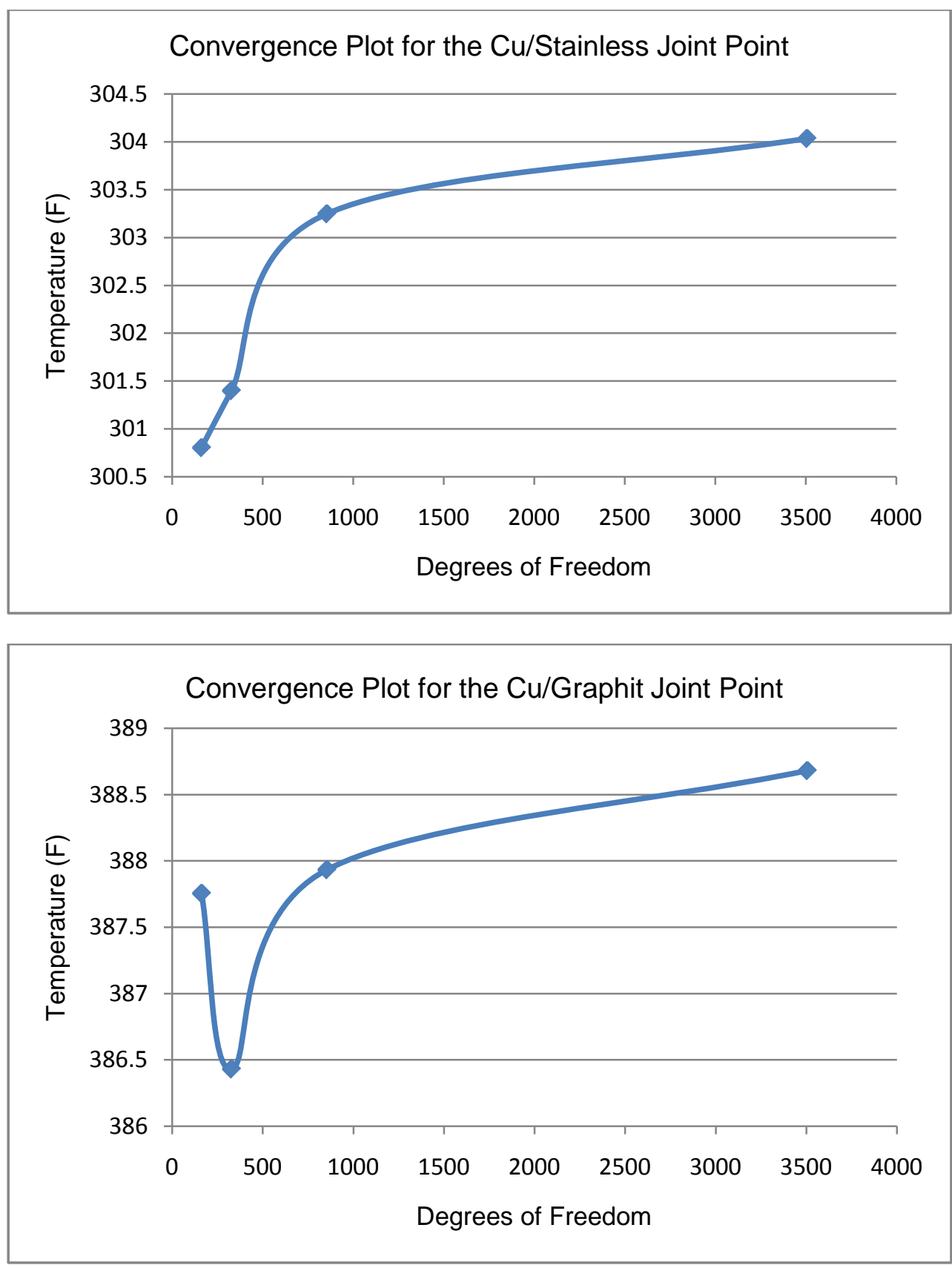
FULL 2D AXISYMMETRIC MODEL
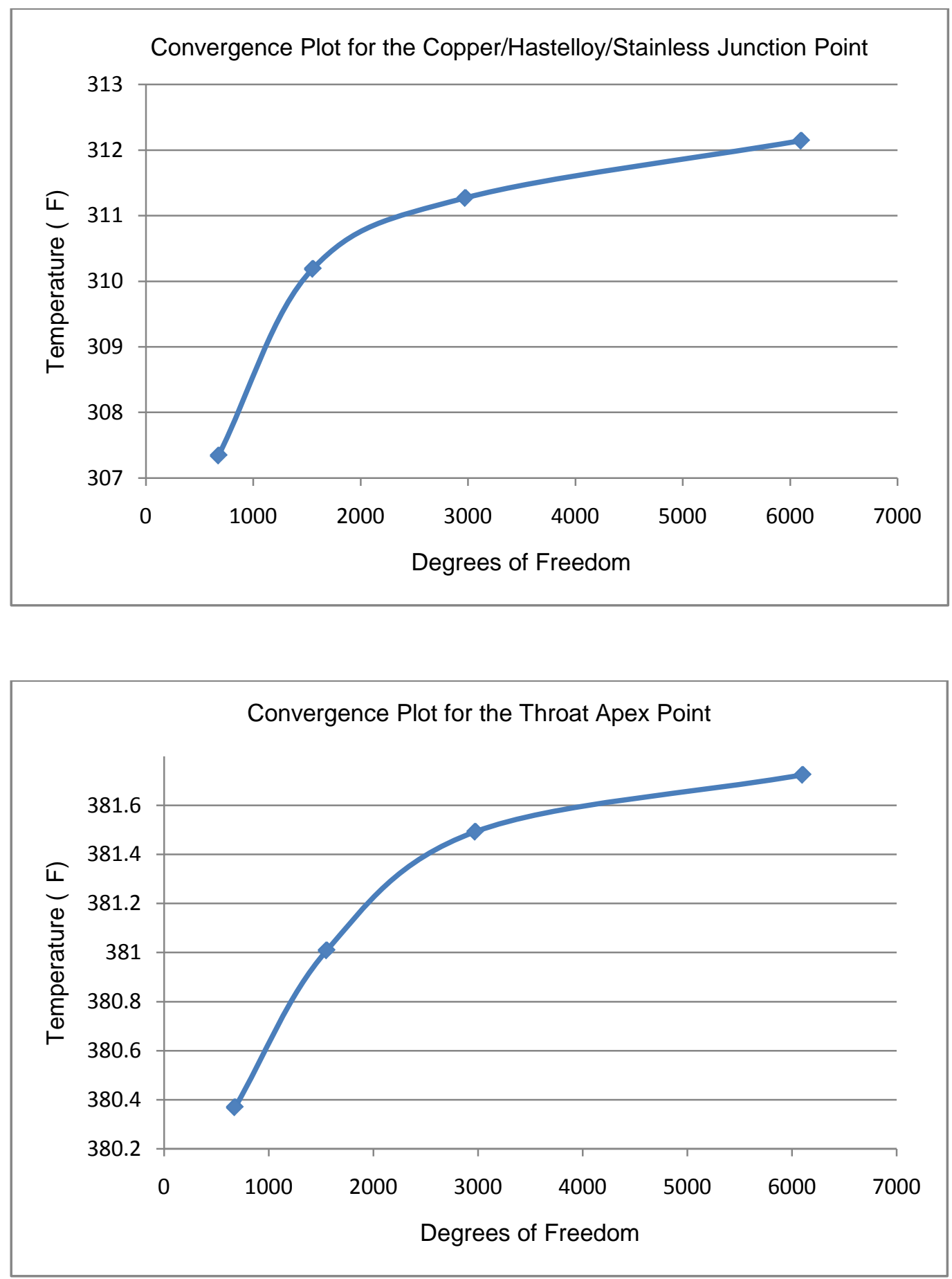


\section{APPENDIX B: MATERIAL PROPERTIES}

OFHC Annealed Copper

\begin{tabular}{|rr|}
$\begin{array}{l}\text { Conductivity } \\
\left.\text { (BTU/in·sec }{ }^{\circ} \mathrm{F}\right)\end{array}$ & Temperature $\left({ }^{\circ} \mathrm{F}\right)$ \\
\hline $\mathbf{0 . 0 0 5 4 6 3}$ & 70 \\
\hline $\mathbf{0 . 0 0 5 3 2 4}$ & 200 \\
\hline $\mathbf{0 . 0 0 5 2 3 1}$ & 400 \\
\hline $\mathbf{0 . 0 0 5 0 9 3}$ & 600 \\
\hline $\mathbf{0 . 0 0 5}$ & 800 \\
\hline $\mathbf{0 . 0 0 5}$ & 1500 \\
\hline
\end{tabular}

\begin{tabular}{|rr|}
$\begin{array}{l}\text { Mass Density } \\
\left(\mathrm{lbm} / \mathrm{in}^{3}\right)\end{array}$ & Temperature $\left({ }^{\circ} \mathrm{F}\right)$ \\
\hline $\mathbf{0 . 3 2 1}$ & 70 \\
\hline $\mathbf{0 . 3 2}$ & 200 \\
\hline $\mathbf{0 . 3 1 8}$ & 400 \\
\hline $\mathbf{0 . 3 1 6}$ & 600 \\
\hline $\mathbf{0 . 3 1 5}$ & 800 \\
\hline $\mathbf{0 . 3 1 5}$ & 1500 \\
\hline
\end{tabular}

\begin{tabular}{|rr|}
\hline $\begin{array}{l}\text { Specific Heat } \\
\left(\mathrm{BTU} / \mathrm{lbm} \cdot{ }^{\circ} \mathrm{F}\right)\end{array}$ & $\begin{array}{l}\text { Temperature } \\
\left({ }^{\circ} \mathrm{F}\right)\end{array}$ \\
\hline $\mathbf{0 . 0 9 4}$ & 70 \\
\hline $\mathbf{0 . 0 9 5}$ & 200 \\
\hline $\mathbf{0 . 0 9 6}$ & 400 \\
\hline $\mathbf{0 . 0 9 8}$ & 600 \\
\hline $\mathbf{0 . 1 0 1}$ & 800 \\
\hline $\mathbf{0 . 1 0 2}$ & 1150 \\
\hline
\end{tabular}




\begin{tabular}{|rrr|}
\hline E (psi) & $\mathbf{v}(\mathbf{n u})$ & Temperature $\left({ }^{\circ} \mathrm{F}\right)$ \\
\hline $\mathbf{1 8 7 0 0 0 0 0}$ & 0.355 & 70 \\
\hline $\mathbf{1 8 2 0 0 0 0 0}$ & 0.355 & 200 \\
\hline $\mathbf{1 7 6 0 0 0 0 0}$ & 0.36 & 400 \\
\hline $\mathbf{1 6 8 0 0 0 0 0}$ & 0.365 & 600 \\
\hline $\mathbf{1 5 9 0 0 0 0 0}$ & 0.37 & 800 \\
\hline $\mathbf{1 4 7 0 0 0 0 0}$ & 0.375 & 1150 \\
\hline $\mathbf{1 1 1 0 0 0 0 0}$ & 0.385 & 1500 \\
\hline
\end{tabular}

\begin{tabular}{|c|c|}
\hline $\begin{array}{l}\text { CTE } \\
\text { (in. } /^{\circ} \mathrm{F} \text { ) }\end{array}$ & $\begin{array}{l}\text { Temperature } \\
\left({ }^{\circ} \mathrm{F}\right)\end{array}$ \\
\hline 9.00E-06 & 70 \\
\hline 9.23E-06 & 200 \\
\hline 9.50E-06 & 400 \\
\hline 9.75E-06 & 600 \\
\hline 1.08E-05 & 800 \\
\hline 1.10E-05 & 1150 \\
\hline 1.20E-05 & 1500 \\
\hline
\end{tabular}

\begin{tabular}{|c|c|c|}
\hline Plasticity & gamma=45 & \\
\hline $\begin{array}{l}\text { Yield } \\
\text { Stress } \\
\text { (psi) }\end{array}$ & $\begin{array}{l}\text { Kinematic } \\
\text { Hardening } \\
\text { Parameter C }\end{array}$ & $\begin{array}{l}\text { Temperature } \\
\left({ }^{\circ} \mathrm{F}\right)\end{array}$ \\
\hline 8000 & 900000 & 70 \\
\hline 7540 & 800000 & 200 \\
\hline 6630 & 650000 & 400 \\
\hline 5260 & 525000 & 600 \\
\hline 4110 & 375000 & 800 \\
\hline 2800 & 100000 & 1000 \\
\hline
\end{tabular}




\section{CRES STAINLESS STEEL}

\begin{tabular}{|ll|}
\hline $\begin{array}{l}\text { Conductivity } \\
\left(\mathrm{BTU} / \mathrm{in} \cdot \mathrm{sec}^{\circ} \mathrm{F}\right)\end{array}$ & $\begin{array}{l}\text { Temperature } \\
\left({ }^{\circ} \mathrm{F}\right)\end{array}$ \\
\hline $\mathbf{0 . 0 0 0 2 0 1 4}$ & 100 \\
\hline $\mathbf{0 . 0 0 0 2 1 4 1}$ & 200 \\
\hline $\mathbf{0 . 0 0 0 2 2 5 0}$ & 300 \\
\hline $\mathbf{0 . 0 0 0 2 4 1 9}$ & 400 \\
\hline $\mathbf{0 . 0 0 0 2 5 2 3}$ & 500 \\
\hline $\mathbf{0 . 0 0 0 2 6 1 5}$ & 600 \\
\hline $\mathbf{0 . 0 0 0 2 7 0 0}$ & 700 \\
\hline $\mathbf{0 . 0 0 0 2 8 0 1}$ & 800 \\
\hline $\mathbf{0 . 0 0 0 2 8 7 0}$ & 900 \\
\hline $\mathbf{0 . 0 0 0 2 9 2 8}$ & 1000 \\
\hline
\end{tabular}

\section{Mass Density}

$\left(\mathrm{lbm} / \mathrm{in}^{3}\right)$

0.287

\begin{tabular}{|ll|}
\hline $\begin{array}{l}\text { Specific Heat } \\
\left(\mathrm{BTU} / \mathrm{lbm} \cdot{ }^{\circ} \mathrm{F}\right)\end{array}$ & $\begin{array}{l}\text { Temperature } \\
\left({ }^{\circ} \mathrm{F}\right)\end{array}$ \\
\hline $\mathbf{0 . 1 1 5}$ & 100 \\
\hline $\mathbf{0 . 1 2 0}$ & 200 \\
\hline $\mathbf{0 . 1 2 5}$ & 300 \\
\hline $\mathbf{0 . 1 2 6}$ & 400 \\
\hline $\mathbf{0 . 1 3 0}$ & 500 \\
\hline $\mathbf{0 . 1 3 5}$ & 600 \\
\hline $\mathbf{0 . 1 3 6}$ & 700 \\
\hline $\mathbf{0 . 1 3 7}$ & 800 \\
\hline $\mathbf{0 . 1 3 8}$ & 900 \\
\hline $\mathbf{0 . 1 4 0}$ & 1000 \\
\hline
\end{tabular}




\begin{tabular}{|lll|}
\hline$E$ (psi) & $\mathbf{v}$ (nu) & $\begin{array}{l}\text { Temperature } \\
\left({ }^{\circ} \mathrm{F}\right)\end{array}$ \\
\hline $\mathbf{2 . 9 0 E + 0 7}$ & 0.27 & 70 \\
\hline $2.85 \mathrm{E}+07$ & 0.28 & 200 \\
\hline $\mathbf{2 . 7 5 E + 0 7}$ & 0.31 & 400 \\
\hline $\mathbf{2 . 6 0 E + 0 7}$ & 0.315 & 600 \\
\hline
\end{tabular}

\begin{tabular}{|lll|}
\hline \multicolumn{3}{|l|}{ Plastic Isotropic Hardening } \\
\hline $\begin{array}{l}\text { Yield Stress } \\
\text { (psi) }\end{array}$ & Plastic Strain & $\begin{array}{l}\text { Temperature } \\
\left({ }^{\circ} \mathrm{F}\right)\end{array}$ \\
\hline $\mathbf{2 5 0 0 0}$ & 0.000000 & 70 \\
\hline $\mathbf{3 0 0 0 0}$ & 0.000023 & 70 \\
\hline $\mathbf{4 0 0 0 0}$ & 0.000157 & 70 \\
\hline $\mathbf{5 0 0 0 0}$ & 0.000699 & 70 \\
\hline $\mathbf{1 8 0 0 0}$ & 0.000000 & 200 \\
\hline $\mathbf{2 0 0 0 0}$ & 0.000090 & 200 \\
\hline $\mathbf{2 7 0 0 0}$ & 0.000200 & 200 \\
\hline $\mathbf{3 5 0 0 0}$ & 0.000900 & 200 \\
\hline
\end{tabular}

\begin{tabular}{|ll|}
\hline CTE $\left(\right.$ in $\left./{ }^{\circ} \mathrm{F}\right)$ & $\begin{array}{l}\text { Temperature } \\
\left({ }^{\circ} \mathrm{F}\right)\end{array}$ \\
\hline $\mathbf{0 . 0 0 0 0 0 7 9 5}$ & -100 \\
\hline $\mathbf{0 . 0 0 0 0 0 8 7 0}$ & 80 \\
\hline $\mathbf{0 . 0 0 0 0 0 9 0 0}$ & 200 \\
\hline $\mathbf{0 . 0 0 0 0 0 9 4 5}$ & 100 \\
\hline $\mathbf{0 . 0 0 0 0 0 9 8 0}$ & 600 \\
\hline $\mathbf{0 . 0 0 0 0 1 0 1 0}$ & 800 \\
\hline
\end{tabular}


Hastelloy Properties

\begin{tabular}{|ll|}
$\begin{array}{l}\text { Conductivity } \\
\left.\text { (BTU/in-sec }{ }^{\circ} \mathrm{F}\right)\end{array}$ & $\begin{array}{l}\text { Temperature } \\
\left({ }^{\circ} \mathrm{F}\right)\end{array}$ \\
\hline $\mathbf{0 . 0 0 0 1 2 1 9 1 4}$ & 70 \\
\hline $\mathbf{0 . 0 0 0 1 4 4 6 7 6}$ & 212 \\
\hline $\mathbf{0 . 0 0 0 1 8 8 8 5}$ & 572 \\
\hline $\mathbf{0 . 0 0 0 2 4 1 1 2 7}$ & 932 \\
\hline $\mathbf{0 . 0 0 0 3 3 1 7 9}$ & 1290 \\
\hline $\mathbf{0 . 0 0 0 3 4 7 2 2 2}$ & 1650 \\
\hline
\end{tabular}

\begin{tabular}{|ll|}
$\begin{array}{l}\text { Specific } \\
\text { Heat } \\
\left(\mathrm{BTU} / \mathrm{lbm} \cdot{ }^{\circ} \mathrm{F}\right)\end{array}$ & $\begin{array}{l}\text { Temperature } \\
\left({ }^{\circ} \mathrm{F}\right)\end{array}$ \\
\hline $\mathbf{0 . 0 8 9 1}$ & 32 \\
\hline $\mathbf{0 . 0 9 3}$ & 212 \\
\hline $\mathbf{0 . 0 9 7}$ & 392 \\
\hline $\mathbf{0 . 1 0 1}$ & 572 \\
\hline $\mathbf{0 . 1 0 3}$ & 752 \\
\hline $\mathbf{0 . 1 0 6}$ & 932 \\
\hline $\mathbf{0 . 1 0 9}$ & 1110 \\
\hline
\end{tabular}

Mass Density (lbm/in3)

0.321 
Graphite Properties

Conductivity

(BTU/in'sec. ${ }^{\circ} \mathrm{F}$ )

0.0003221

Specific Heat

(BTU/lbm. ${ }^{\circ} \mathrm{F}$ )

.16914

Mass Density

$\left(\mathrm{lbm} / \mathrm{in}^{3}\right)$

0.0813 


\section{APPENDIX C: FORTRAN SUBROUTINES}

Simplified 2D Model - Special thanks to Rusty Browning for providing a basic framework from which to work and expand

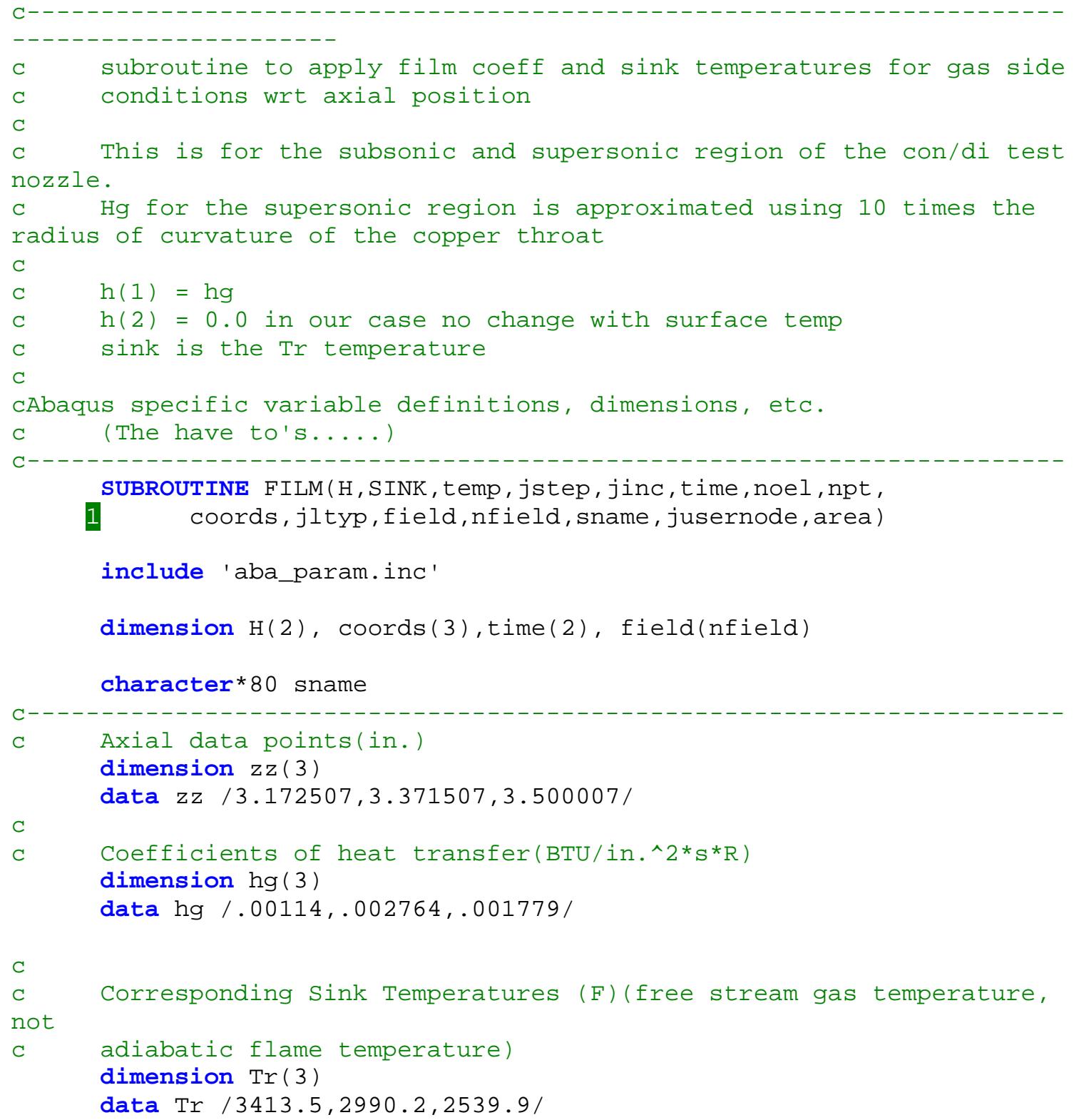




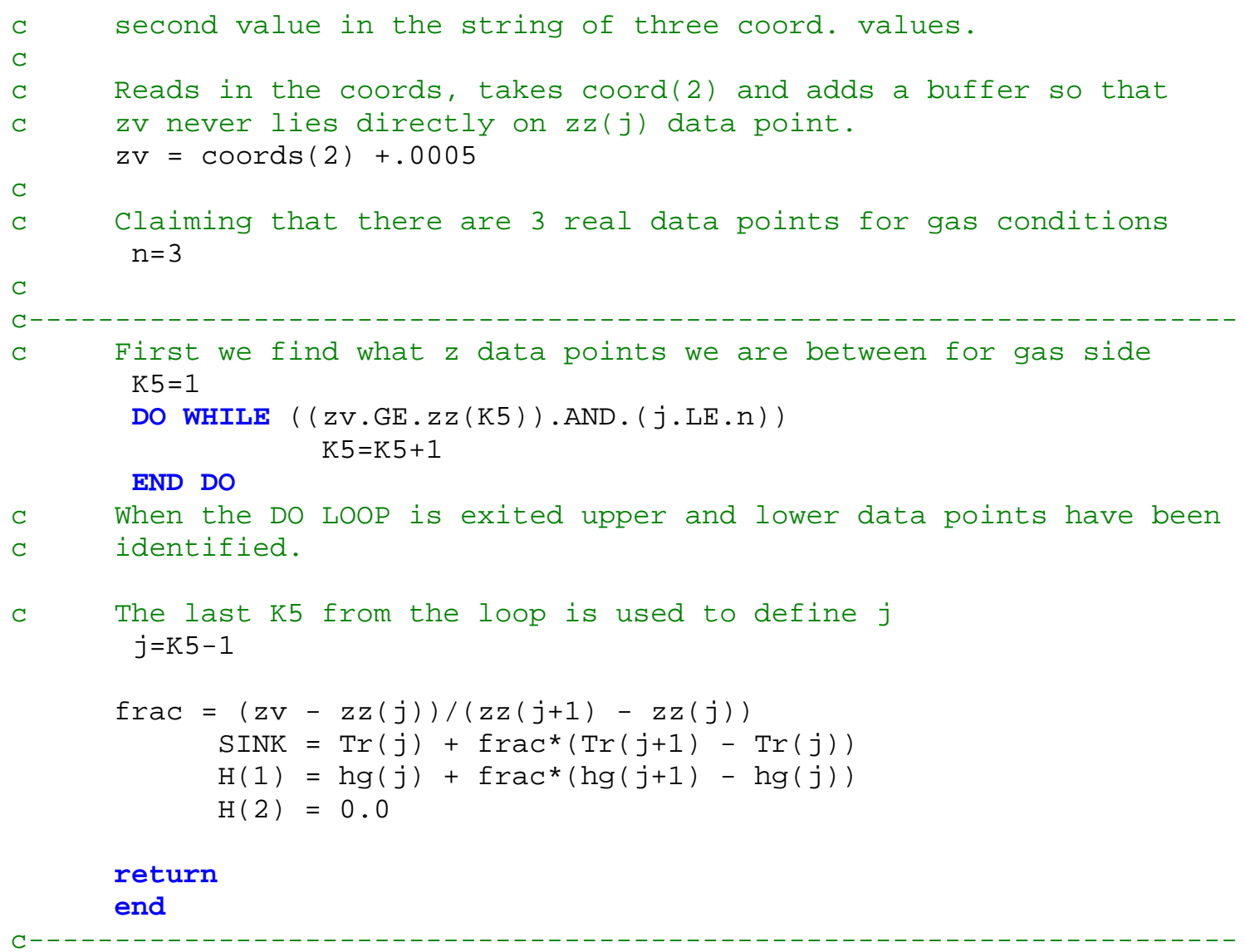


Full Nozzle Model

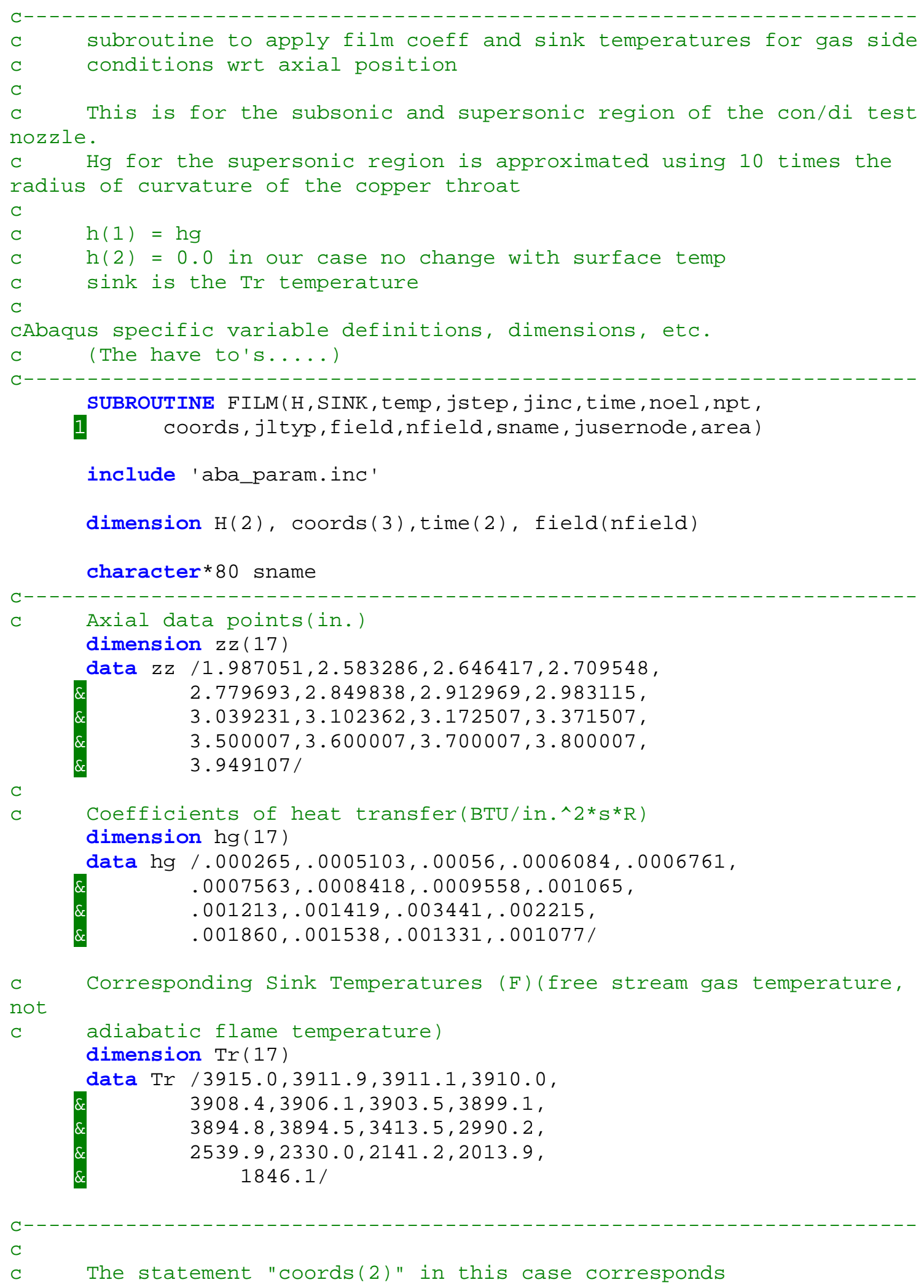




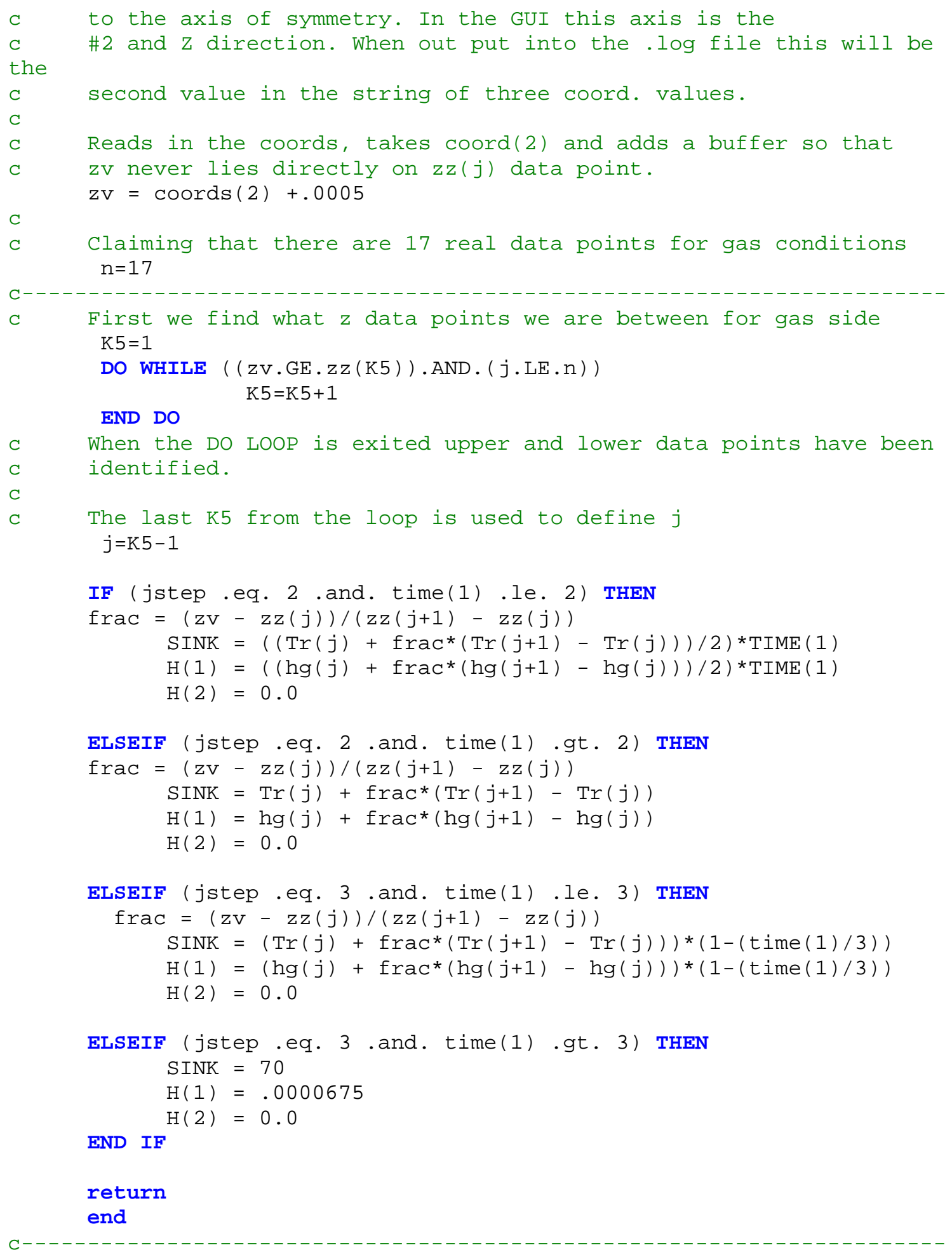


Simplified 3D Model

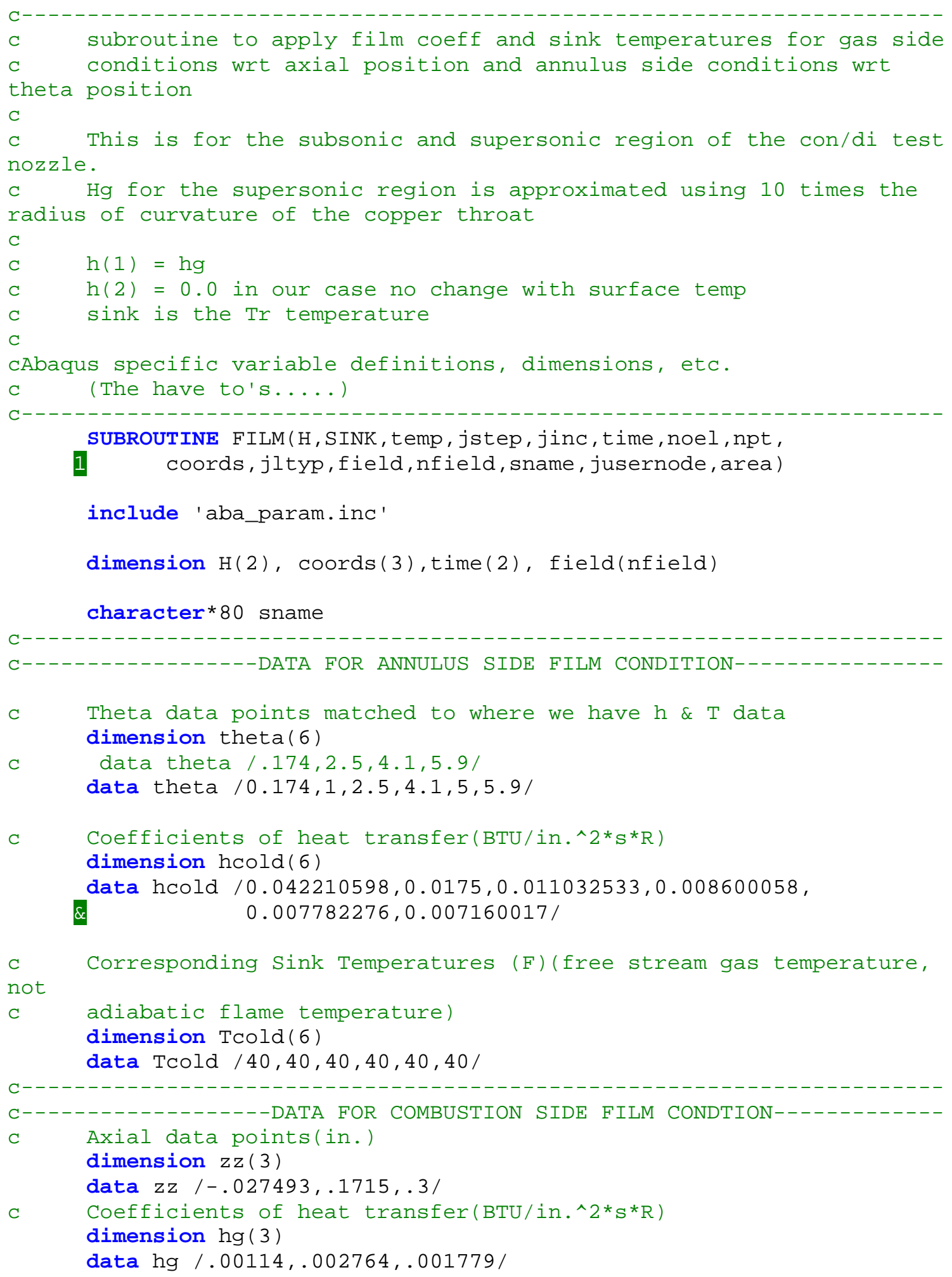




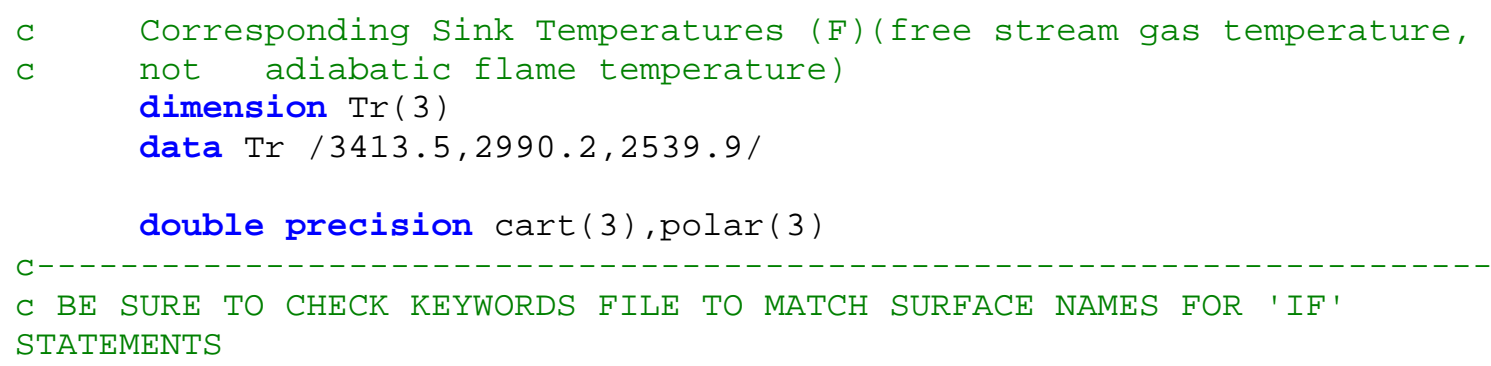

IF ( sname .eq. 'ASSEMBLY_PICKEDSURF64') THEN

$\operatorname{cart}(1)=\operatorname{coords}(1)$

cart (2)=coords $(2)$

cart $(3)=\operatorname{coords}(3)$

$\operatorname{polar}(3)=\operatorname{cart}(3)$

c $\quad n$ number of theta positions

$n=6$

c polar (1) is the ' $r$ ' coordiate

polar (1) $=\operatorname{sqrt}\left(\left(\operatorname{cart}(1){ }^{*} \operatorname{cart}(1)\right)+\left(\operatorname{cart}(2){ }^{*} \operatorname{cart}(2)\right)\right)$

c polar (2) is the theta coordinate calculated using the arc tangent,

c coded to provide positive values starting from $\odot$ radians

c to $2{ }^{*} \mathrm{Pi}$ radians

if (cart(1).ge. $\odot$. and. $\operatorname{cart}(2), \mathrm{ge}, \odot)$ then

$\operatorname{polar}(2)=\operatorname{atan} 2(\operatorname{cart}(2), \operatorname{cart}(1))$

if (polar(2).lt. $\odot$.or. polar(2).gt. 1.57079632679) then WRITE $\left(6,{ }^{*}\right)$ "WARNING 1st Quadrant Mistake, Polar", polar(2),

\& "X", $\operatorname{cart}(1), " Y ", \operatorname{cart}(2)$ endif

elseif (cart(1).ge. $\odot$.and. $\operatorname{cart}(2)$.lt. $\odot)$ then

polar $(2)=\operatorname{atan} 2(\operatorname{cart}(2), \operatorname{cart}(1))+(2 * 3.1415927)$

if (polar(2).1t. 4.7123889.or. polar(2).gt. 6.283185)

then

WRITE $\left(6,{ }^{*}\right)$ "WARNING 4th Quadrant Mistake, Polar", polar(2),

\& "X", $\operatorname{cart}(1)$, "Y", $\operatorname{cart}(2)$ endif

elseif (cart(1) .lt. $\odot$. and. cart(2) .lt. $\odot$ ) then

$\operatorname{polar}(2)=\operatorname{atan} 2(\operatorname{cart}(2), \operatorname{cart}(1))+(2 * 3.1415927)$

if (polar(2).1t. 3.141592.or. polar(2) .gt. 4.7123889)

then

WRITE $\left(6,{ }^{*}\right)$ "WARNING 3rd Quadrant Mistake, Polar", polar(2), "X", $\operatorname{cart}(1)$, "Y", $\operatorname{cart}(2)$

endif

elseif (cart(1) .lt. $\odot$. and. $\operatorname{cart}(2)$.ge. $\odot)$ then $\operatorname{polar}(2)=\operatorname{atan} 2(\operatorname{cart}(2), \operatorname{cart}(1))$ 
then

if (polar(2) .lt. 1.5707963 .or. polar(2) .gt. 3.141592)

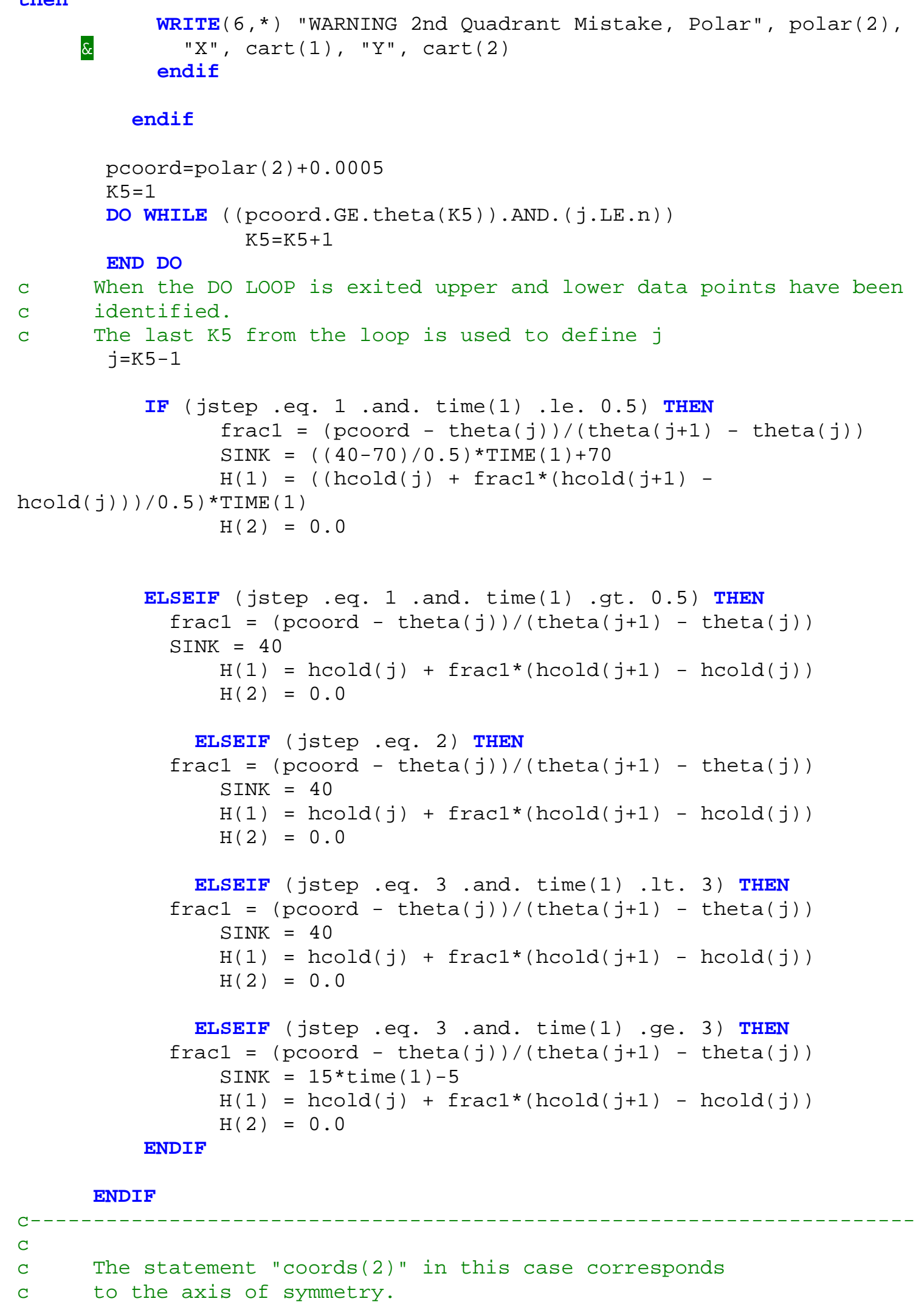


c Reads in the coords, takes coord(2) and adds a buffer so that

c $\quad$ zv never lies directly on $z z(j)$ data point.

IF ( sname .eq. 'ASSEMBLY_PICKEDSURF51') THEN

$z v=\operatorname{coords}(3)+.0005$

c If true then interpolate $\operatorname{Tr}$ and hg between $j$ and $j+1$

c Note: $j$ should start out as $\odot$ by default

$\mathrm{C}$

C

$\operatorname{WRITE}\left(6,{ }^{*}\right)$ "coord set=" , coords(1), coords(2), coords(3)

Claiming that there are 3 real data points for gas conditions $\mathrm{n}=3$

$\mathrm{C}$

$\mathrm{C}$

c

First we find what $\mathrm{z}$ data points we are between for gas side $\mathrm{K} 5=1$

DO WHILE (( $z \vee \cdot G E \cdot z Z(K 5)) \cdot A N D \cdot(j \cdot L E \cdot n))$

END DO

$\mathrm{K} 5=\mathrm{K} 5+1$

When the DO LOOP is exited upper and lower data points have been identified.

The last $\mathrm{K} 5$ from the loop is used to define $\mathrm{j}$ $\mathrm{j}=\mathrm{K} 5-1$

IF (jstep .eq. 2 .and. time(1) .le. 2) THEN

frac $=(z v-z z(j)) /(z z(j+1)-z z(j))$

SINK $=\left(\left(\operatorname{Tr}(j)+f r a c^{*}(\operatorname{Tr}(j+1)-\operatorname{Tr}(j))-40\right) / 2\right) * \operatorname{time}(1)+4 \Theta$

$H(1)=\left(\left(h g(j)+\operatorname{frac}^{*}(h g(j+1)-h g(j))\right) / 2\right) *$ time $(1)$

$H(2)=0.0$

ELSEIF (jstep .eq. 2 .and. time(1) .gt. 2) THEN

frac $=(z v-z z(j)) /(z z(j+1)-z z(j))$

SINK $=\operatorname{Tr}(j)+f r a{ }^{*}(\operatorname{Tr}(j+1)-\operatorname{Tr}(j))$

$H(1)=h g(j)+\operatorname{frac}^{*}(h g(j+1)-h g(j))$

$H(2)=0.0$

ELSEIF (jstep .eq. 3 .and. time(1) .le. 3) THEN

frac $=(z v-z z(j)) /(z z(j+1)-z z(j))$

SINK $=\left(\operatorname{Tr}(j)+\operatorname{frac}^{*}(\operatorname{Tr}(j+1)-\operatorname{Tr}(j))\right) *(1-(\operatorname{time}(1) / 3))$

$H(1)=\left(h g(j)+\operatorname{frac}^{*}(h g(j+1)-h g(j))\right) *(1-(\operatorname{time}(1) / 3))$

$H(2)=0.0$

ELSEIF (jstep .eq. 3 .and. time(1) .gt. 3) THEN SINK $=0$

$H(1)=0$

END IF

$H(2)=0.0$

END IF
$\quad \begin{aligned} & \text { return } \\ & \text { end }\end{aligned}$




\section{Full 3D Model}

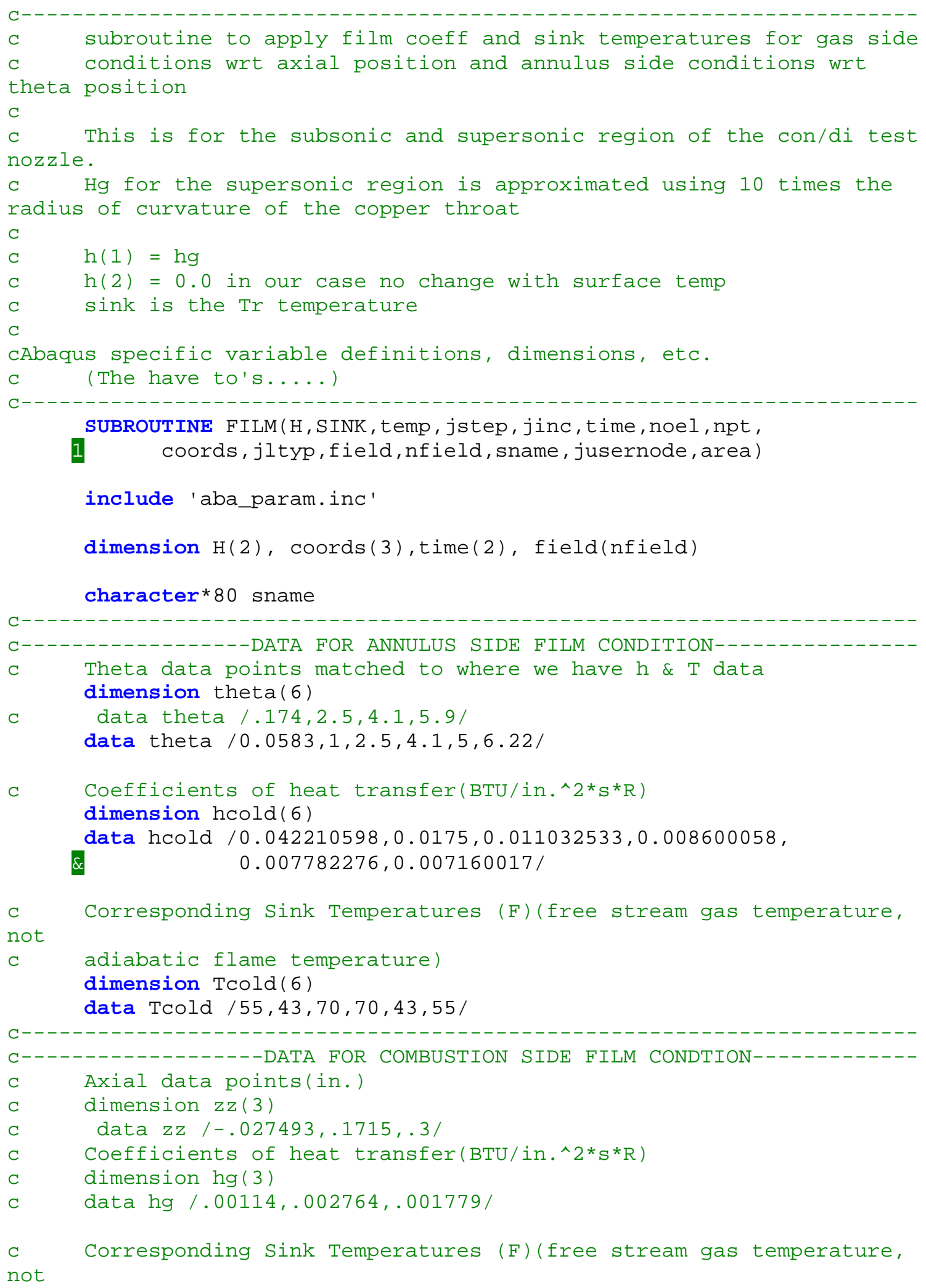




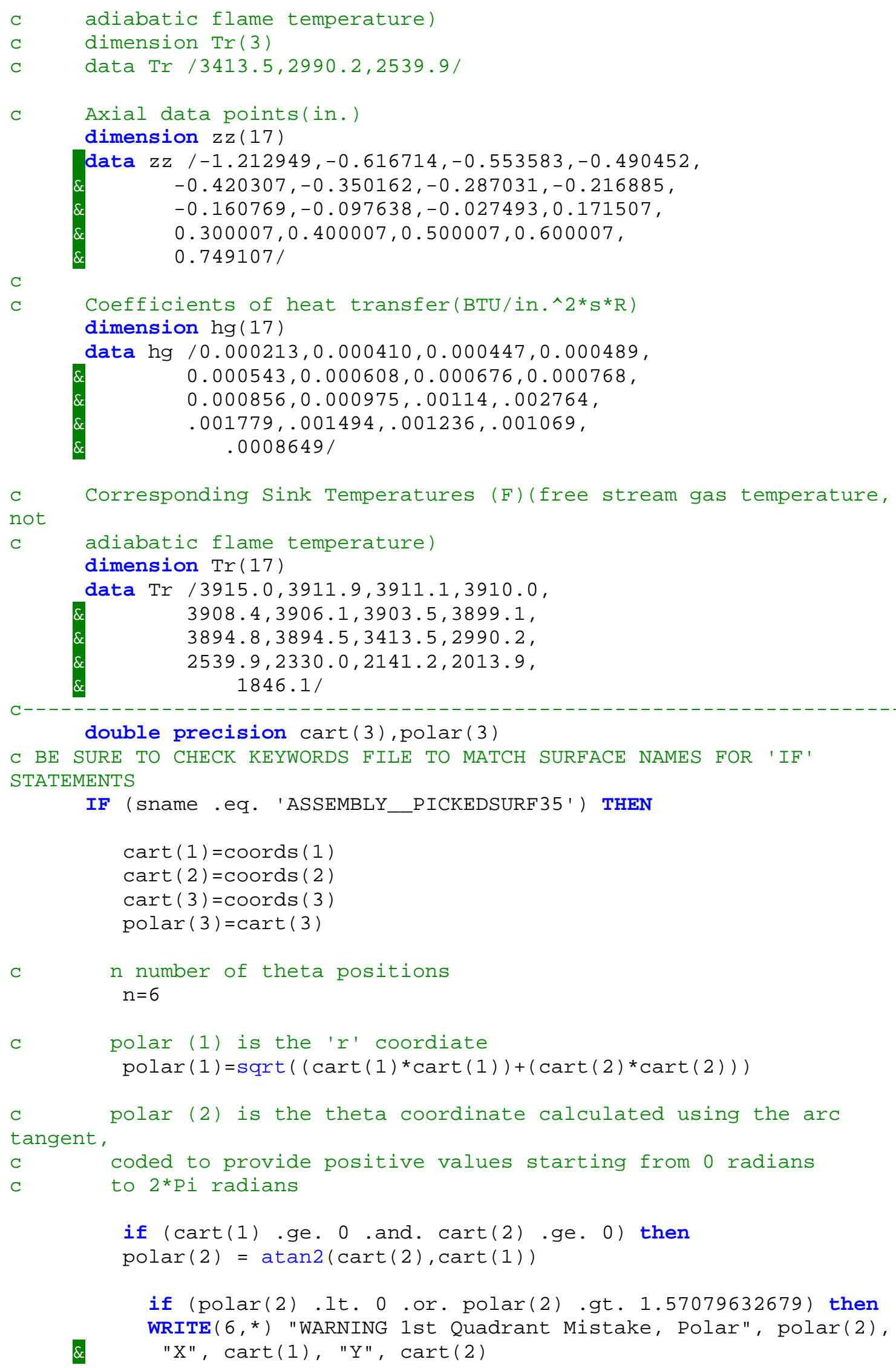




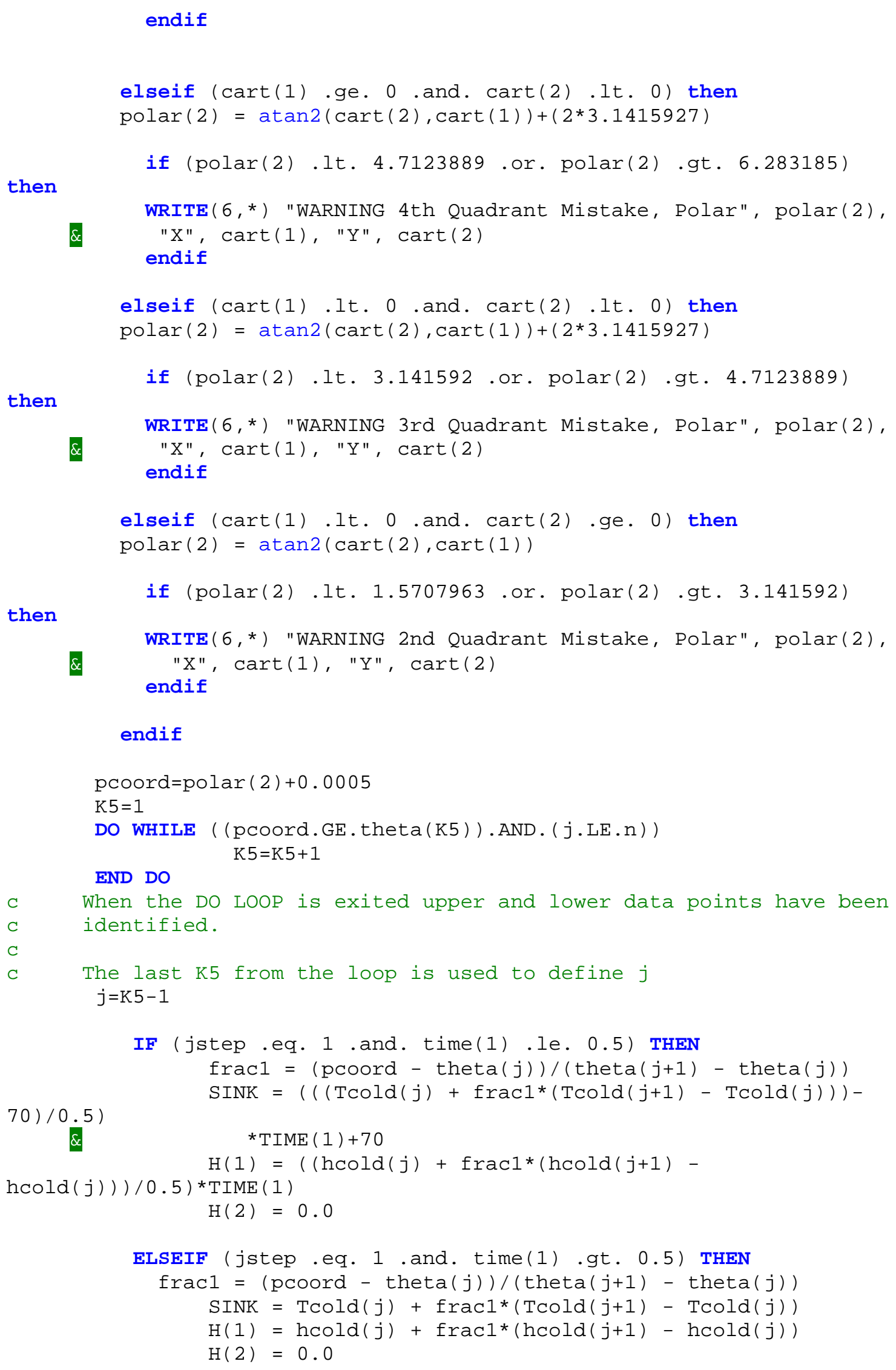




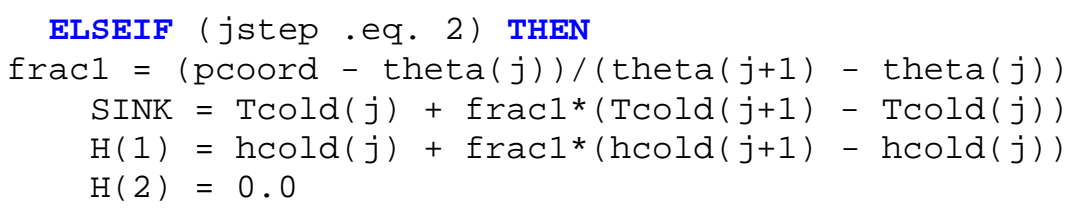

ELSEIF (jstep .eq. 3 .and. time(1) . lt. 3) THEN frac1 $=($ pcoord $-\operatorname{theta}(j)) /($ theta $(j+1)-\operatorname{theta}(j))$ $\operatorname{SINK}=\operatorname{Tcold}(j)+\operatorname{frac1}{ }^{*}(\operatorname{Tcold}(j+1)-\operatorname{Tcold}(j))$ $H(1)=\operatorname{hcold}(j)+f r a c 1 *(h \operatorname{hold}(j+1)-\operatorname{hcold}(j))$ $H(2)=0.0$

ELSEIF (jstep .eq. 3 .and. time(1) .ge. 3 ) THEN frac1 $=($ pcoord $-\operatorname{theta}(j)) /(\operatorname{theta}(j+1)-\operatorname{theta}(j))$ $\operatorname{SINK}=((\operatorname{Tcold}(j)+\operatorname{frac1} *(\operatorname{Tcold}(j+1)-\operatorname{Tcold}(j)))-70)$ * $(1-(\operatorname{TIME}(1)-3) / 2)+70$

\section{ENDIF} $H(1)=\operatorname{hcold}(j)+\operatorname{frac1}^{*}(\operatorname{hcold}(j+1)-\operatorname{hcold}(j))$ $H(2)=0.0$

\section{ENDIF}

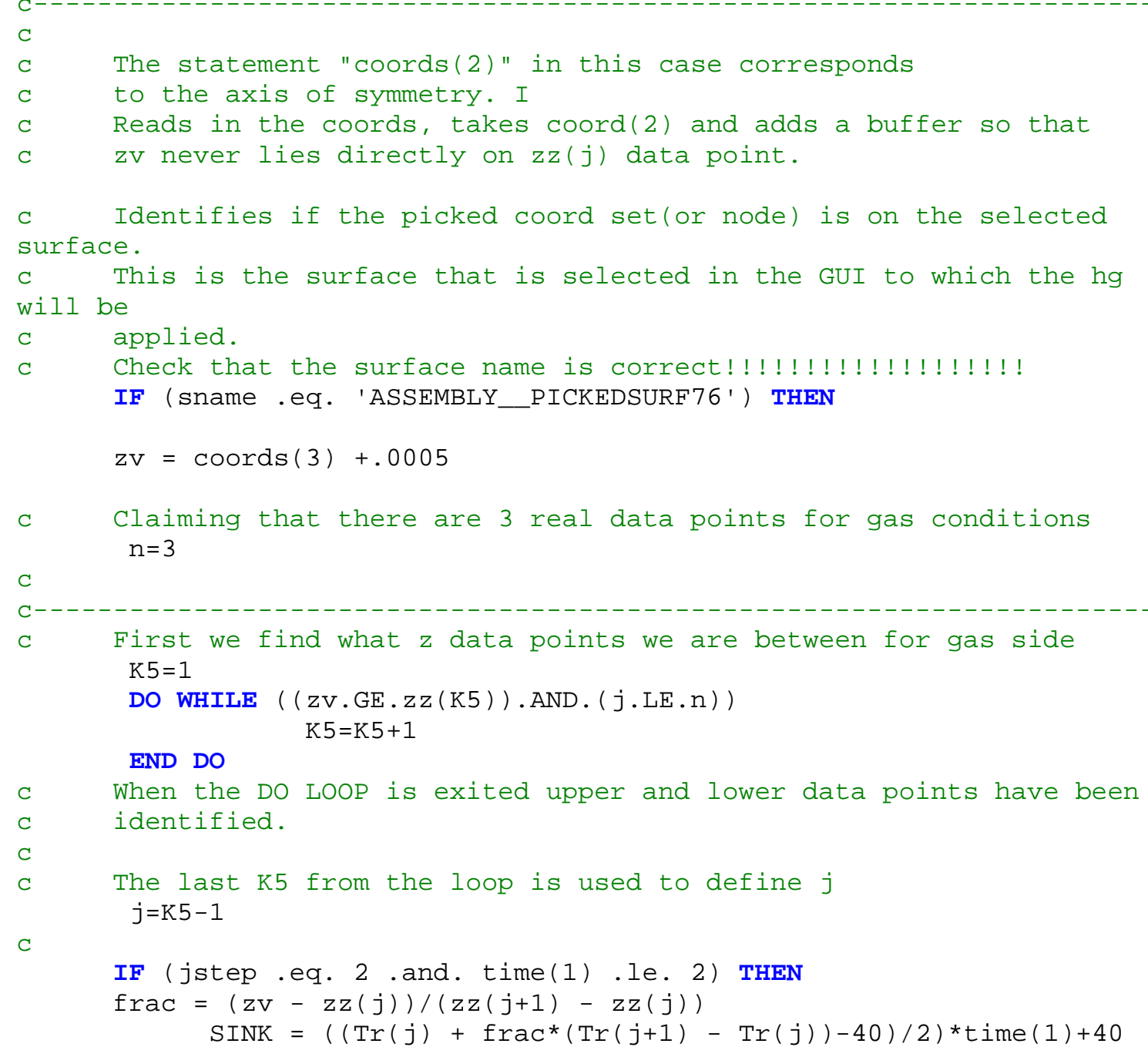




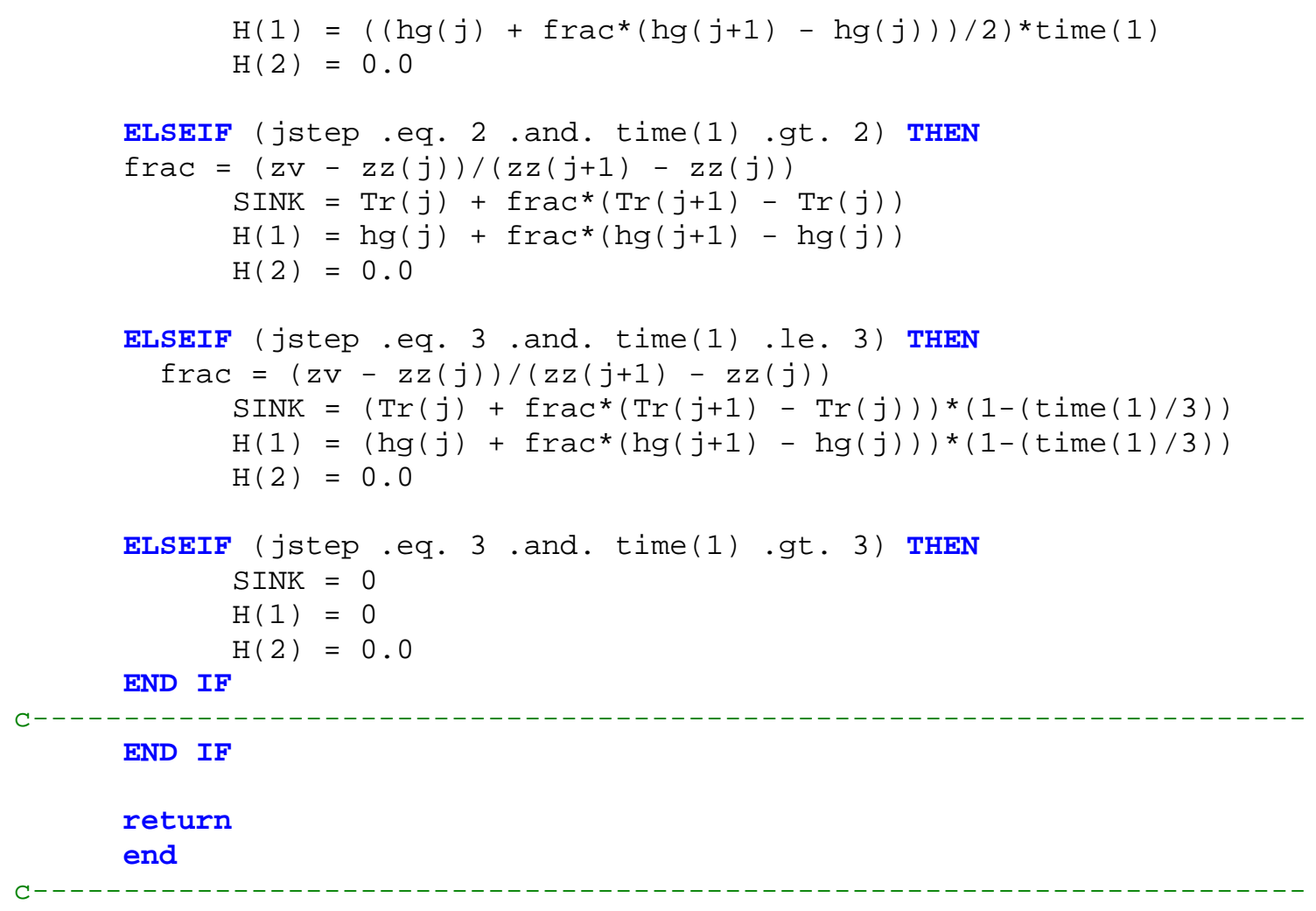

